Florida International University FIU Digital Commons

$11-7-2016$

\title{
Characterization of Interaction Between Brevetoxin and Its Native Receptor and Identification of the Role of Brevetoxin in Karenia brevis
}

Wei Chen

Florida International University, wchen020@fiu.edu

DOI: $10.25148 /$ etd.FIDC001236

Follow this and additional works at: https:// digitalcommons.fiu.edu/etd

Part of the Biochemistry Commons, and the Marine Biology Commons

\section{Recommended Citation}

Chen, Wei, "Characterization of Interaction Between Brevetoxin and Its Native Receptor and Identification of the Role of Brevetoxin in Karenia brevis" (2016). FIU Electronic Theses and Dissertations. 2988.

https://digitalcommons.fiu.edu/etd/2988 


\section{FLORIDA INTERNATIONAL UNIVERSITY}

Miami, Florida

CHARACTERIZATION OF INTERACTION BETWEEN BREVETOXIN AND ITS NATIVE RECEPTOR AND IDENTIFICATION OF THE ROLE OF BREVETOXIN IN KARENIA BREVIS

A dissertation submitted in partial fulfillment of the requirements for the degree of DOCTOR OF PHILOSOPHY in CHEMISTRY

by

Wei Chen 
To: Dean Michael R. Heithaus

College of Arts, Sciences and Education

This dissertation, written by Wei Chen, and entitled Characterization of Interaction Between Brevetoxin and Its Native Receptor and Identification of the Role of Brevetoxin in Karenia brevis, having been approved in respect to style and intellectual content, is referred to you for judgment.

We have read this dissertation and recommend that it be approved.

Yuan Liu

Xiaotang Wang

Jose M. Eirin-Lopez

Rudolf Jaffe

Kathleen Rein, Major Professor

Date of Defense: November 7, 2016

The dissertation of Wei Chen is approved.

Dean Michael R. Heithaus

College of Arts, Sciences and Education

Andrés G. Gil

Vice President for Research and Economic Development and Dean of the University Graduate School

Florida International University, 2016 
(C) Copyright 2016 by Wei Chen

All rights reserved. 


\section{DEDICATION}

I dedicate this work to my parents, my grandparents, my boyfriend and his family for their endless love and support. Without their understanding and encouragement, the completion of this work would not have been possible. 


\section{ACKNOWLEDGMENTS}

I am really grateful to the numerous people who help me a lot in the pursuit of this Ph.D degree. Without their guidance and support the accomplishment of this dissertation would not have been possible. It is my great pleasure to express my gratitude to all of them in my humble acknowledgment

First and foremost, I would like to thank my major professor Dr. Kathleen Rein for the opportunity to study and work in her group to pursue a doctoral degree. Without her endless support, patience and supervision, my skill of writing and presenting could not be improved during entire degree process. I do appreciate everything she has done for encouraging me to overcome lots of obstructions during the past five years.

I would also like to thank my other committee members, Dr. Yuan Liu, Dr. Xiaotang Wang, Dr. Rudolf Jaffe and Dr. Jose M. Eirin-Lopez for their suggestion, guidance and valuable time througout the years.

I would like to acknowledge all the faculty and staff members of the chemistry department for the support, help and coordination. Big thanks to the dean's office of the College of Arts, Sciences and Education for travel funding.

I would like to thank my lab mates for their support and friendship. Because of you, my five years are full with love and happiness. Special thanks to Li Liu, Ryan Cassell Pengfei Sun and Freddy Rodriguez for their help in my study.

Finally, I wish to express my appreciation to those who have helped me in any respect during my study at FIU, as well as expressing my apology that I could not mention personally one by one. 


\section{ABSTRACT OF THE DISSERTATION}

CHARACTERIZATION OF INTERACTION BETWEEN BREVETOXIN AND ITS

NATIVE RECEPTOR AND IDENTIFICATION THE ROLE OF BREVETOXIN IN

KARENIA BREVIS

by

Wei Chen

Florida International University, 2016

Miami, Florida

\section{Professor Kathleen Rein, Major Professor}

Algae are important to marine and fresh-water ecosystems. However, some species of algae are harmful or even toxic. They can consume oxygen or block sunlight that is essential for other organisms to live. Indeed, some algae blooms can produce toxins that damage the health of the environment, plants, animals, and humans. Harmful algal blooms (HABs) which are often more green, brown, or dark-colored than red have spread along the coastlines and in the surface waters of the United States. Therefore, scientists are making great efforts to study HABs in order to maintain human and ecosystem health.

Karenia brevis, the major harmful algal bloom dinoflagellate of the Gulf of Mexico, plays a destructive role in the region. Karenia brevis, responsible for Florida red tide, is the principle HAB dinoflagellate in the Gulf of Mexico. K. brevis blooms can produce brevetoxin: ladder-shaped polyether (LSP) compounds, which can lead to adverse human health effects, like reduced respiratory function through inhalation exposure, or neurotoxic shellfish poisoning through consumption of contaminated shellfish. The poisoning has been attributed to their affinity for voltage-sensitive sodium ion channels causing channel opening and depolarization of excitable cell 
membranes. Conservative estimate suggests that the economic impact from all harmful algal bloom events in the United States is at least $\$ 82$ million/year. The public health costs occupy $\$ 37$ million alone.

The study presented herein utilized fluorescent and photolabile brevetoxin probes to demonstrate that brevetoxin localizes in the chloroplast of $K$. brevis where it binds to light harvest complex II (LHC II) and thioredoxin (Trx). It had been discovered that the TrxR/Trx system was inhibited by brevetoxin-2 (PbTx-2) with an $\mathrm{IC}_{50}$ of 25 $\mu \mathrm{M}$. The mechanism of the inhibition was discussed in this work. The research also revealed that the $K$. brevis high-toxic and low-toxic strains have a significant difference in their ability, not only to produce brevetoxin, but also to perform NPQ and in the production of ROS. I compared and contrasted various metabolic and biochemical parameters in two strains of $K$. brevis which had a ten-fold difference in toxin content. The work could shed light on the physiological role that brevetoxin fills for K. brevis and may contribute to understanding the effect of ladder-shaped polyether compounds on both marine animals and exposed humans and shall inform improved treatments for brevetoxicosis. 


\section{TABLE OF CONTENTS}

Chapter 1 Introduction 1

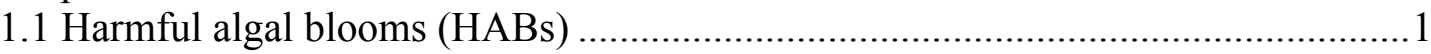

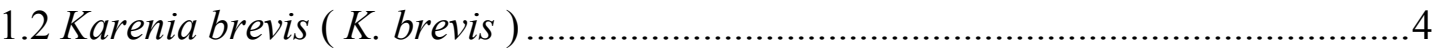

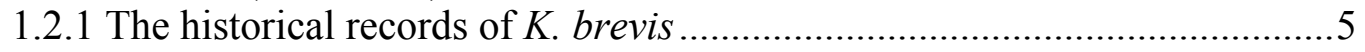

1.2.2 The historical effects of $K$. brevis .............................................................6

1.3 Brevetoxins and related ladder-shaped polyether (LSP) compounds.....................

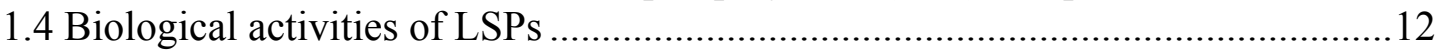

1.4.1 Biological activities of brevetoxin on animal .........................................12

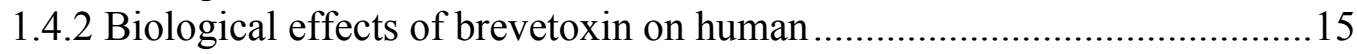

1.4.3 The effect of brevetoxin on cellular process ...........................................16

1.5 LSP compounds bind to transmembrane protein ................................................. 18

1.6 The interaction between PbTxs VGSC at the molecular level ...........................20

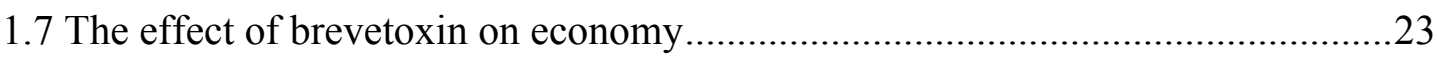

1.8 Brevetoxins play an important role in $\mathrm{K}$. brevis, but it is still elusive ..................24

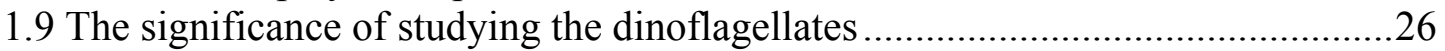

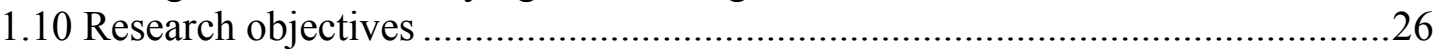

Chapter 2 Localization of PbTxs to a subcellular organelle and identification of a

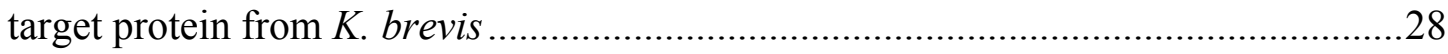

2.1 Localize PbTxs to one or more organelles or cellular structures in K.brevis ........28

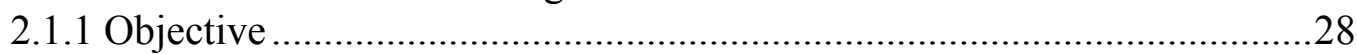

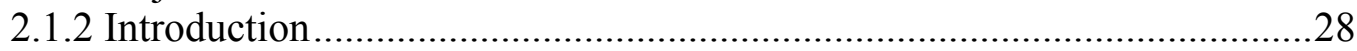

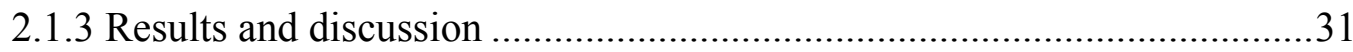

2.2 Isolation of a target protein from $K$. brevis as $\mathrm{PbTxs}$ natural receptor...................33

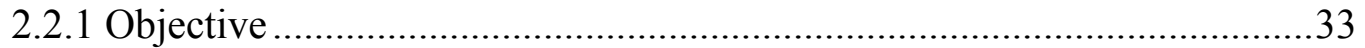

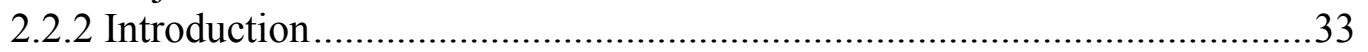

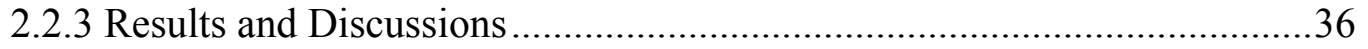

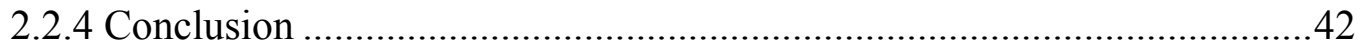

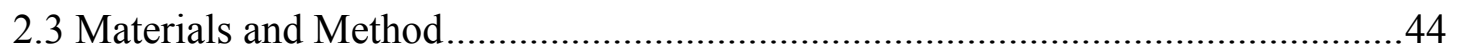

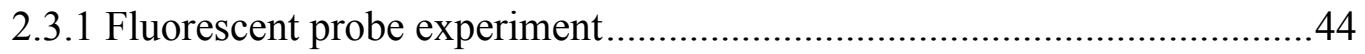

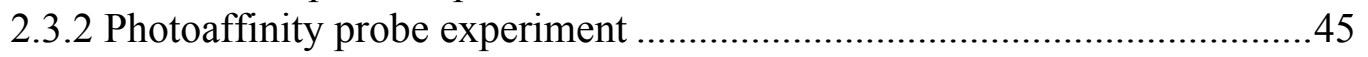

Chapter 3 The effects of brevetoxins on the thioredoxin reductase/thioredoxin system

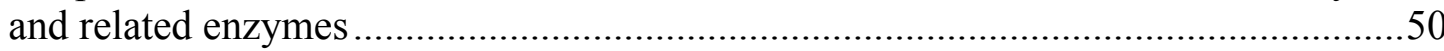

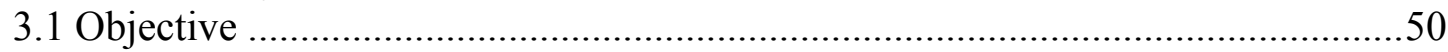

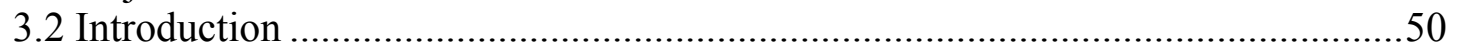

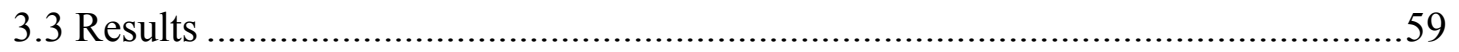

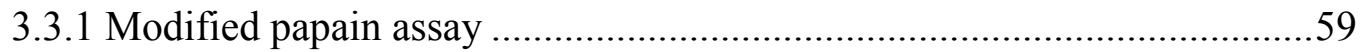

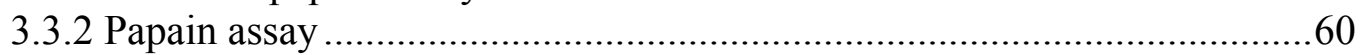

3.3.3 Fluorescent assay for $\operatorname{Tr} \mathrm{x} / \mathrm{TrxR}$ system ................................................64

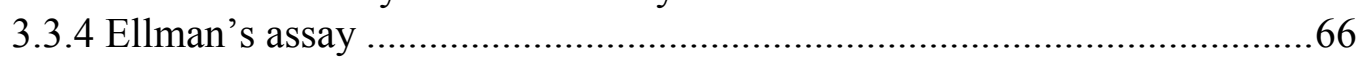

3.3.5 Adduct formation between PbTx-2 and selenocysteine............................72

3.3.6 Adduct formation between PbTx-2 and TrxR ........................................73

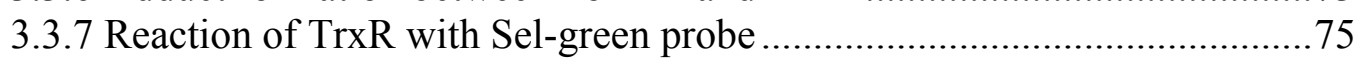

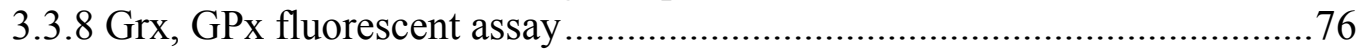




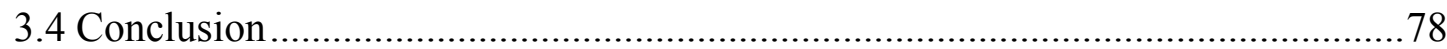

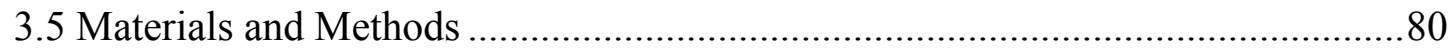

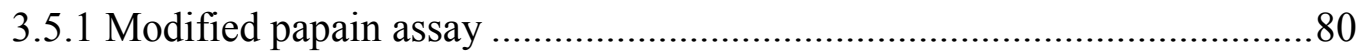

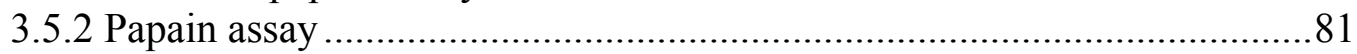

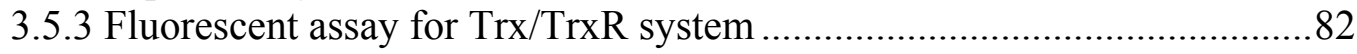

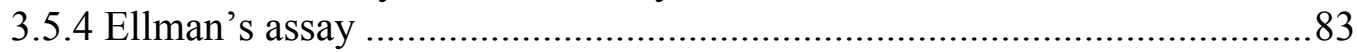

3.5.5 The preparation of selenocysteine $-\mathrm{PbTx}-2$ adduct .................................8

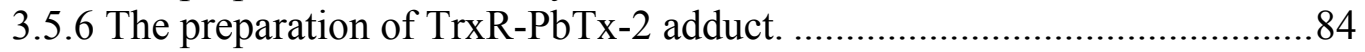

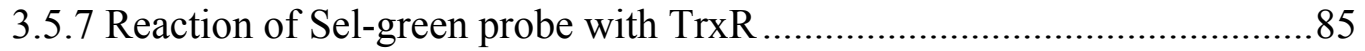

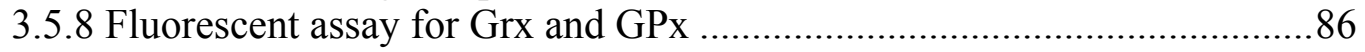

Chapter 4 Comparison of biochemical parameters in high toxin and low toxin

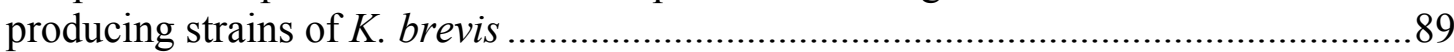

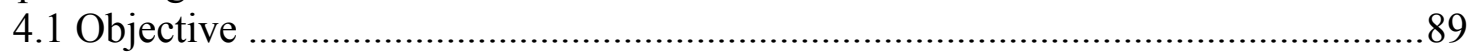

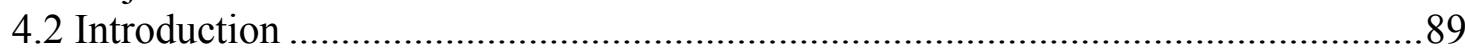

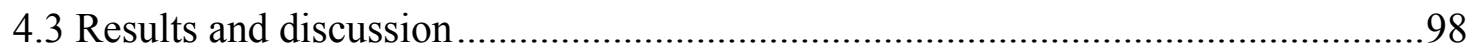

4.3.1 The antioxidants in two strains of $K$. brevis ...........................................99

4.3.2 Redox state of protein and non-protein thiols in low vs high toxin

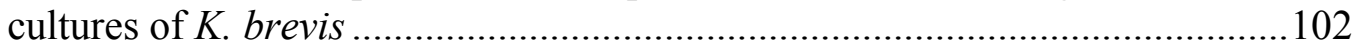

4.3.3 The reaction of Sel-green probe in two K. brevis strains.........................105

4.3.4 The activity of Trx and Grx in two K. brevis strains ...............................106

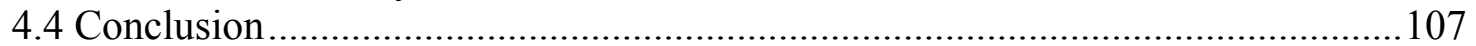

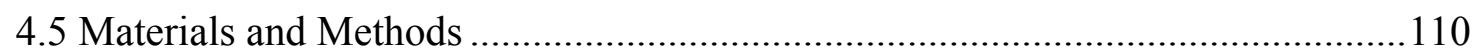

4.5.1 Culture methods .................................................................................. 110

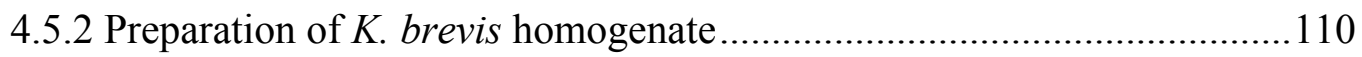

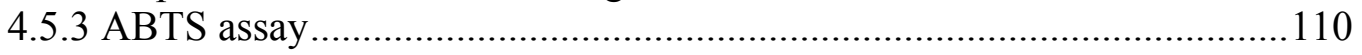

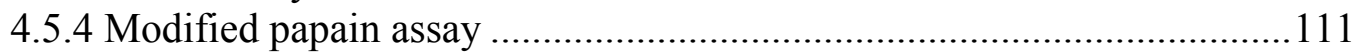

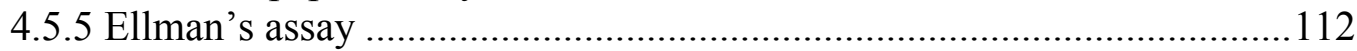

4.5.6 Sel- green reacts with homogenate of tow K. brevis strains ...................113

4.5.7 Thioredoxin activity in homogenate of two strains $K$. brevis .................114

4.5.8 Grx activity in homogenate of two strains K. brevis ............................115

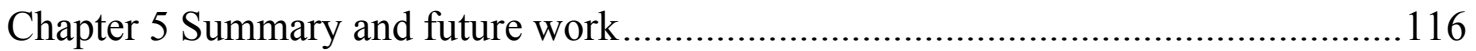

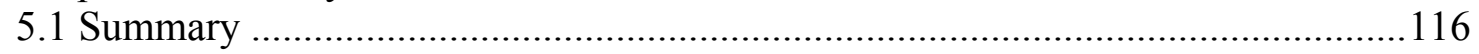

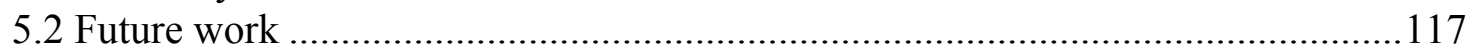

5.2.1 Identify all biological receptors for brevetoxin in $K$. brevis and localize the binding site on native receptors ..........................................................117

5.2.2 Analysis of the essential proteins, carotenoids and lipids for NPQ in

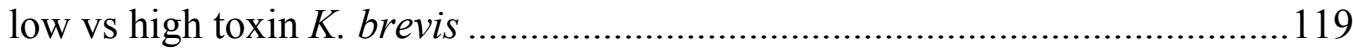

5.2.3 Determination the role of brevetoxin in two K. brevis strains ................120

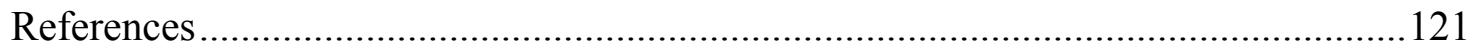

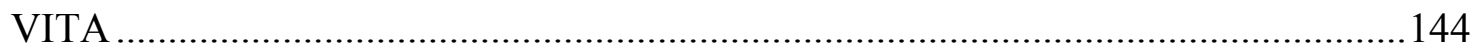




\section{LIST OF TABLE}

TABLE

PAGE

Table 1 Human poisoning syndromes caused by HAB 4

Table 2 The peptide sequence of $27 \mathrm{kD}$ band and the proteins with matching sequences.

Table 3 The intensity of all bands on SDS-PAGE gel

Table 4 The peptide sequence of the $12 \mathrm{kDa}$ band the proteins with matching sequences

Table 5 The motifs in thioredoxin, glutaredoxin, PDI and DsbA .............................51

Table 6 Relative $V_{0}$ for the assays shown above in Figure 24,26 and 27. .63

Table 7 The inhibition \% for the assays shown above in Fig 24,26 and 27 .64

Table 8 The predicted Se isotopic ratio .73

Table 9 The major ROS molecules and their metabolism .90

Table 10 The alignments of TrxR in K. brevis, Homo sapiens and Emiliania huxleyi .99

Table 11 Comparison of NPQ and ROS in two K. brevis strains 108

Table 12 Comparison of various biochemical parameters in two K. brevis strains at $19^{\text {th }}$ days 108 


\section{LIST OF FIGURES}

FIGURE

PAGE

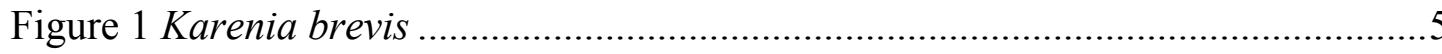

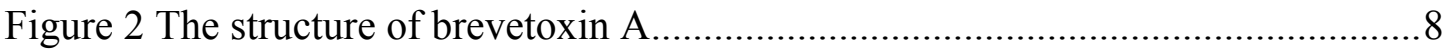

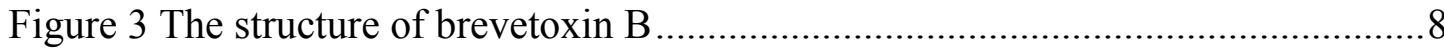

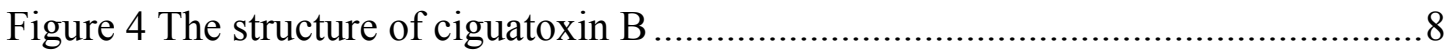

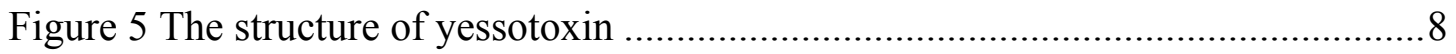

Figure 6 Structures of small polyether ladder toxins produced by …..........................

Figure 7 Synthesis of fluorescent brevetoxin probe ................................................ 31

Figure 8 The photograph of localization of brevetoxin in $K$. brevis live cells ............32

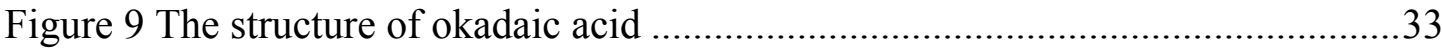

Figure 10 The most reliable and common high efficiency labeling of target

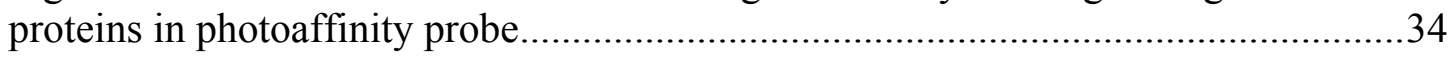

Figure 11 The synthesis of brevetoxin photoaffinity probe........................................

Figure 12 SDS-PAGE of protein fractions from photoaffinity experiments ...............37

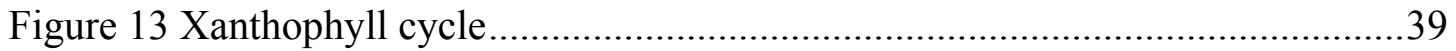

Figure 14 Spinach homogenate was incubated with the photoaffinity probe in

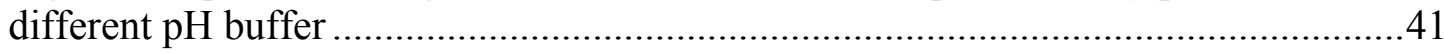

Figure 15 Trx catalyzes the reaction as a nucleophilic substitution reaction $\left(\mathrm{S}_{\mathrm{N}} 2\right) \ldots . .52$

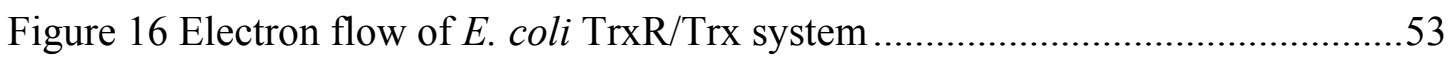

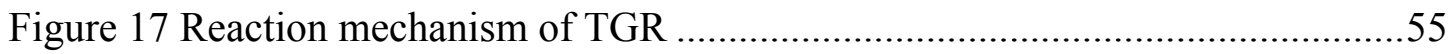

Figure 18 Electron flow of mammalian TrxR/Trx system......................................56

Figure 19 The Trx/TrxR system plays a key role in biochemical processes

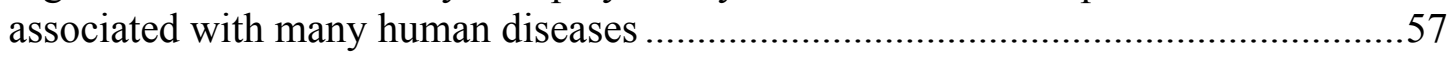

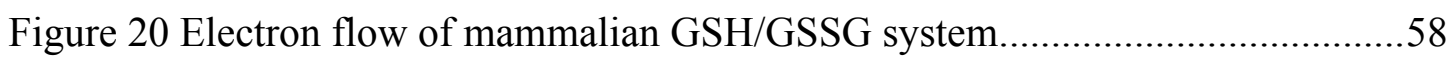

Figure 21 The redox cycle of GPx coupled with mammalian GSH/GSSG system.....59 
Figure 22 The equation of modified papain assay..... .59

Figure 23 The principle of modified papain assay to determine Trx activity .60

Figure 24 The modified papain assay with / without $\mathrm{PbTx}-2$

Figure 25 The modified papain assay with / without PbTx-2 but without cystamine. 62

Figure 26 The modified papain assay with / without $\mathrm{PbTx}-3$ with cystamine .62

Figure 27 The papain assay with / without brevetoxin .63

Figure 28 The reaction in sensitive fluorescent assay for Trx/TrxR system .64

Figure 29 The effect of PbTx-2 on Trx/TrxR system .65

Figure 30 The effect of PbTx-3 on Trx/TrxR system .66

Figure 31 The reduction of Ellman's reagent .66

Figure 32 The effect of PbTx-2 on the Ellman's assay .67

Figure 33 The electron flow in C-terminal reaction center in mammalian TrxR .68

Figure 34 The Michael acceptors demonstrated to inhibit TrxR

Figure 35 The hypothesized explanation for the observation in fluorescent Trx/TrxR assay with PbTx-2 .70

Figure 36 The hypothesized explanation for the observation in DTNB assay with TrxR and PbTx-2 ..... .70

Figure 37 The effect of truncated recombinant human. .71

Figure 38 The effect of PbTx-3 on DTNB reduction by mammalian TrxR .72

Figure 39 The mass spectrum of adduct formation between $\mathrm{PbTx}-2$ with selenocysteine .73

Figure $40 \mathrm{MS} / \mathrm{MS}$ analysis of the peptides from rat liver TrxR .74

Figure $41 \mathrm{MS} / \mathrm{MS}$ analysis of the peptides from the adduct between PbTx-2 and TrxR

Figure 42 Reaction of Sel-Green probe with selenocysteine

Figure 43 Release of fluorescent reporter from Sel-green probe upon incubation with TrxR in the presence and absence of PbTx-2 compared to standards of $L$ selenocysteine 
Figure 44 The principle of sensitive fluorescent assay for activity of Grx

Figure 45 The reaction in sensitive fluorescent assay for GPx system......................77

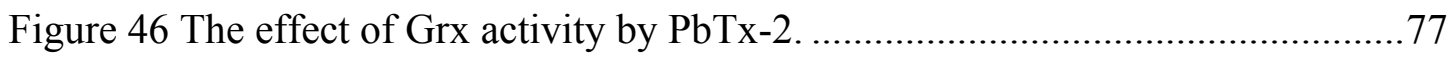

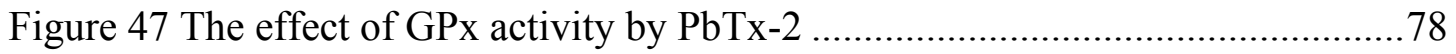

Figure 48 The common pathways to produce ROS ................................................93

Figure 49 Major physiological function of the mammalian thioredoxin system.........95

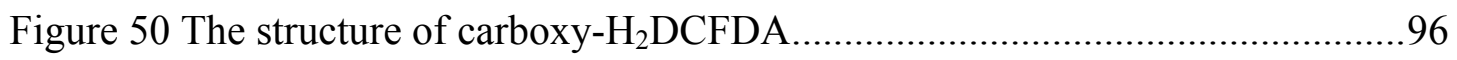

Figure 51 The ROS production in two strains of K. brevis .....................................96

Figure 52 NPQs for the low and high toxic algal cultures to the pulses of four

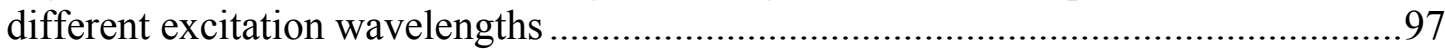

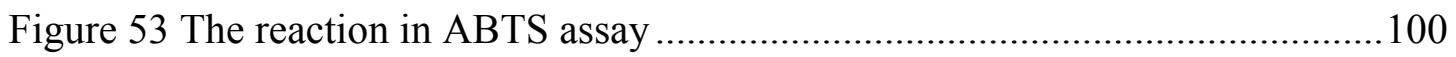

Figure 54 The antioxidant capacity in two strains of $K$. brevis ................................101

Figure 55 The total amount of ascorbic acid in two stains of $K$. brevis ....................101

Figure 56 The detection of thiols in K. brevis homogenate by modified papain assay

Figure 57 The concentration of cells over the lifetime of high toxin and low toxic strains

Figure 58 The redox state of high toxic and low toxic strains.

Figure 59 The totally glutathione in two strains of $K$. brevis and the ratio of native reduced glutathione to total glutathione in two strains of $K$. brevis

Figure 60 The fluorescence is released by the reaction of sel-green probe with thiol groups and selenol groups in K. brevis homogenate 106

Figure 61 Using the fluorescent Trx / TrxR system kit detects the Trx activity in K. brevis homogenate.

Figure 62 Using the fluorescent Grx kit detects the Grx activity in K. brevis homogenate.

Figure 63 Spinach homogenate was incubated with photoaffinity probe in PBS for 1 hour. 
Figure 64 A-ring derivative from $\mathrm{PbTx}-2$ or $\mathrm{PbTx}-3$ A-ring diol . 118 


\section{LIST OF ABBREVIATIONS}

$\mathrm{AAO}$

ABTS

Abs

ASP

ATP

AZ

AZP

BP

BSA

CFP

CSD

Cys

Chl

${ }^{1} \mathrm{Chl}^{*}$

${ }^{3} \mathrm{Chl}^{*}$

DAPI

D

DD

DIA

$\mathrm{DMF}$

DNase

DNA

DSP

DTNB ascorbic acid oxidase

2,2'-azino-bis(3-ethylbenzothiazoline-6-sulphonic acid

absorbance

amnesic shellfish poisoning

adenosine triphosphate

tetrafluorophenyl azides

azaspiracid poisoning

benzophenone

bovine serum albumin

ciguatera fish poisoning

Cambridge Structural Database

cysteine

chlorophyll

singlet chlorophyll

triplet chlorophyll

4, 6-diamidino-2-phenylin-dole)

dinoxanthin

diadinoxanthin

trifluoromethylphenyl diazirines

dimethylfomamide

deoxyribonuclease

deoxyribonucleic acid

diarrhefic shellfish poisoning

5, 5'-dithio-bis-(2-nitrobenzoic acid) 
DTT

E. coli

EDTA

FAD

FITC

FT-ICR

FTR

GpA

Gpx

GR

Grx

GSH

GSSG

$\mathrm{H}_{2} \mathrm{O}_{2}$

hTrxR

IAC

ICW

$\mathrm{IC}_{50}$

IPCC

K. brevis

$\mathrm{kDa}$

$\mathrm{K}_{\mathrm{i}}$

$\mathrm{K}_{\mathrm{m}}$ dithiothreitol

Emilliania huxlei

ethylenediaminetetraacetic acid

flavin adenine dinucleotide

fluorescein isothiocyanate

fourier transform ion cyclotron resonance mass spectrometer

ferredoxin thioredoxin reductase

glycophorin A

glutathione peroxidase

glutathione reductase

glutaredoxin

glutathione

glutathione disulfide

hydrogen peroxide

human thioredoxin reductase

iodoacetamide

Intracoastal Waterway

half maximal inhibitory concentration

Intergovernmental Panel on Climate Change

K. brevis

kilodalton

the concentration to produce half maximum inhibition

the substrate concentration to produce half maxium velocity 


\begin{tabular}{|c|c|}
\hline LipDH & lipoarmide dehydrogenase \\
\hline LSP & ladder shape polyether \\
\hline mRNA & messenger ribonucleic acid \\
\hline MW & molecular weight \\
\hline NADPH & nicotinamide adenine dinucleotide phosphate \\
\hline $\mathrm{NCBI}$ & National Center for Biotechnology information \\
\hline NMR & nuclear magentic resonance spectroscopy \\
\hline NO & nitric oxide \\
\hline NPQ & non-photochemical quenching \\
\hline NSP & neurotoxic shellfish poisoning \\
\hline NTRC & NADPH dependent thioredoxin reductase \\
\hline $\mathrm{OA}$ & okadaic acid \\
\hline $\mathrm{O}_{2}^{-}$ & superoxide anion \\
\hline $\mathrm{OH}$ & hydroxyl radical \\
\hline PAL & photoaffinity labeling \\
\hline PAM & pulsed amplitude modulation \\
\hline PBS & phosphate buffered saline \\
\hline $\operatorname{PbTx}$ & brevetoxin \\
\hline PDI & protein disulfide isomerase \\
\hline $\mathrm{PE}$ & polyether \\
\hline Prx & peroxiredoxins \\
\hline PSP & paralytic shellfish poisoning \\
\hline ROS & reactive oxygen species \\
\hline SDS-PAGE & $\begin{array}{l}\text { sodium dodecyl sulfate polyacrylamide gel } \\
\text { electrophoresis }\end{array}$ \\
\hline
\end{tabular}


$\mathrm{Sec}$

$\mathrm{S}_{\mathrm{N}} 2$

$\mathrm{S}_{\mathrm{N}} \mathrm{Ar}$

SOD

SPR

TCEP

TEAC

TGR

Tris

TNB

Trx

TrxR

VDE

VGSC

YTX

ZE

2-Cys Prxs

$\beta$

$\alpha$

${ }^{0} \mathrm{C}$

g

$\mathrm{hr}$

1

$\mu$

$\lambda$ selenocysteine

nucleophilic substitution reaction

nucleophilic aromatic substitution

superoxide dismutase

surface plasmon resonance

tris (2-carboxyethyl) phosphine hydrochloride

trolox equivalent antioxidant capacity

thioredoxin glutathione reductase

Tris(hydroxymethyl)aminomethane

2-nitro-5-thiobenzoic acid

thioredoxin

thioredoxin reductase

violaxanthin de-epoxidase

voltage-gated sodium channel

yessotoxin

zeaxanthin epoxidase

2-cysteine peroxiredoxins

bata

alpha

degress Celsius

gram

hour

liter

micro

lamdba 
milli

mol

mole

$\min$

minute

$\%$

percentage 


\section{Chapter 1 Introduction}

\subsection{Harmful algal blooms (HABs)}

Microscopic algae, or phytoplankton are common in coastal waters. Although phytoplankton are small, they can grow explosively under certain conditions that are not yet well understood, creating a phenomenon commonly known as algae blooms. Algal blooms may occur in freshwater as well as in marine environments. During a bloom, algae may become concentrated enough to turn the water red, brown or black. These blooms are often referred to as red tides.

The algae reproduce rapidly when the nutrient levels increase above the normal conditions. An intense bloom can cause harmful impacts on marine ecosystems. It can consume oxygen or block sunlight that is essential for the survival of other organisms. As a result, the concentrated algal blooms, which spread across the surface of the ocean or freshwater, can inhibit the growth of other species (Baden, Bourdelais et al. 2005). Algal blooms may or may not occur seasonally, are often localized to specific geographic regions, and may be triggered or exacerbated by environmental factors (Baden, Bourdelais et al. 2005). These may be related to changes in species of algae's composition or other environmental cues. It has been hypothesized that eutrophication, nutrient sources and some natural processes contribute to the occurrence of harmful algae bloom, such as river runoff, pollution, changes in the temperature of the oceans and so on. These all have been associated with blooms (Baden, Bourdelais et al. 2005). Because of the nutrient rich environments, coastal regions are most severely impacted by marine blooms. It has been suggested that blooms have increased in frequency and duration along the coastlines and in the surface waters of the United States as a result 
of human activities (Fleming, Backer et al. 2005). Many of the nutrients which support algal growth may be found in certain fertilizers which are discharged into the water as agricultural waste (Stumpf, Culver et al. 2003). Increased nitrogen (N) and phosphorus (P) input resulting from human activities can stimulate bloom growth along the coast (Harrison, Caraco et al. 2005, Seitzinger, Harrison et al. 2005, Burkholder, Dickey et al. 2006, Bricker, Longstaff et al. 2008). In some cases, the connections between algal blooms and eutrophication are clear and well documented. For example, in the 1970 s a reduction in red tide, which was proportional to mandated pollution reductions, was observed in the Inland Sea of Japan for a decade (Takahashi, Kawamura et al. 2009). Also, an increase in nutrient input in the northwestern Black Sea in the 1980s, is correlated with an increase in algal blooms during the subsequent two decades (Bodeanu, Moncheva et al. 1998). Over the past several decades, red tide has occurred almost annually along the Gulf Coast of Florida, has spread along the Texas and eastern Florida coasts, and occasionally along the coasts of Louisiana, Mississippi, and Alabama (Thyng, Hetland et al. 2013). It is indicated that eutrophication is responsible for the increasing of the red tide in Gulf of Florida (Heisler, Glibert et al. 2008). However, the mechanisms of the stimulation of algal bloom by nutrients are not always clear and remain controversial.

In addition to eutrophication, climate change is among the suspected factors for the increased frequency of blooms. Global warming has led to the temperature rising on the surface of ocean. Recently, the Intergovernmental Panel on Climate Change (IPCC) verified that over the past 40 years, the ocean absorbed 90 percent of earth's net energy, resulting in nearly $4{ }^{\circ} \mathrm{C}$ increase in the ocean (Collins, Knutti et al. 2013). Warmer water provides blooms a favorable environment to grow. As a result, a range 
expansion of algal bloom has been observed under warm weather conditions. However, debate on the ultimate cause of range expansions is ongoing (Smayda 2007, Hallegraeff 2010).

Although algae are essential to marine and fresh-water ecosystems, some species of algae are harmful or even toxic. Some algae can produce toxins that damage the health of the environment, plants, animals, and humans. These algal blooms, which can cause environmental or public health threats, are referred to as harmful algal blooms (HABs) (Hallegraeff 1993). Some HABs are associated with the production of algal toxins. Toxins are a form of secondary metabolite; or organic compounds that are not essential to the normal growth or development of an organism. Secondary metabolites are typically produced by one species or a few closely related species and are generally believed to convey a selective advantage to the producing organism. Toxins pose a serious threat to other species sharing the aquatic environment with the algae. Animals, who consume contaminated seafood, sea grass, and contaminated seawater or inhale contaminated aerosols can suffer severe poisoning often resulting in mass mortalities of marine animals. For example, the historical records have shown that Florida red tide bloom can cause massive mortalities of at least 100 species of marine animals, such as shellfish, sea birds, manatees and dolphins (Martin and Martin 1976). A number of human poisoning syndromes are caused by ingestion of HAB related toxins in contaminated seafood (Table 1) (Anderson, Moore et al. 2015), such as paralytic shellfish poisoning (PSP), neurotoxic shellfish poisoning (NSP), amnesic shellfish poisoning (ASP), ciguatera fish poisoning (CFP) and azaspiracid poisoning (AZP), which are caused by HAB related toxins (Anderson, Moore et al. 2015). An alternate exposure route resulting from human activities or wave action can 
release toxins into ambient water or air. Algal toxins are generally very stable molecules and can persist in the environment unchanged for long periods.

Table 1 Human poisoning syndromes caused by HAB

\begin{tabular}{|c|c|c|c|}
\hline SYNDROME & SPECIES & TOXIN & Symptoms \\
\hline $\begin{array}{l}\text { Paralytic Shellfish } \\
\text { Poisoning (PSP) }\end{array}$ & $\begin{array}{l}\text { Alexandrium spp. } \\
\text { Pyrodinium spp. } \\
\text { Gymnodiunium spp. }\end{array}$ & Saxitoxin & $\begin{array}{l}\text { Numbness, vomiting, } \\
\text { diarrhea and others. }\end{array}$ \\
\hline $\begin{array}{c}\text { Neurotoxic } \\
\text { Shellfish Poisoning } \\
\text { (NSP) }\end{array}$ & Karenia spp & Brevetoxin & $\begin{array}{l}\text { Nausea, vomiting and } \\
\text { muscle weakness }\end{array}$ \\
\hline $\begin{array}{l}\text { Amnesic Shellfish } \\
\text { poisoning (ASP) }\end{array}$ & $\begin{array}{c}\text { Pseudo-nitzschia spp. } \\
\text { Nitzschia navis-varingica }\end{array}$ & Domoic Acid & $\begin{array}{c}\text { Nausea, vomiting, } \\
\text { headache, dizziness and } \\
\text { others } 1\end{array}$ \\
\hline $\begin{array}{l}\text { Ciguatera Fish } \\
\text { Poisoning (CFP) }\end{array}$ & Gambierdiscus spp. & Ciguatoxins & $\begin{array}{c}\text { Nausea, vomiting, } \\
\text { diarrhea, rash and others }\end{array}$ \\
\hline $\begin{array}{c}\text { Azaspiracid } \\
\text { poisoning (AZP) }\end{array}$ & Azadinium spp. & Azaspiracid & $\begin{array}{c}\text { Nausea, vomiting, } \\
\text { abdominal cramps and } \\
\text { others } 1\end{array}$ \\
\hline $\begin{array}{l}\text { Diarrhetic shellfish } \\
\text { poisoning (DSP) }\end{array}$ & $\begin{array}{l}\text { Dinophysis spp. } \\
\text { Prorocentrum spp. }\end{array}$ & Okadaic acid & $\begin{array}{c}\text { Nausea, vomiting } \\
\text { abdominal cramps and } \\
\text { others }\end{array}$ \\
\hline
\end{tabular}

\subsection{Karenia brevis ( K. brevis )}

Karenia brevis, formerly known as Gymnodinium breve and Ptychodiscus brevis, is the major $\mathrm{HAB}$ forming organism in the Gulf of Mexico. Karenia brevis is a microscopic, single-celled, photosynthetic dinoflagellate which is responsible for the Florida "red tide". Karenia brevis cell size is usually between 20 and $40 \mathrm{~nm}$ in diameter. The organism has cellulose plates, called theca, surrounding the cell as protection, which creates the boundary for the cell. On the cellulose plates there are two flagellum located in two grooves called the transverse and longitudinal grooves. Two flagella allow K. brevis to move through water with a spinning motion. Usually, one of flagellum wraps around the cell in the transverse groove whereares the other 
one extends on the longitudinal groove. Both the theca and flagella are visible in Figure. 1. The nucleus is located in the lower part of the cell. Usually, becuase of the presence of chloroplasts, K. brevis is yellow-green in color. Karenia brevis is an obligate autotroph with facultative heterotrophy. It can gain energy from some organic molecules and utilizes inorganic molecules such as nitrogen and phosphorus. It also can produce energy from photosynthesis (Hitchcock, Kirkpatrick et al. 2010).

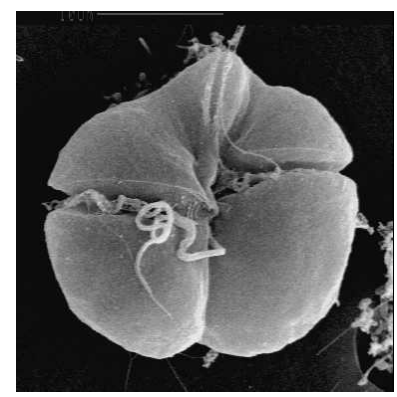

Figure 1 Karenia brevis. Image courtesy of Florida Fish and Wildlife Conservation Commission

Light is an essential requirement for K. breivs, thus it cannot survive at depths below 200 feet. Normally K. brevis is found on the surface of the water. The optimal temperature range for $K$. brevis is $22-28$ degrees Celsius. In addition, $K$. breivs can live in a salinity range of $25-45$ ppt. Under the appropriate conditions including sufficient light and nutrients, $K$. brevis can concentrate from 100,000 to 250,000 cells/ liter within 2 months (Tester and Steidinger 1997). Blooms of K. brevis may also provide a significant source of fixed carbon thorough photosynthesis (Vargo, Heil et al. 2002).

\subsubsection{The historical records of $K$. brevis}

Karenia brevis blooms were first recorded centuries ago. According to historical records, a red tide was first mentioned and documented in Gulf of Mexico in 1658 (Magaña, Contreras et al. 2003). It has been documented on the Florida west coast 
since the 1800 s. In the past decade, the Florida red tide blooms have been widespread in the Gulf of Mexico, especially from Clearwater to Sanibel Island (Backer, Kirkpatrick et al. 2005). Most commonly, K. brevis blooms can last more than two months in regions of the Gulf of Mexico including: the west Florida shelf, the Campeche Bay between Rio Ciatzacoalcos and Rio Grijalva, and Texas coast between Port Arthur and Galveston Bay (Tester and Steidinger 1997). A bloom which occurred in 2005 persisted for nearly one year (Hoagland, Jin et al. 2014).

Blooms of $K$. breveis result in detrimental effects to marine life and local economies and as people living, working, and visiting the affected coastal areas (Backer, Kirkpatrick et al. 2005). It is documented that cell densities as low as $10^{3}$ cell/L will cause respiratory irritation, whereas a concentration of more than $5 \times 10^{3}$ cells/L can induce neurotoxic effects. Massive fish kills can be caused by densities over $10^{5}$ cell/L, and cell densities over $10^{6}$ cell/L result in water discoloration (Backer, Fleming et al. 2003). An offical government record described the first reported fish kill in the Gulf of Mexico in 1792 in the city of Veracruz, Mexico (Magaña, Contreras et al. 2003). It was reported that multitudes of dead fish washed onto the beaches of Veracruz. The document also recored that same phenomenon occurred repeatedly in that port.

\subsubsection{The historical effects of $K$. brevis}

It has been proposed that there are different effects which led to the massive fish and marine animals killed by Florida red tide such as oxygen deprivation and air-born aerosols. 
Oxygen deprivation: Biochemical decomposition begins when the red tide organisms die, which can cause oxygen level to decrease rapidly. In July 1971, a large spread of red tide in Tampa Bay completely devastated the benthic ecosystem in the Bay. Oxygen deprivation, rather than toxin, was one of the considerable contributors to the death of creatures such as turtles, barnacles, birds and sponges (Simon and Dauer 1972).

Air-born aerosols: In the late 1800s massive fish kills along with human respiratory irritation and dry cough in Veracruz, Mexico were reported when a K. brevis bloom reached high concentration (Tester and Steidinger 1997, Magaña, Contreras et al. 2003). It is believed that highly concentrated $K$. brevis blooms played an essential role in the poisoning of marine life. In 1996, at least 149 manatees died along the southwest coast of Florida. According to lung pathology, a K. brevis produced toxin was detected in the lung (Flewelling, Naar et al. 2005). It is highly likely that the toxin had been inhaled by the manatees.

\subsection{Brevetoxins and related ladder-shaped polyether (LSP) compounds}

Brevetoxin are the parent of a small class of compounds called polyether ladders which are classified as polyketides according to their biogenic origin (Lee, Qin et al. 1989). The best known LSP are brevetoxin A (PbTx-A) (Figure 2), brevetoxin B (PbTx-B) (Figure 3), ciguatoxin (Figure 4) and yessotoxin (Figure 5). 


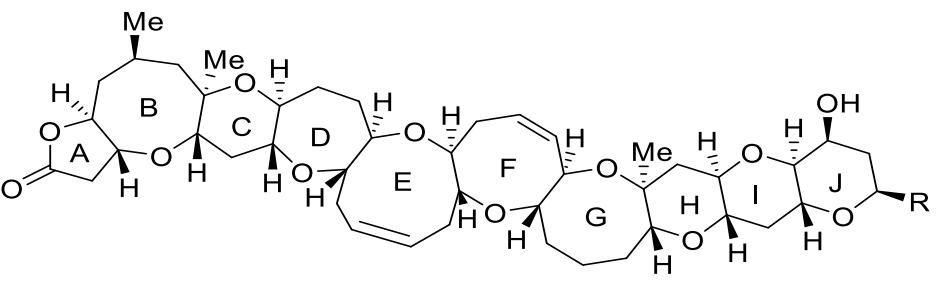

Brevetoxin-1 $(\mathrm{PbTx}-1) \mathrm{R}=-\mathrm{CH}_{2} \mathrm{C}\left(=\mathrm{CH}_{2}\right) \mathrm{CHO}$

Brevetoxin-7 (PbTx-7) R=- $\mathrm{CH}_{2} \mathrm{C}\left(=\mathrm{CH}_{2}\right) \mathrm{CH}_{2} \mathrm{OH}$

Brevetoxin-10 $(\mathrm{PbTx}-10) \mathrm{R}=-\mathrm{CH}_{2} \mathrm{CH}\left(-\mathrm{CH}_{3}\right) \mathrm{CH}_{2} \mathrm{OH}$

Figure 2 The structure of brevetoxin A

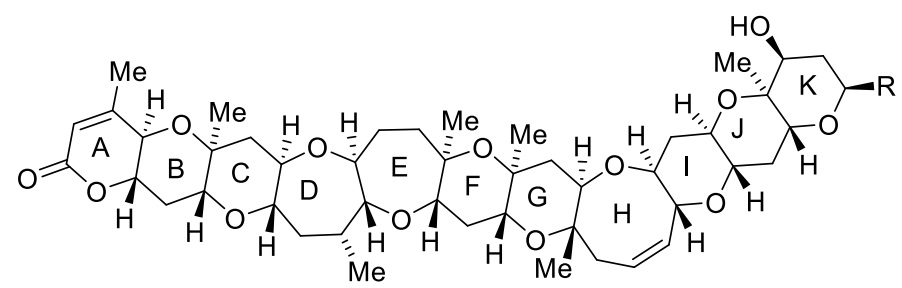

Brevetoxin-2 $(\mathrm{PbTx}-2) \mathrm{R}=-\mathrm{CH}_{2} \mathrm{C}\left(=\mathrm{CH}_{2}\right) \mathrm{CHO}$

Brevetoxin-3 (PbTx-3) R=- $\mathrm{CH}_{2} \mathrm{C}\left(=\mathrm{CH}_{2}\right) \mathrm{CH}_{2} \mathrm{OH}$

Brevetoxin-8 $(\mathrm{PbTx}-8) \mathrm{R}=-\mathrm{CH}_{2} \mathrm{COCH}_{2} \mathrm{Cl}$

Brevetoxin-9 (PbTx-9) R=- $\mathrm{CH}_{2} \mathrm{CH}\left(\mathrm{CH}_{3}\right) \mathrm{CH}_{2} \mathrm{OH}$

Figure 3 The structure of brevetoxin B

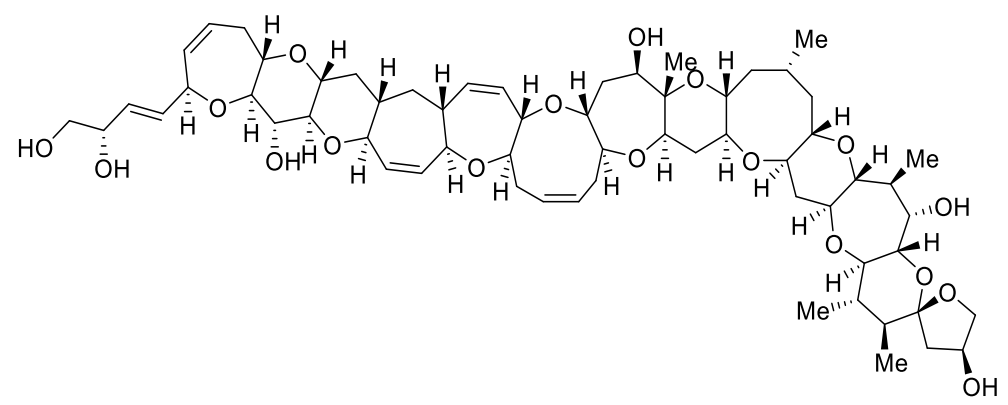

Figure 4 The structure of ciguatoxin B

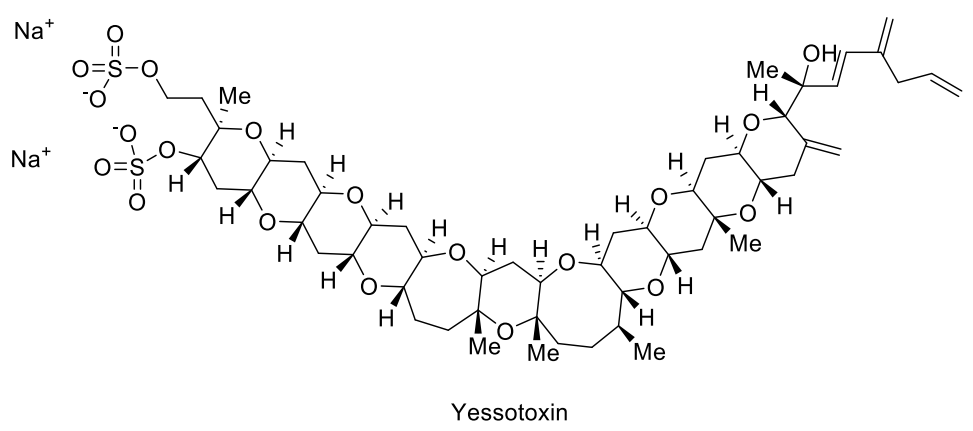

Figure 5 The structure of yessotoxin 
Inspection of these structures reveals numerous common features: these compounds consist of trans fused polyether rings with oxygen atoms that alternate from the bottom to top of the molecule (Rein and Borrone 1999). In the past decades, there are not only numerous polycyclic ethers were isolated from blooms or laboratory culture of $K$. brevis, such as brevisamide, hemibrevetoxin and brevisin (Figure 6) (Satake, Campbell et al. 2009) and brevenal (Bourdelais, Campbell et al. 2004).

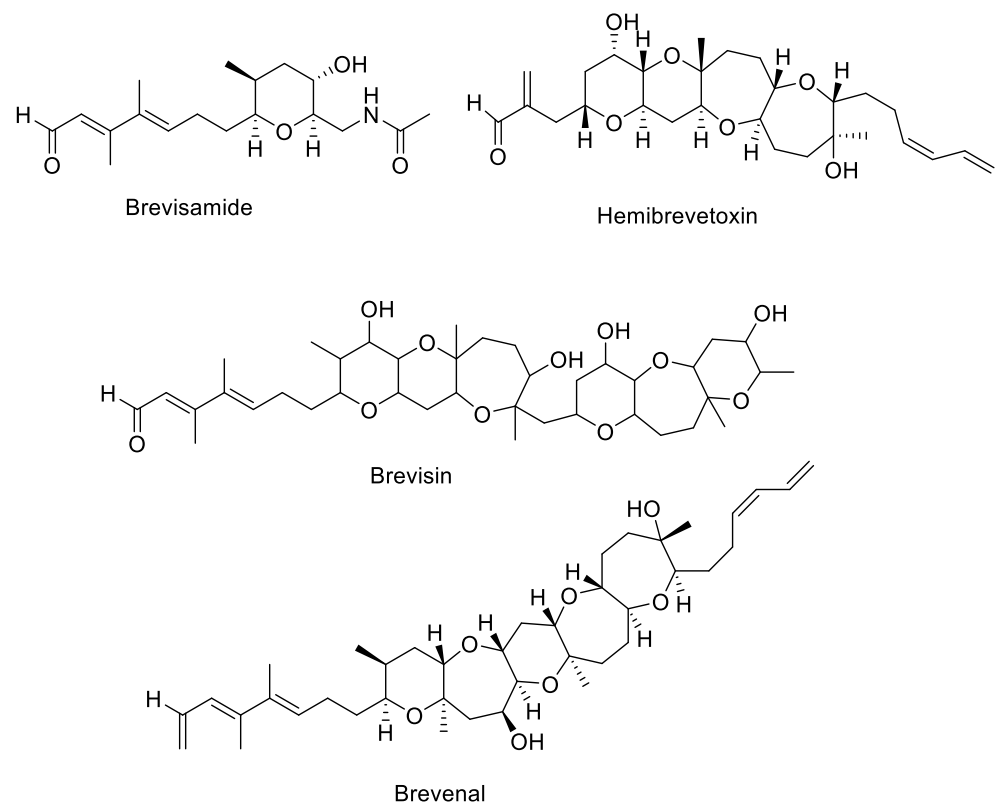

Figure 6 Structures of small polyether ladder toxins produced by dinoflagellates

Brevisin is a polycyclic ether that is consisted of two separate fused polyether rings linked with a methylene group. Brevisin and brevenal are both natural competitors of brevetoxin for its binding site (Bourdelais, Campbell et al. 2004, Satake, Campbell et al. 2009). Those polyether compounds hold great interest among many scientific groups because of their unique structure and enigmatic biosynthetic origin. However, the first challenge was characterization of polyether compounds. The molecular structure of brevetoxin B was first determined by Nakanishi's group in 1981 (Lin, Risk et al. 1981). The absolute stereochemistry of brevetoxin B was elucidated by X- 
ray crystallography (Shimizu, Bando et al. 1986). The determination of the first polyether ladder structure by X-ray crystallography simplified the subsequent structure elucidation of other polyether ladders. The structure of brevisin was determined by MS and 2D NMR (Satake, Campbell et al. 2009). The structure of the even more complex polyether ladder, ciguatoxinn, which is isolated from dinoflagellate G. toxicus was elucidated by NMR (Murata, Legrand et al. 1989, Murata, Legrand et al. 1990).

The biosynthetic pathways for these natural polyether ladder products remain a puzzle. As a result of the lack of enzymes or gene sequence for biosynthetic pathways, stable isotope labeling experiments and structural features were used to develop the biosynthetic principles. In 1985, Nakanishi proposed the currently held hypothesis for the biosynthetic pathway of brevetoxin. It was hypothesized that these polyether ladder compounds arise from the cyclization of a polyepoxide precursor (Nakanishi 1985).

Numerous individual brevetoxins (PbTxs) have been isolated and characterized from K. brevis bloom as well as laboratory culture. Taken together, PbTxs are lipid-soluble polyether compounds with molecular weights around $1000 \mathrm{D}$ (Backer, Fleming et al. 2003; Backer, Kirkpatrick et al. 2005). There are two principal types of PbTxs that differ according to the carbon skeleton; $\mathrm{PbTx}-\mathrm{A}$ and $\mathrm{PbTx}-\mathrm{B}$. A flexible backbone of 10 fused polyether rings makes up $\mathrm{PbTx}-\mathrm{A}$ which is the minor, but most toxic congener. $\mathrm{PbTx}-\mathrm{B}$, the most abundant of the two, is comprised of a rigid backbone of 11 polyether rings (Nakanishi 1985, Baden 1989). Almost a dozen derivatives of $\mathrm{PbTx}-\mathrm{A}$ and $\mathrm{PbTx}-\mathrm{B}$ occur naturally. Principal A-type brevetoxin include $\mathrm{PbTx}-1$, 
PbTx-7 and PbTx-10, while PbTx-2, PbTx-3, PbTx-8 and PbTx-9 belong to B-types brevetoxins. Others, such as $\mathrm{PbTx}-8$, a chloromethyl ketone derivative of $\mathrm{PbTx}-2$, appears to be an artifact of chloroform extraction of PbTx-2 (Nakanishi 1985, Matile, Berova et al. 1996, Baden, Bourdelais et al. 2005, Murrell and Gibson 2009); In the Florida red tide $\mathrm{PbTx}-2$ is the major brevetoxin congener in bloom water, while PbTx-3 is contained as greatest amount in aerosols (Pierce, Henry et al. 2005). Furthermore, some polar brevetoxin derivatives were isolated from $K$. brevis cultures and natural blooms as well. $\mathrm{PbTx}-1$ and $\mathrm{PbTx}-2$ both possess a lactone functionality in the A- ring and share a common, rigid region in the terminal four rings with a side chain allowing modification (Rein, Baden et al. 1994, Rein, Lynn et al. 1994). All natural brevetoxins and derivatives have these features. However, in fact no derivative is more toxic than PbTx-1 or PbTx-2 (Baden, Bourdelais et al. 2005). As identified by LC/MS, some brevetoxin derivatives were confirmed as open A-ring of brevetoxin PbTx-1, PbTx-7, PbTx-2 and PbTx-3. Some are oxidized from PbTx-1 and PbTx-2 (Abraham, Plakas et al. 2006).

The synthesis of LSPs remains a significant challenge. After twelve years of effort, the first total synthesis of brevetoxin B was reported in 1995 (Nicolaou 1996, Nicolaou, Yang et al. 1998). In the first generation strategy, hydroxyl epoxide cyclization and the intramolecular conjugate addition were used as key reactions to form the fused tetrahydropyran ring systems (Ring $\mathrm{ABC}$, ring $\mathrm{FG}$ and ring IJK). However, the step to thionate and bridge the last remaining bond required for completion of the brevetoxin B skeleton was unsuccessful (Nicolaou, Hwang et al. 1995). It failed to construct the fused oxepane rings in brevetoxin B simultaneously. Thus, stepwise bis (oxepane) synthesis approach was used to display the first strategy. 
However, the goal to fuse additional rings onto the DEFG ring system is still elusive (Nicolaou, Theodorakis et al. 1995). Finally, in his third strategy he successfully formed the ring $\mathrm{ABCDEF}$ and ring IJK, leaving the didehydrooxocane ring $\mathrm{H}$ as final ring to construct. In total, this process consists of 123 steps (Nicolaou, Rutjes et al. 1995). Nowadays, several groups have synthesized brevetoxin successfully. In 2004, brevetoxin B was synthesized in 90 steps (Stephen and Kettle 1997, Matsuo, Kawamura et al. 2004).

\subsection{Biological activities of LSPs}

The LSP compounds are responsible for a variety of some poisonings. Maitotoxin and ciguatoxin both isolated from G. toxicus are associated with the CFP symptoms such as chills, sweating, neurologic dysfunction and generalized weakness lasting from 10 min to 30 hours from consuming contained fish or food (Levine 1995). Yessotoxin (YTX) which is produced by the dinoflagellate Protoceratium reticulatum, accumulates in the gland of Japanese scallops (Murata, Kumagai et al. 1987, Satake, MacKenzie et al. 1997). Yessotoxin associated lethality occurs through acute heart disease. According to histopathology, mice exposed to yessotoxin, exhibited intercytoplasmic edema (Satake, MacKenzie et al. 1997). Thus, cardiac muscle cells are affected by yessotoxin.

\subsubsection{Biological activities of brevetoxin on animal}

Brevetoxins can persist in the ecosystem for up to eight months after the absence of K. brevis blooms. For an instance, in 2007 K. brevis was first observed in early September near Jacksonville, FL. Subsequently, it expands through the east coast of 
Florida, including the Indian River Lagoon and the Atlantic Intracoastal Waterway (ICW) (Walsh, Weisberg et al. 2009). The maximum concentration of K. brevis was up to $10^{6}$ cell / L in October. The bloom terminated in December 2007. However, brevetoxin had been detected in sediments and seagrass epiphytes in July and August 2008 in ICW. The highest concentration of brevetoxin in sediments has been found near Patrick Air Force Base at 89 ng per gram of dry sediment (Hitchcock, Fourqurean et al. 2012). Average concentration is $<20$ ng per gram of dry sediment during non-bloom periods (Flewelling 2008). At the same time, brevetoxins were detected in six of nine seagrass beds sampled at the south of the Mosquito Lagoon at concentration of 6-18 ng per gram of dry epiphytes (Hitchcock, Fourqurean et al. 2012). In general, brevetoxins can persist almost one year in either seagrass epiphytes or sediments after the termination of a bloom.

Since brevetoxins remain in seagrass and sediments for several months following bloom termination, it seems highly likely that marine life can consume the brevetoxin from contaminated seagrass or sediments. Subsequently, brevetoxins may be transported through the food chain. In the other words, blooms of brevetoxinproducing $K$. brevis have been associated with the mortality of fishery resources as well as the death of marine mammals such as the endangered Florida manatees, dolphins, turtles and shorebirds. The major route of exposure related to the deaths of dolphins, manatees, turtles and seabirds is ingestion of PbTxs. For instance, some shorebirds such as sanderlings (Calidris alba) and ruddy turnstones (Arenaria interpres) scavenged dead fish deposited onshore during a K. brevis bloom. It is reported that those shorebirds picked the eye orbit, gills and abdominal flesh or other tissues that contained lethal levels of PbTxs for these small shorebirds (van Deventer, 
Atwood et al. 2012). In 2006, more than 300 sea turtles stranded along the west coast of Florida during prolonged blooms along the coast. Some strange behavios of sea turtles had been observed, such as swimming in circles, lack of coordination, head bobbing, muscle twitching and jerky body movement. High densities of brevetoxins were detected in the organs or immune cells of sea turtles, which contributed to the stranding or death (Walsh, Leggett et al. 2010). Also, in 1996, Florida red tide caused a significant loss in the population of the highly endangered Florida manatee (Walsh, Leggett et al. 2010). Thus fish and sea grass can be vectors in which high concentrations of brevetoxins accumulate. Analysis of seagrass collected in manatee's stomach revealed the presence of brevetoxin (Flewelling, Naar et al. 2005). In both bloom and non-bloom periods, suspected red tide-related deaths of manatee occurred in southwest Florida in 2002, 2003, 2005, 2007, and most recently in 2013. Representatively, a major dolphin's death, which occurred near the Florida panhandle in the early 2000s, was associated with exposure to brevetoxin via food. High concentrations of brevetoxins were detected from fish within the stomach of the dolphin (Flewelling, Naar et al. 2005, Hoagland, Jin et al. 2009).

Over the last decade, animal studies had demonstrated the possible health effects of both long and short terms of brevetoxin exposure. After short-term treatment, rapid systemic distribution of brevetoxin occurred on mice after exposure to aerosolized brevetoxin. Particularly it is concentrated in the neurologic system (Benson, Stagner et al. 2005, Tibbetts, Baden et al. 2006). Long-term exposure of rodents (rats and mice) to aerosols including brevetoxin showed that viral clearance in the immune system was dysfunctional. Low level exposures $(\sim 10 \mathrm{pg} / \mathrm{ml}$ of PbTx-2 and PbTx-3) of both asthmatic and non- asthmatic sheep resulted in decreased respiratory function. 
However, the asthmatic sheep suffered more intense and longer lasting effects (Abraham, Bourdelais et al. 2005, Abraham, Bourdelais et al. 2005, Abraham and Baden 2006, Fleming, Kirkpatrick et al. 2011).

\subsubsection{Biological effects of brevetoxin on human}

Brevetoxin poisoning of humans can arise through food, water and air (Backer, Fleming et al. 2003, Sikorski 2006, Fleming, Kirkpatrick et al. 2007, Grimes 2009, Fleming, Kirkpatrick et al. 2011). NSP is associated with exposure of brevetoxin through the consumption of contaminated shellfish. The other most common route of exposure to the brevtoxins is inhalation (Backer, Fleming et al. 2003, Backer, Kirkpatrick et al. 2005). The particle size of brevetoxin aerosol formed by wave action during a red tide has a geometric mean of about 8-9 $\mu \mathrm{m}$. In comparison, particles that are less than $5 \mu \mathrm{m}$ can enter the lower airway. That means only about $10-20 \%$ of these particles can enter the human lung (Pierce, Henry et al. 2003, Cheng, McDonald et al. 2005, Cheng, Villareal et al. 2005, Cheng, Zhou et al. 2005, Pierce, Henry et al. 2005, Fleming, Kirkpatrick et al. 2011). Nonetheless, during an active Florida red tide season many respiratory symptoms are reported by people who spend time on or near the west coast beaches, such as lifeguards and tourists (Cheng, Villareal et al. 2005, Cheng, Zhou et al. 2005, Fleming, Backer et al. 2005, Fleming, Jerez et al. 2007, Milian, Nierenberg et al. 2007). On the basis of local health care data from Florida, a significantly higher number of hospital admission for acute and subchronic respiratory effects such as asthma, bronchitis and pneumonia occur during active Florida red tides period, when compared to non-active periods, particularly for coastal residents. A comprehensive review of emergency room admissions in Florida, 
suggested that patients require emergency care during the first hour to prevent respiratory failure (Abraham, Plakas et al. 2008, Watkins, Reich et al. 2008). Humans who consume contaminated shellfish can experience NSP which is characterized by acute gastrointestinal and neurologic symptoms (Kirkpatrick, Fleming et al. 2004). Asthma-like symptoms are related to inhalation of PbTxs by marine mammals or people near the beach (Fleming, Backer et al. 2005, Fleming, Kirkpatrick et al. 2005). Thus, PbTxs are responsible for a variety of negative economic, environmental, and human health effects (Fleming, Backer et al. 2005, Errera, Bourdelais et al. 2010).

\subsubsection{The effect of brevetoxin on cellular process}

Multiple cellular effects are associated with brevetoxin exposure. Adverse effects have been observed in the immune system of many species, including manatee, rat and loggerhead sea turtle. The mechanism of brevetoxin immunotoxicity has not been understood completely. However, several potential mechanisms have been suggested. For example, brevetoxin inhibits the active sites of an important protease called cathepsin (Sudarsanam, Virca et al. 1992, Kirkpatrick, Fleming et al. 2004, Kirkpatrick, Fleming et al. 2006), which can affect the degradation of polypeptides. In order to understand the method of the inhibition, a group developed an approach via 3D structure to search a molecule as an inhibitor for this known homologous protein (Sudarsanam, Virca et al. 1992). They utilized the 3D structure of papain as model, which has similar tertiary structure to cathepsins L to search for inhibitors which filled the binding pocket using a comparative modeling technique. After searching in the Cambridge Structural Database (CSD) of small molecules, brevetoxin B was shown to fit in the binding pocket of papain and cathepsin L. Subsequently, both 
papain and cathepsin $\mathrm{L}$ were shown to be inhibited by brevetoxin with $\mathrm{K}_{\mathrm{i}} \mathrm{s}$ of $25 \mu \mathrm{M}$ and $0.6 \mu \mathrm{M}$, respectively.

Other effects of brevetoxin exposure include DNA damage (Murrell and Gibson 2009), reduced phagocytosis (Benson, Tischler et al. 1999), decreased plaque forming ability (Benson, Hahn et al. 2004, Benson, Stagner et al. 2005) and chromosomal aberration (Sayer, Hu et al. 2006). Several studies have indicated that oxidative stress may occur as the cellular response to brevetoxin exposure. For instance, After the human U-937 cells were treated with PbTx-2, the amount of glutathione was decreased while oxidative stress occurred (Walsh, Leggett et al. 2009). Other studies on marine organisms revealed a link between brevetoxin exposure and oxidative stress. The activity of the oxidative stress marker superoxide dismutase (SOD) was detected and correlated to the plasma brevetoxin levels and reactive oxygen in rescued Florida manatees after exposure to a red tide bloom (Walsh, Stuckey et al. 2007, Walsh, Butawan et al. 2015). When compared to healthy turtles, a two-fold increase in SOD was observed in rescued loggerhead turtles which correlated with plasma brevetoxin levels at $500 \mathrm{ng} / \mathrm{ml}$ (Walsh, Leggett et al. 2010). Brevetoxin exposure at 5.4-15.0 $\mu \mathrm{g} / \mathrm{L}$ increased catalase activity in coral larvae and lipid peroxidation in coral larvae and fish gills (Woo, Liu et al. 2006, Ross, RitsonWilliams et al. 2010). Furthermore, PbTx-2 was shown to induce apoptosis in human Jurkat cells (Walsh, Leggett et al. 2008). When Jurkat cells exposed to 5-10 $\mu \mathrm{g} / \mathrm{ml}$ PbTx-2 or PbTx-6, the decrease of cellular metabolic activity was observed. After $24 \mathrm{~h}$, the viability of cells that were treated with $\mathrm{PbTx}-2$ decreased. In contrast, apoptosis was increased under $\mathrm{PbTx}-2$ or $\mathrm{PbTx}-6$ exposure. Unfortunately, the mechanism for brevetoxin induced oxidative stress is still unknown. 


\subsection{LSP compounds bind to transmembrane protein}

The best-known biological effect of brevetoxins is the activation of voltage-gated sodium channel (VGSC), a transmembrane protein, which induces the ion influx resulting in numerous physiological effects.

The VGSC is composed in large part of transmembrane $\alpha$-helices, and membraneintegral $\alpha$-helix peptides are considered as common interacting motifs of LSPs. Voltage-gated sodium channel is essential for the initiation and propagation of action potentials in excitable cells. Voltage-gated sodium channel has long been believed to be the principle mammalian target of the brevetoxins. In addition, because of the similarity of yessotoxin to brevetoxin, it has been suggested that yessotoxin increased the permeability of sodium ions in cell membrane, resulting in the symptoms of CFP. For example, the $\alpha$-helices of glycophorin A (GpA), a membrane protein found in erythrocytes, have been used as a model system for evaluating the interaction between LSPs and $\alpha$-helices. The association between $\alpha$-helical glycine and valine residues of GpA result in dimer formation in membrane environments (Bormann, Knowles et al. 1989). The association of LSPs such as YTX, desulfated YTX, PbTxs and artificial polyethers with GpA results in disruption of the oligomers or dimers. The disruption can be evaluated by SDS-PAGE. The results demonstrated that the LSPs interact with the transmembrane portion of glycophorin A to induce the dissociation of oligomers of the protein. In order to quantify the interaction of LSPs with GpA, surface plasmon resonance (SPR) and saturation transfer difference NMR were applied. The dissociation constants $\left(\mathrm{K}_{\mathrm{d}}\right)$ of YTX and desulfated YTX with a transmembrane domain peptide of GpA were determined to be in the submillimolar range (Ujihara, 
Oishi et al. 2008). All results suggested that hydrophobic matching is important for LSP binding to transmembrane $\alpha$-helices. Moreover, taken together, it indicated that hydrophobic interactions play a key role in molecular recognition of the $\alpha$-helical peptides by LSPs.

Both brevetoxins and ciguatoxin bind to and activate the VGSC at site 5 . These site 5 toxins induce channel opening at normal resting potentials leading to a change in the biophysical properties of the VGSCs. Like brevetoxins, VGSC opening at normal cell resting membrane potentials results in an influx of $\mathrm{Na}^{+}$ions and cell depolarization. Although ciguatoxin acts at the same receptor site of the $\mathrm{Na}^{+}$channel as brevetoxin, the affinity of brevetoxin for sodium channel is around 30 times lower than that of CTX-1. In addition, CTX-1 competitively inhibits the binding of brevetoxin to the voltage-dependent $\mathrm{Na}^{+}$channel of rat membranes. As a consequence, ciguatoxin cause the an abnormally prolonged $\mathrm{Na}^{+}$channel opening in nerve membranes, slowing the nerve conduction velocity (Lehane and Lewis 2000, Kumar-Roiné, Matsui et al. 2011). In addition, compared to the short-term effects on nerve and muscle tissue by brevetoxin, ciguatoxin induces long-term nerve damage. The plasma membrane is unable to maintain the internal environment of cells and volume control, resulting in cell and mitochondrial swelling and bleb formation. Thus, ciguatoxin is responsible for the disruption of important ion exchange system (Lehane and Lewis 2000). Fortunately, intravenous (IV) mannitol infusion is the most common treatment for CFP (Friedman, Fleming et al. 2008). Mannitol is given at a dose of 0.5 to 1.0 $\mathrm{g} / \mathrm{kg}$ body weight over 30-45 minutes. However, it must be administered within 24 hours of exposure to be effective. Also, the osmotic reduction of neuronal edema was 
indicated to mediate the effect of mannitol infusion (Pearn 2001, Friedman, Fleming et al. 2008).

Last but not least, maitotoxin, a water soluble toxin, acts on calcium channels (Taglialatela, Amoroso et al. 1986). Treatment of cells with low concentrations of maitotoxin results in activation of voltage sensitive calcium channels demonstrating that maitotoxin affects the uptake of calcium ion in cells. However, no affinity was found by maitotoxin for voltage-gated sodium channel through binding experiment on rat brain cortical synaptosomes. Furthermore, it is also reported maitotoxin is associated with neurotransmitter, hormone release, phospholipid metabolism and smooth muscle contractions (Schettini, Koike et al. 1984, Berta, Phaneuf et al. 1988, Gusovsky and Daly 1990).

\subsection{The interaction between PbTxs VGSC at the molecular level}

\subsubsection{PbTxs exert their effects through specific binding of PbTx to the VGSC}

Previous work has shown that there are multiple distinct receptor sites for neurotoxins in sodium channels. For example, receptor site 1 binds the inhibitors tetrodotoxin and saxitoxin, which block ion transport through the sodium channel. Grayanotoxin and the alkaloids veratridine, batrachotoxin and aconitine bind to receptor site 2 , which cause repetitive firing and persistent activation of sodium channels (Catterall 1980, Catterall, Morrow et al. 1981, Catterall 1986). Receptor site 3 binds the $\beta$-scorpion toxins and sea anemone toxins, which can inhibit sodium channel inactivation and enhance persistent activation of sodium channels by veratridine and other toxins acting at receptor site 2 (Tejedor and Catterall 1988, Rogers, Qu et al. 1996). Receptor site 4 binds $\beta$-scorpion toxins from American scorpions, which can shift the 
voltage dependence of sodium channel activation (Catterall 1977). These other neurotoxins that bind to the sodium-voltage gate channel failed to displace ${ }^{3} \mathrm{H}$ labeled PbTx from its binding site. The previous experiments led to the conclusion that the PbTxs bind to a unique site in the VGSC that was termed site 5 (Poli, Mende et al. 1986). The specific binding is reversible and temperature-dependent. Through analysis, $\mathrm{PbTx}-3$ binding was determined have a $\mathrm{K}_{\mathrm{d}}$ of $2.9 \mathrm{nM}$ (at $4^{\circ} \mathrm{C}$ ). Equilibrium binding was also observed after incubation of ${ }^{3} \mathrm{H}$ labeled PbTx-3 with Tilapia brain synaptosomes with a $\mathrm{K}_{\mathrm{d}}$ of $6.1 \mathrm{nM}$ (Stuart and Baden 1988). It was also determined that $\mathrm{PbTx}-3$ can be displaced by $\mathrm{PbTx}-1$ and $\mathrm{PbTx}-2$ at specific binding site.

Electrophysiological studies revealed that specific binding of PbTx to the VGSC results in membrane depolarization in a dose dependent manner (Huang, Wu et al. 1984). When PbTx is incubated with crayfish giant axons, the extent of maximum depolarization is about $40 \mathrm{mV}$, with an $\mathrm{EC}_{50}$ of $1.7 \mathrm{nM}$ (Huang, Wu et al. 1984). Thus, PbTxs cause depolarization of excitable membranes, facilitating the inward flow of sodium ions into the cells (Trainer and Baden 1991, Dechraoui, Naar et al. 1999). Binding of PbTxs to the sodium channel causes a shift the channel activation potential to more negative values, inhibits channel inactivation and prolongs mean open times of the channel (Jeglitsch, Rein et al. 1998). Thus, PbTxs disrupt the normal transmission of electrical signals within the neurological system. A massive release of neurotransmitter is stimulated by the depolarization of nerve terminals, which results in a wide range of responses in the organs. Therefore the consumption of seafood contaminated with PbTxs has the potential to disrupt normal neurological systems causing the illness clinically described as NSP (Twiner, Bottein Dechraoui et al. 2007). 


\subsubsection{Specific interactions between brevetoxin and the VGSC}

The VGSC is composed of an $\alpha$-subunit and two $\beta$-subunits. The $\alpha$-subunit is the major subunit and made up of four domains. The four domains of the channel containing six transmembrane $\alpha$-helices with the connecting amino acid sequence between helices 5 and 6 coming together to line the pore through which the ions travel (Heinemann, Terlau et al. 1992, Hille 2001). Early studies, which helped to define the interaction between the PbTxs and the VGSC at the molecular level included structure activity studies, conformational analysis and photoaffinity labeling of the receptor (Poli, Mende et al. 1986, Trainer and Baden 1991, Trainer, Thomsen et al. 1991, Rein, Baden et al. 1994).

Brevetoxin-A and brevetoxin-B bind to the same unique site of the VGSC at site 5 which is located on domain IV of the $\alpha$-subunit of the channel. Using photoaffinity labeled $\mathrm{PbTx}$ in rat brain synaptosomes the $\mathrm{PbTx}$ high affinity receptor site was localized to the $\alpha$-subunit. After binding of the photoaffinity probe, a $p$-azidobenzoate tritium-labeled brevetoxin derivative, to the VGSC and photoloysis, it was shown that the VGSC was covalently labeled with the PbTx-3 derivative. After digestion with proteolytic enzymes, antibody mapping of the proteolytic fragments localized the covalent incorporation of this neurotoxin to the sodium channel $\alpha$-subunit on the extracellular side of S5 in domain IV and on the extracellular end of the S6 in domain I (Rein, Baden et al. 1994, Trainer, Baden et al. 1994).

Neuronal tissues in marine mammal have similar sodium channel density as terrestrial mammals. Brevetoxin (PbTx-3) binds to manatee brain synaptosomes with nanomolar 
affinity at $37{ }^{\circ} \mathrm{C}$. (Trainer and Baden 1999). The dissociation constant $\left(\mathrm{K}_{\mathrm{d}}\right)$ is $7.5 \pm 2.5$

$\mathrm{nM}$ for manatee synaptosomes, which is a similar affinity to terrestrial mammals (Trainer and Baden 1999). Since 1982 to 2005, hundreds of manatees were found dead or dying on the beaches of the Florida west coast when high densities of $K$. brevis were present, including 39 deaths in 1982, 149 deaths in 1996 and 34 deaths in 2002. Unbelievably, in 2005 it is reported that 85 manatees died because of $K$. brevis (O'Shea, Rathbun et al. 1991, Bossart, Baden et al. 1998). In Assuming 11 pg brevetoxin was produced from a single cell (Stuart and Baden 1988). If the affinity of manatee for brevetoxin is $7.5 \mathrm{nM}$, approximately, $3 \times 10^{5}$ cell/L brevetoxins are required. Whereas in fact concentration of brevetoxin cells at that period persisted at $100,000 \mathrm{cells} / \mathrm{L}$. This discovery indicated that manatees were exposed to a lethal dose of brevetoxin in 1996 (Trainer and Baden 1999). Neuronal cells, skeletal muscle cells and cardiac cells are all excitable tissues, which contain VGSC to mediate the rapidly activation and inactivation of $\mathrm{Na}^{+}$influx. A comparative study examined the binding properties of brevetoxins with skeletal muscle and cardiac sodium channel $\alpha$-subunit isoforms of human embryonic cells. Brevetoxin B was found to have isoform selectivity with cardiac channel and skeletal muscle channel (Dechraoui and Ramsdell 2003). It is determined that the inhibitory constants $K_{i}$ for PbTx-3 were $4.7 \mathrm{nM}$ for skeletal muscle channels, while it is $20.5 \mathrm{nM}$ for cardiac sodium channels.

\subsection{The effect of brevetoxin on economy}

As a consequence of a bloom along coastal waters, local economies suffer not only direct losses to fishing and tourism but also economic effects associated with animal death, clean-up, rescue and rehabilitation, and public health also cause additional 
losses. A single toxic bloom can result in as much as \$22 million in lost revenue from tourism and related business (Dyson and Huppert 2010, Anderson, Moore et al. 2015). In 2000, a large bloom of $K$. brevis occurred in Galveston County, Texas. It required \$18 million for direct cleanup and subsequent losses to fishing and tourism (Evans and Jones 2001). The economic costs caused by the harmful effect of K. brevis are estimated to exceed \$38 million annually (Twiner, Bottein Dechraoui et al. 2007). A cost model using the data on emergency room visits for respiratory damage, the $K$. brevis density, measurement of pollutant, annual population change and tourism estimated that the cost of illness associated with $K$. brevis in Sarasota county alone can range from $\$ 0.5-\$ 4$ million (Hoagland, Anderson et al. 2002, Hoagland, Jin et al. 2009, Kirkpatrick, Bean et al. 2010). Furthermore, during an active Florida red tide period the costs resulting from lifeguard absenteeism can reach up to $\$ 100,000$ in Sarasota Beach alone. In 2014, Hoagland estimated that annual costs of illness caused by Florida red tide ranged from $\$ 60,000$ and $\$ 700,000$ per year. However, it is assumed that this cost could be increased to $\$ 1$ million per year by several long-last Florida red tide. Furthermore, in future the cost of illness would range between $\$ 2$ and \$24 million under a worst case scenario (Hoagland, Jin et al. 2014).

\subsection{Brevetoxins play an important role in $K$. brevis, but it is still elusive}

Because PbTxs are retained in K. brevis cells, it has been presumed that they play a functional role for $K$. brevis. Although a primary cellular function for PbTxs has remained elusive, it is reported that the responses to environmental conditions, such as salinity, influence the growth potential and toxin production of harmful dinoflagellates (Grzebyk, Béchemin et al. 2003, Magaña, Contreras et al. 2003). In 2011, it was proposed that PbTxs play an important role in osmoregulation by $K$. 
brevis. It was found that osmotic stress triggered $\mathrm{PbTx}$ production by $K$. brevis in three $K$. brevis clones under variable salinity conditions that result in changing osmotic stress. A rapid decrease in salinity from typical oceanic conditions of $35 \mathrm{ppt}$ to approximate coastal conditions of $27 \mathrm{ppt}$ resulted the concentration of brevetoxin per cell increasing within 5 days under hypoosmotic stress and provided evidence to suggest PbTxs play a role in osmoregulation. Furthermore, in order to understand the response of $K$. brevis to osmotic stress, a time course experiment to measure changes in cell volume and PbTxs production was performed. $<3 \mathrm{~h}, 24 \mathrm{~h}, 6 \mathrm{~d}, 67 \mathrm{~d}$, and $111 \mathrm{~d}$ after the rapid salinity shift PbTxs content was examined. Brevetoxin increased within $3 \mathrm{~h}$ after the hypoosmotic stress and continued to increase through day 6 . After 6 days the concentration of PbTxs reached the highest level (Errera and Campbell 2011). However, in 2012 this conclusion was challenge by several other research groups who attempted to repeat Errera and Campbell's experiments. Two separate laboratories reported that a sudden decrease in salinity from $35 \mathrm{ppt}$ to $27 \mathrm{ppt}$, did not trigger brevetoxin production. These results were consistent across each of eight K. brevis strains (Sunda, Burleson et al. 2013). Consequently, this debate generated much attention from researchers. Still, the cellular function of PbTxs is under debate.

Chemical and predatory defense has been proposed as the reasons for brevetoxin production by $K$. brevis. Feeding experiment experiments using PbTxs have been conducted to better understand how $K$. brevis escapes predation pressure. Rotifers are common microzooplankton grazers which co-exist in coastal water with $K$. brevis. Compared to a known palatable food for rotifers, when $K$. brevis cells were offered as a sole diet for rotifers, all rotifers stopped grazing and breeding. However, it is not clear that the deterrence of grazing was a result of the presence of PbTxs. Rotifers fed 
with yeast containing pure $\mathrm{PbTx}-2, \mathrm{PbTx}-3$ and $\mathrm{PbTx}-9$ were not deterred from grazing (Kubanek, Snell et al. 2007). Thus, defending K. brevis against grazing by may or may not be a role for brevetoxins.

\subsection{The significance of studying the dinoflagellates}

In the past decades, scientists have made significant progress in determining the effects and the underlying mechanisms of dinoflagellate toxins on higher organisms. Because of the extensive damage and pharmacological effects caused by K. brevis, there is considerable interest in understanding the function of PbTxs. If a metabolic or biochemical role for brevetoxins can be identified, this may provide for more accurate prediction of bloom dynamics and toxicity. The role of brevetoxin in cells can lead to more accurate predictions, mitigation and management of toxic blooms. While numerous hypotheses have been proposed and several studies performed, the intrinsic role of dinoflagellate toxins remains unknown In addition; the discovery of the native role of brevetoxin in $K$. brevis may provide insight into understanding the role of other polyether compounds in dinoflagellates such as ciguatoxin, maitotoxin and yessotoxin.

\subsection{Research objectives}

The research will focus on identifying the intrinsic biochemical function of PbTxs and identification of a molecular receptor for brevetoxin in K. brevis. Localization of PbTxs to a subcellular organelle and identification of a target protein from K. brevis, which interacts with PbTxs as well as comparison of biochemical and metabolic indicators in K. brevis strains with vastly different toxin content, may point towards a native function for PbTxs. 


\section{Objectives}

1.To localize brevetoxin in K. brevis using a fluorescently labeled brevetoxin probe.

2.To identify one or more target protein(s) of brevetoxins from K. brevis.

3. To characterize interaction between brevetoxin and its native receptor protein

4. Compare and contrast various metabolic and biochemical parameters in two strains of $K$. brevis which have a tenfold difference in toxin content. 
Chapter 2 Localization of PbTxs to a subcellular organelle and identification of a target protein from $K$. brevis

\subsection{Localize PbTxs to one or more organelles or cellular structures in $\mathbf{K}$. brevis}

\subsubsection{Objective}

The localization of brevetoxin to one or more organelles in K. brevis cells should provide clues as to the intrinsic role of brevetoxin in $K$. brevis. In this section, we describe the use of a fluorescently labeled brevetoxin probe along with fluorescence microscopy to identify the site of localization of brevetoxin.

\subsubsection{Introduction}

Labeling of biological molecules is one of the most common imaging methods used in bioanalytical fields, such as medicine, pharmacy, cellular biology and environmental science. Labels can be radioactive or molecules with absorption or fluorescence. Fluorescence techniques have been used for biological imaging for many decades. Thousands of fluorescence probes are used to stain the organelles in living cells and many fluorescence stains are commercially available. For instances, DAPI (4', 6diamidino-2-phenylin-dole) is a fluorescent dye which is specific for DNA. In the 1970s DAPI was discovered to stain the DNA of yeast cells. It was demonstrated that DAPI fluorescence was sensitive to DNase (Williamson and Fennell 1975). DAPI forms a fluorescent complex through its high affinity binding of DAPI with the minor grove of A-T rich sequence of DNA (Williamson and Fennell 1975). Thus, DAPI can be a biological stain for nucleic acids and chromosomes (Lin and Alfi 1976, Schweizer 1976, Schweizer 1976, Lin, Comings et al. 1977). Blue-fluorescent 
Hoechst 33342 dye also stains the nuclei and hematoxylin is a stain for nuclei in living cells (Fischer, Jacobson et al. 2008). Rhodamine is one of numerous histological stains, which have been utilized for many years as a specific probe to localize the mitochondria in living cells. Rhodamine 123 also can be used in detection of the energy state of isolated mitochondria (Azzone 1972, Johnson, Walsh et al. 1980). MitoFluor ${ }^{\mathrm{TM}}$ Far Red 680 accumulates in mitochondria, and its fluorescence (emission maximum $700 \mathrm{~nm}$ ) was red. Green-fluorescent LysoTracker ${ }^{\circledR}$ Green dye accumulates in the lysosomes.

The dyes described above are general dyes for staining organelles. Reactive reporter dyes may be used to detect specific classes of molecules within a cell. In 2008, a type of fluorescent probe called MitoPY1 for imaging hydrogen peroxides within mitochondria of live cells was determined. MitoPY1 was synthesized with a peroxideresponsive element and mitochondrial targeting phosphonium moiety to localize hydrogen peroxide to cellular mitochondrial (Dickinson and Chang 2008). A rhodamine modified as an electron donor (4-amino- or 4- hydroxyphenyl ether), is used for detection of highly reactive oxygen species (ROS) in mitochondria of live cells. thereby ROS should cause cleavage of the ether moiety resulting in fluorescence in mitochondria (Koide, Urano et al. 2007). Thus, these indirect and modified fluorescent probes are utilized to selectively detect biomolecules in live cells.

The fluorescent tagging of specific molecules is a promising technique for localizing molecules in live cells. For example, immunofluorescent staining is able to detect biomolecules in living cells as long as the specific antibody is provided. The fluorochrome-labeled antibody is used to stain intracellular biomolecules as a 
common and direct method. Permeabilization of the plasma membrane is an essential and often problematic, step in this method (Suzuki, Matsuzaki et al. 2007). For additional examples, labeled oligonucleotide probes were used to image individual mRNA molecules in fixed cells, which made each mRNA molecule visible as fluorescent microscopy (Raj, Van Den Bogaard et al. 2008). Using a designed and synthesized fluorescent probe included a small receptor domain and ligand label some recombinant proteins which contains four cysteines at 5 positions of an $\alpha$ helix. The small receptor domain is composed of six natural amino acids that could be genetically mutated-bind to proteins of interest. The ligand is membrane-permeant and nonfluorescent until it binds specifically with high affinity to the tetracysteine domain (Griffin, Adams et al. 1998).

In order to understand the biochemical function for brevetoxins, our first goal is to localize brevetoxins to one or more organelles or cellular structures in K. brevis. Consequently, using a fluorescently tagged brevetoxin probe is an effective and direct approach to localize PbTxs in $K$. brevis. The site of localization can be visualized via fluorescence microscopy

The synthesis of a fluorescently labeled brevetoxin probe has been reported previously (Cassell, Chen et al. 2015). Briefly, Alexa Fluor ${ }^{\circledR} 488$ alkyne (4) is used as fluorescent dye linked to brevetoxins, which are highly lipophilic molecules (Figure7). The fluorescently labeled $\mathrm{PbTx}-2$ probe (5) was prepared by coupling brevetoxin with an Alexafluor alkyne derivative (4). A thiol-Michael reaction between $\mathrm{PbTx}-2$ (1) and an azidothiol (2) provided a azide functionalized thiazepine linker (3), which was subjected to a 1, 3-dipolar cycloaddition reaction with Alexa Fluor 488 alkyne (4). 
The Alexa Fluor dye was chosen specifically because it is cell-impermeable. Thus, if the brevetoxin - Alexa Fluor ${ }^{\circledR} 488$ Alkyne conjugate can penetrate the membranes, it is only because of brevetoxin. The thiol-Michael reaction has been described as a "click" reaction (Nair, Podgorski et al. 2013). "Click chemistry" is commonly used to combine an azide labeled molecule and an alkyne labeled molecule. A "click "reaction is a fast reaction which can be performed under mild conditions (Nair, Podgórski et al. 2013). Subsequently, the probe was incubated with two K. brevis strains, a high toxin producing strain and a low toxin producing strain. Stained cells emitting light at 500-540 nm were observed using fluorescence microscopy. Thus using live cell imaging, the location of brevetoxins in $K$. brevis cells can be identified.

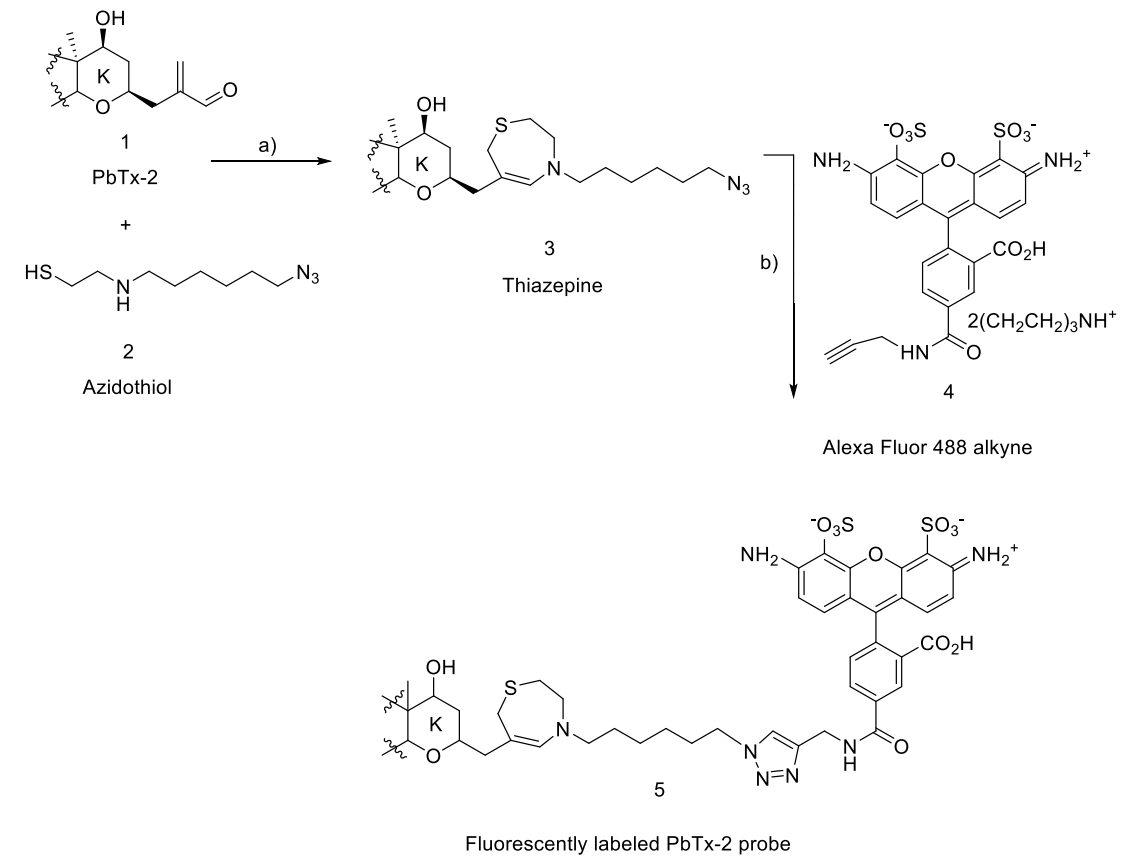

Figure 7 Synthesis of fluorescent brevetoxin probe. For brevity, only the K-ring of $\mathrm{PbTx}-2$ is shown. a) $\mathrm{MeOH}$, b) $\mathrm{tBuOH} / \mathrm{H}_{2} \mathrm{O} / \mathrm{DMF}, \mathrm{CuSO}_{4} \cdot-5 \mathrm{H}_{2} \mathrm{O}$, sodium ascorbate

\subsubsection{Results and discussion}

In order to determine the location of brevetoxin in K. brevis, the fluorescent probe (5) and Alexa Fluor ${ }^{\circledR} 488$ Alkyne (4) were each incubated for $1 \mathrm{hr}$ with $K$. brevis living cells. After washing the cells with culture medium, the cells were visualized by using 
a fluorescent microscope equipped with a $450-490 \mathrm{~nm}$ band pass/515 nm long pass EX/EM filter set. Chlorophyll auto fluorescence (red) could be clearly seen in both treatments (Figure 8). However, incubation with the fluorescent $\mathrm{PbTx}-2$ probe also demonstrated localization of the fluorescent $\mathrm{PbTx}$ conjugate (yellow) to the chloroplasts (Figure $8 \mathrm{~A}$ and $\mathrm{B}$ ). Additive color is produced by combining a number of primary colors such as green, red and blue in equal proportions. Thus, although Alexa Fluor ${ }^{\circledR} 488$ alkyne is a green dye, based on the additive color mixing, the green color combines with red color resulting in yellow. However, the control experiment, with Alexa Fluor $^{\circledR} 488$ alkyne alone, failed to label $K$. brevis cells (Fig 8 C). This experiment demonstrated that $\mathrm{PbTx}$ localize to the chloroplast of $K$. brevis

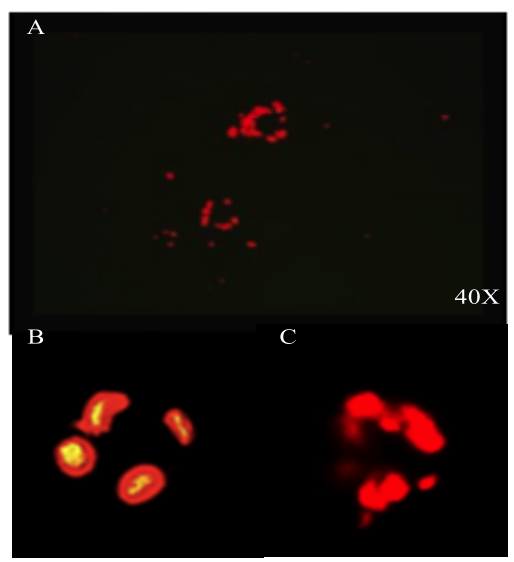

Figure 8 The photograph of localization of brevetoxin in $K$. brevis live cells (A) Fluorescent brevetoxin derivative $(0.4 \mathrm{mg} / \mathrm{ml})$ was incubated with live $K$. brevis culture for $30 \mathrm{mins}$ in dark. The cells were observed through $40 \mathrm{X}$ lenses of a fluorescent microscope equipped with a $450-490 \mathrm{~nm}$ band pass $/ 515 \mathrm{~nm}$ long pass EX/EM filter set. (B): The zoom in image of labeled cells. (C): The zoom in image of cells in control experiment: Alexa Fluor ${ }^{\mathbb{B}} 488$ Alkyne $(0.06 \mathrm{mg} / \mathrm{ml})$ was incubated with live K. brevis culture for 30 mins in dark

The finding is consistent with the localization of okadaic acid (OA) (Fig 9), a marine toxin produced by some dinoflagellates of the genera Prorocentrum and Dinophysis (Zhou and Fritz 1994). The location of OA has been identified first with immunofluorescence. Toxin-producer cells were incubated with anti-OA fluorescein isothiocyanate (FITC) - conjugated antibody. Fluorescence was observed at the 
plastids. In order to obtain even more specific localization, immunogold labelling of anti-OA antibody was used. Using the immunofluorescence micrographs through transmission electron microscope operating at $80 \mathrm{kV}$, the gold particles were visible with the pyrenoid region of the chloroplast. Thus, it had been proposed that OA was localized primarily within chloroplasts of toxin-producing Prorocentrum species (Zhou and Fritz 1994).<smiles>C=C1C(O)C2OC3(CCC(/C=C/C(C)C4CC(C)=CC5(O4)OC(C)(CC(C)(O)C(=C)O)CCC5O)O3)CCC2OC1C(O)CC(C)CC1OC2(CCCCO2)CCC1C</smiles>

Figure 9 The structure of okadaic acid

\subsection{Isolation of a target protein from $K$. brevis as $\mathrm{PbTxs}$ natural receptor}

\subsubsection{Objective}

Identification of a brevetoxin binding protein in K. brevis may provide some clues to the intracellular function of PbTxs in $K$. brevis cells.

\subsubsection{Introduction}

Photoaffinity labeling (PAL) provides a direct and general method to identify binding proteins. Photoaffinity labeling can directly identify the interacting site at the molecular level. In photoaffinity labeling, a new covalent linkage is created between a light-sensitive, detectable ligand and a biopolymer upon irradiation, in a reversibly bound state (Dormán and Prestwich 2000). A typical photoaffinity probe incorporates three groups, a ligand, a photoreactive group, and a tag for purification. The photoreactive groups should have some essential features: the photoreactive groups (1) must be stable under ambient light with an activation wavelength longer than $300 \mathrm{~nm}$ 
(Dormán and Prestwich 2000). (2) should preferably provide a single covalent adduct between the probe and target protein avoiding release of an activated form that results in non-specific labeling (3) have an activated form that reacts with $\mathrm{C}$ - $\mathrm{H}$ groups and $\mathrm{X}$ $\mathrm{H}$ bonds. The most reliable and common high efficiency labeling of target proteins are tetrafluorophenyl azides (AZ), trifluoromethylphenyl diazirines (DIA) and benzophenone (BP) (Fleming 1995, Weber and Beck-Sickinger 1997)(Figure10 ). These photoactiveatable groups have been used extensively to identify the target of drugs, to determine the affinity and selectivity of the drug-target interaction, and to identify the binding site on the target.

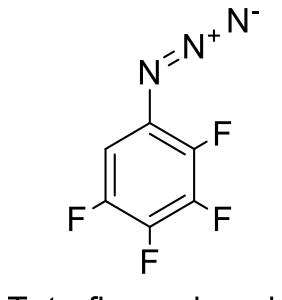

Tetrafluorophenyl azide<smiles>FC(F)(F)C1(c2ccccc2)N=N1</smiles>

Trifluoromethylphenyl diazirines<smiles>O=C(c1ccccc1)c1ccccc1</smiles>

Benzophenone

Figure 10 The most reliable and common high efficiency labeling of target proteins in photoaffinity probe

Although less common, photoaffinity labeling has also been used in nonpharmaceutical applications as well, with several studies using DIA as the photophore. In 2003, using DIA modified photoaffinity probe that attached to 2' -position of the sugar moiety, a potential binding site to the receptor molecule, successfully detected the potential membrane receptor proteins for leaf movement of legumes (Sugimoto, Fujii et al. 2004). DIA that linked to maitotoxinin with a biotin detectable group was used to identify a binding protein for maitotoxin in red blood cells (Konoki, Hashimoto et al. 2009). Although the target protein has not been characterized, based on the SDS-PAGE, a $23 \mathrm{kD}$ protein was specifically labeled. Competition binding experiments with $\mathrm{PbTx}-2$ demonstrated that both toxins bound to the same site on this 
protein. Thus, the use of a $\mathrm{PbTx}-2$ photoaffinity probe could be a direct and effective method to discover the target protein of PbTxs in K. brevis.

The synthesis of the photoaffinity probe has been previously reported (Cassell, Chen et al. 2015). The photoaffinity probe (10) was consisted of a photolabile diazirine and a biotin tag. In order to isolate a target protein, the biotin-streptavidin interaction was used to separate the target protein from others. Briefly, the known aldehyde (6) (Hashimoto, Hatanaka et al. 2001) was alkylated with 1-azido-6-bromohexane to provide azide (7). "Click chemistry" was used to link the azide functionalized diazirine with an alkyne functionalized biotin to provide (8). Reductive alkylation of the aldehyde moiety with cystamine, followed by reduction of the intermediate disulfide, provided the thiol (9). Thiol (9) then underwent a thiol-Michael reaction with PbTx-2 (1), followed by cyclization to the thiazapeine provided photoaffinity probe (10) (Figure 11). 

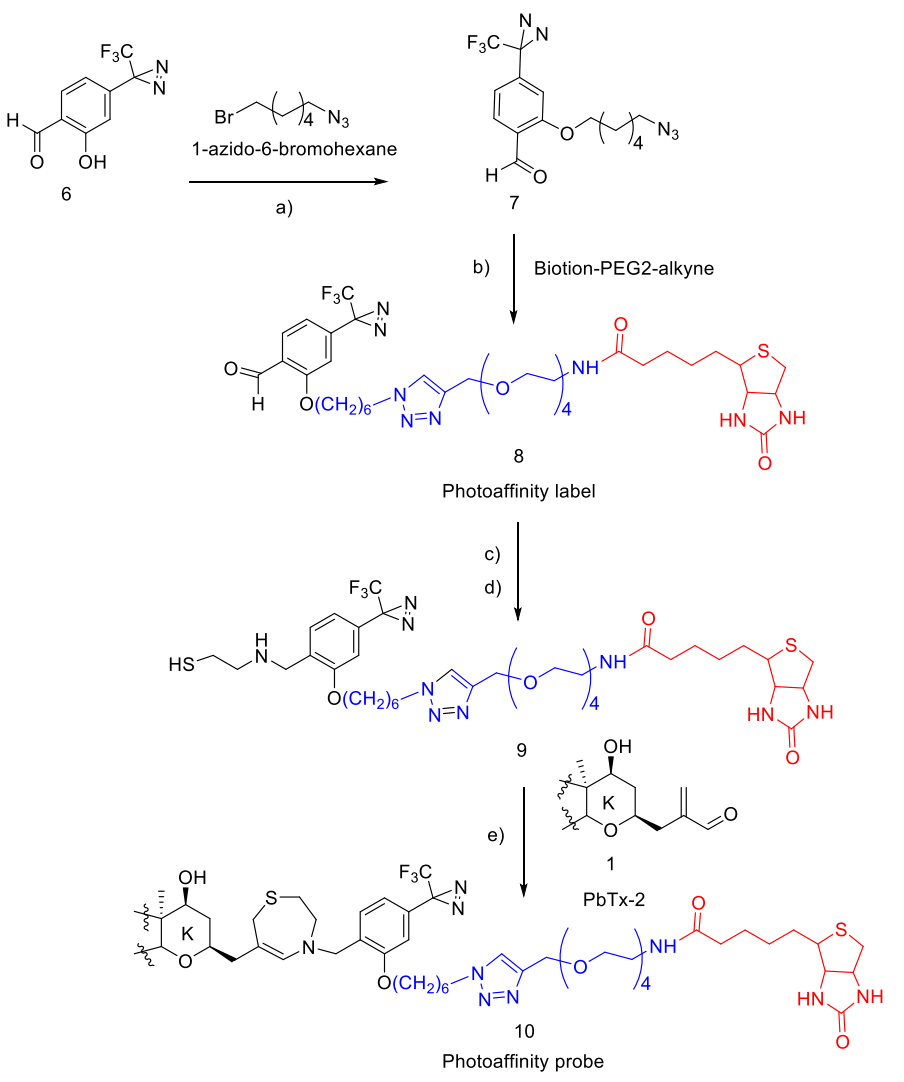

Figure 11 The synthesis of brevetoxin photoaffinity probe (10). For brevity, only the K-ring of $\mathrm{PbTx}-2$ is shown. a) $\mathrm{K}_{2} \mathrm{CO}_{3}$, KI, DMF; b) $\mathrm{tBuOH} / \mathrm{H}_{2} \mathrm{O} / \mathrm{DMF}, \mathrm{CuSO}_{4} \cdot 5 \mathrm{H}_{2} \mathrm{O}$, sodium ascorbate; c) $\left(\mathrm{NH}_{2} \mathrm{CH}_{2} \mathrm{CH}_{2} \mathrm{~S}\right)_{2}, \mathrm{NaBH}_{4}, \mathrm{EtOH}$; d) DTT, $\mathrm{MeOH}$; e) MeOH;

\subsubsection{Results and Discussions}

A homogenate of $K$. brevis cells was separated into soluble and membrane fractions by centrifugation. These fractions were each incubated either with the photoaffinity probe $\mathbf{( 1 0 )}$ or the photoaffinity label $(\mathbf{8})$, followed by photolysis and protein isolation using streptavidin immobilized on magnetic beads. After incubation of the brevetoxin photoaffinity probe $(\mathbf{1 0})$ with the soluble protein fraction and photolysis no proteins were observed in SDS PAGE after purification on streptavidin beads. However, incubation and photolysis of the membrane fraction with the brevetoxin photoaffinity probe (10) consistently revealed a protein with an apparent mass of $27 \mathrm{kD}$ when analyzed by SDS-PAGE (12). A control experiment with photoaffinity label (8) alone did not yield any bands by SDS-PAGE. 
The $27 \mathrm{kD}$ bands were subjected to digestion with trypsin. After analysis of the excised band by ESI LC-MS/MS followed by BLAST (basic local alignment search tools) analysis of the amino acid sequence against NCBI non-redundant database, it was determined that there were two thylakoid proteins which interacted with brevetoxin: the light harvesting complex II (LHC II) of the photosynthetic apparatus and thioredoxin (Trx). The identified peptide fragments and their closest match in the BLAST analysis are shown in Table 2. Subsequently, we determined that our photoaffinity probe also binds to the LHC II of spinach (Figure13 lane 6).

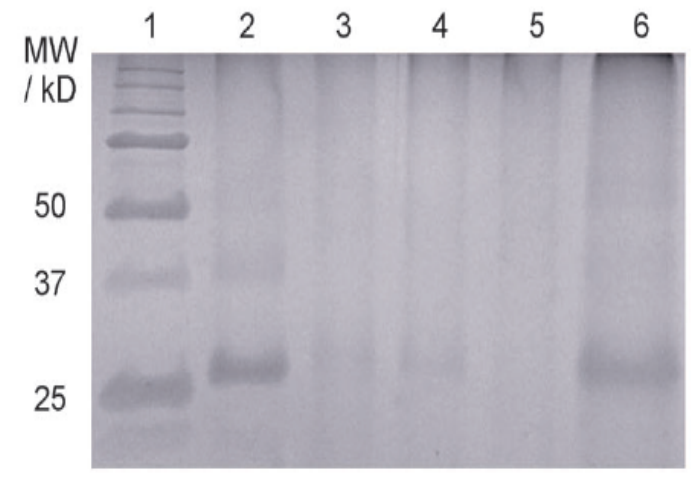

Figure 12 SDS-PAGE of protein fractions from photoaffinity experiments. $K$. brevis membrane fractions incubated with photoaffinity probe $(\mathbf{1 0})$ or $(\mathbf{8})$. Lane 1: molecular weight markers. Lane 2: K. brevis membrane fraction incubated with (10) $(7 \mathrm{mg}$ protein). Lane 3 : pre-incubation membrane fraction $(7 \mathrm{mg}$ protein). Lane $4: K$. brevis homogenate incubated with (8) (18 $\mathrm{mg}$ protein). Lane 5: pre-incubation membrane fraction (6 $\mathrm{mg}$ protein). Lane 6: spinach homogenate incubated with (10) (16 $\mathrm{mg}$ protein)

Table 2 The peptide sequence of $27 \mathrm{kD}$ band and the proteins with matching sequences.

\begin{tabular}{|c|c|c|}
\hline Protein name & Organism & Peptide sequence \\
\hline LHCII & Emiliania huxlei & GGKPGYFPTFK \\
\hline LHCII & Emiliania huxlei & PGYFPTFK \\
\hline LHCII & Emiliania huxlei & LAMLGLFSLISEAK \\
\hline LHCII & Emiliania huxlei & VPGAVPALAGK \\
\hline Thioredoxin & Emiliania huxlei & IIHLTDDSFDTDVLK \\
\hline Thioredoxin & Emiliania huxlei & MIAPILDEIADEYQGK \\
\hline Thioredoxin & Emiliania huxlei & GIPTLLLFK \\
\hline Thioredoxin 1 & Aliivibrio salmonicida & LNIDQNAGTPPK \\
\hline
\end{tabular}


Thylakoids are membrane-bound structures that are located in chloroplast stroma. The light-dependent reactions of photosynthesis occur in the thylakoids. The thylakoid is composed of a thylakoid membrane surrounding a thylakoid lumen. In the thylakoid membrane the photosynthetic pigments are bound to proteins which are embedded in the membrane. There are many integral membrane proteins that play important roles in light harvesting and the light dependent reactions of photosynthesis take place in thylakoid membranes. Photosystems I and II, cytochrome b6f complex and ATP synthase are four major protein complexes in the thylakoid membrane. LHC is a complex of subunit protein that is a part of a larger supercomplex of a photosystem. LHC II surrounds the photosynthetic reaction center in thylakoid membranes to both harvest and transfer light energy to photosystem II and to protect it from oxidative damage that is caused by excess sunlight. The molecular weight of LHC II is $27 \mathrm{kDa}$. It is highly conserved across species. It is essential for both light harvesting and nonphotochemical quenching (NPQ). NPQ is a mechanism to quench chlorophyll fluorescence and dissipate the excess chemical energy as heat rather than chlorophyll fluorescence which results in the formation of ROS. Thus, an important function of LHCII is to prevent oxidative damage to photosystem II. LHCII binds to 14 chlorophyll and 4 carotenoid molecules. These pigments are used for light harvesting and energy dissipation. In terrestrial plants, the four carotenoids are two luteins, neoxanthin and zeaxanthin or violaxanthin. In dinoflagellates the zeaxanthin and violaxanthin are replaced by dinoxanthin (D) and diadinoxanthin (DD) respectively. Lutein and neoxanthin are replaced by fucoxanthin in K. brevis (Demers, Roy et al. , Arsalane, Rousseau et al. 1994, Moisan, Olaizola et al. 1998, Vijayan and Somayajula 2014). The zeaxanthin/violaxanthin interconversion facilitates light energy 
dissipation through the xanthophyll cycle (Figure 13). Under high light conditions, the violaxanthin is converted to zeaxanthin in a process catalyzed by the enzyme violaxanthin de-epoxidase (VDE). It has been assumed that zeaxanthin binds to LHC II which undergoes a conformational change moving zeaxanthin into close proximity to the chlorophyll molecule permitting the quenching of chlorophyll fluorescence. Under low-light conditions zeaxanthin is converted back to violaxanthin by the enzyme zeaxanthin epoxidase (ZE) (Fuciman, Enriquez et al. 2012). However, it is not clear if violaxanthin is released from LHC II or converted within LHC II.

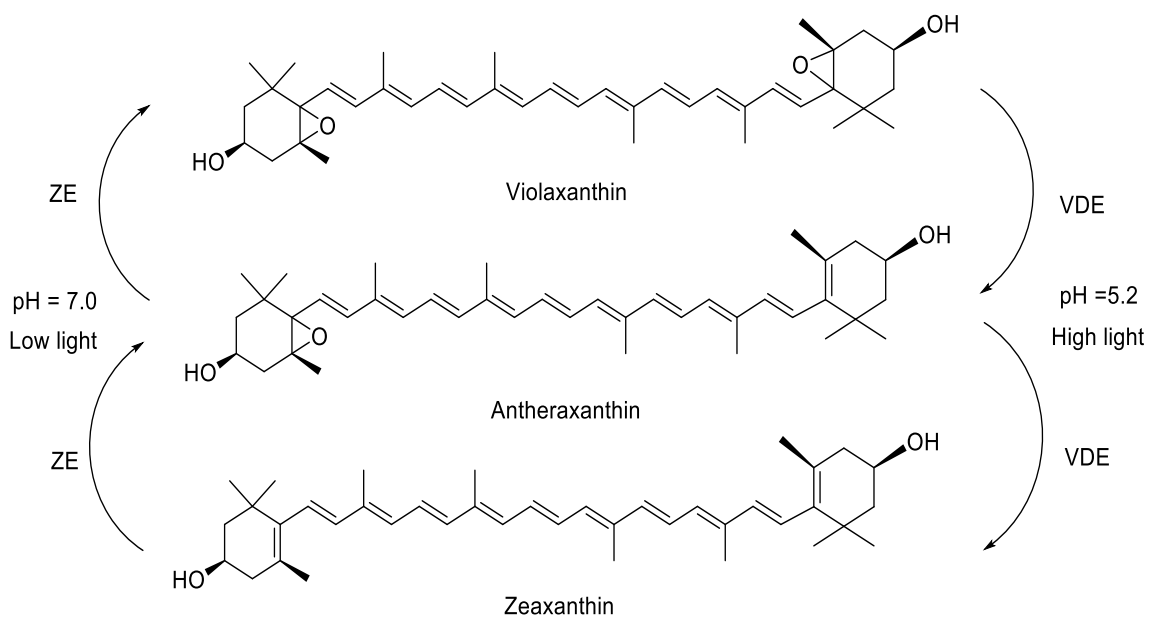

Figure 13 Xanthophyll cycle

Under excess light condition, photosynthesis begins; the lumenal side of the thylakoid membrane experiences a significant drop in $\mathrm{pH}$ (from 8 to 5). NPQ is initiated by this drop in $\mathrm{pH}$ on the lumenal side of the thylakoid membranes in response to light. In oreder to determine if brevetoxin binding to LHCII is $\mathrm{pH}$ dependent, the binding of brevetoxin photoaffinity probe to LHCII in spinach membranes was examined by using a $\mathrm{pH}$ range from $\mathrm{pH} 2$ (simulating high light conditions) to $\mathrm{pH} 8$ (simulating low light conditions). After incubation of the crude spinach homogenate with the brevetoxin photoaffinity probe, photolysis at $312 \mathrm{~nm}$ for $20 \mathrm{~min}$ and affinity 
purification on magnetic streptavidin beads, SDS PAGE analysis was performed on the eluant. Inspection of the SDS PAGE gel revealed a $\mathrm{pH}$ dependence on binding (Figure14). In the Figure 14, the red box is actin added as an internal standard for normalization. The green box is the $27 \mathrm{kD}$ band contained LHCII. The orange box is the smaller band which has numerous photosystem I and II membrane proteins, Rubisco small subunit, thioredoxin and a serine/threonine protein kinase. Brevetoxin bind more strongly to $27 \mathrm{kD}$ protein at low $\mathrm{pH}$ (or conditions which simulate high light). Nevertheless, at high $\mathrm{pH}$ (or conditions which simulate low light) brevetoxin binds with several lower molecular weight proteins (below $20 \mathrm{kDa}$, Figure 14) The lower molecular weight band was also observed in every experiment. In order to determine the relative intensities of each band, a constant amount of actin was mixed with the eluant as an internal standard (Table 3). The lower molecular weight band was also subjected to digestion with trypsin followed by MS/MS analysis. After analysis of the digested band by ESI LC-MS/MS followed by BLAST analysis of the amino acid sequence against NCBI non-redundant database, five different photosystem I and six different photosystem II membrane proteins were identified., as well as three proteins which are located in the stroma: thioredoxin, a protein kinase, and Rubisco (Table 4). Thus, it appears that at high $\mathrm{pH}$ or high light, brevetoxin may be simply released from LHC II into the thylakoid membrane where it might interact with many proteins. 


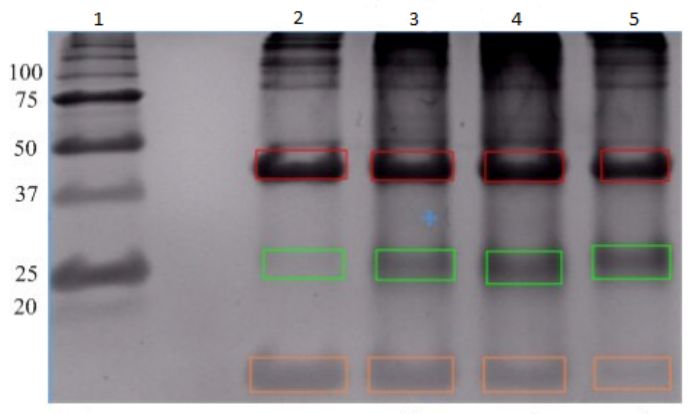

Figure 14 Spinach homogenate was incubated with the photoaffinity probe in different $\mathrm{pH}$ buffer (Lane 2: $\mathrm{pH}=8$, Lane 3: $\mathrm{pH}=6$, Lane 4: $\mathrm{pH}=4$, Lane 5: $\mathrm{pH}=2$ ). Red Box: actin (added as an internal standard) for normalization; Green box: 27KD LHCII; Orange box: numerous photosystem I and II membrane proteins, Rubisco small subunit, thioredoxin and a serine/threonine protein kinase

Table 3 The intensity of all bands on SDS-PAGE gel

\begin{tabular}{|l|c|c|c|c|c|c|c|}
\hline & $\begin{array}{c}\text { Intensity } \\
\text { of Actin }\end{array}$ & $\begin{array}{c}\text { Intensity } \\
\text { of 27 kD } \\
\text { band }\end{array}$ & $\begin{array}{c}\text { Intensity } \\
\text { of 12 kD } \\
\text { band }\end{array}$ & $\begin{array}{c}\text { The ratio } \\
\text { of 27 kD } \\
\text { band to } \\
\mathbf{1 2} \mathbf{k D} \\
\text { band }\end{array}$ & $\begin{array}{c}\text { The ratio } \\
\text { of 27 kD } \\
\text { band to } \\
\text { Actin }\end{array}$ & $\begin{array}{c}\text { The ratio } \\
\text { of 12 kD } \\
\text { band to } \\
\text { Actin }\end{array}$ & $\begin{array}{c}\text { The } \\
\text { ratio of } \\
\text { two } \\
\text { bands to } \\
\text { actin }\end{array}$ \\
\hline $\mathrm{pH}=2$ & 26641 & 19770 & 10376 & 1.91 & 0.74 & 0.39 & 1.13 \\
\hline $\mathrm{pH}=4$ & 31309 & 22237 & 13294 & 1.67 & 0.71 & 0.42 & 1.13 \\
\hline $\mathrm{pH}=6$ & 28672 & 18287 & 13010 & 1.40 & 0.64 & 0.45 & 1.09 \\
\hline $\mathrm{pH}=8$ & 26675 & 9922 & 13092 & 0.76 & 0.37 & 0.49 & 0.86 \\
\hline
\end{tabular}

Table 4 The peptide sequence of the $12 \mathrm{kDa}$ band the proteins with matching sequences

\begin{tabular}{|c|c|c|}
\hline Protein name & Organism & Peptide sequence \\
\hline Thioredoxin & Escherichia coli & LNIDQNPGTAPK \\
\hline Thioredoxin & Escherichia coli & GIPTLLLFK \\
\hline Protein kinase & Burkholderia cepacia GG4 & VATVELPR \\
\hline Rubisco & Spinacia oleracea & YETLSYLPPLTTDQLAR \\
\hline Rubisco & Spinacia oleracea & QVDYLLNNK \\
\hline Rubisco & Spinacia oleracea & IIGFDSNR \\
\hline Photosystem I subunit $\mathrm{F}$ & Spinacia oleracea & DIAGLTPCK \\
\hline Photosystem I subunit $\mathrm{F}$ & Spinacia oleracea & LYADDSAPALAIK \\
\hline Photosystem I subunit $\mathrm{F}$ & Spinacia oleracea & SYLIAIRDEK \\
\hline Photosystem I subunit $\mathrm{L}$ & Spinacia oleracea & TAVNPLLR \\
\hline Photosystem I subunit $\mathrm{H}$ & Pelargonium $x$ hortorum & FFETFAAPFTK \\
\hline Photosystem I subunit $\mathrm{K}$ & Oryza sativa Japonica Group & FGLAPSANR \\
\hline Photosystem I subunit E & Phillyrea latifolia & GVGSVVAVDQDPK \\
\hline
\end{tabular}




\begin{tabular}{|c|c|c|}
\hline Photosystem II protein D2 & Acutodesmus obliquus & AYDFVSQEIR \\
\hline Photosystem II protein D2 & Acutodesmus obliquus & AAEDPEFETFYTK \\
\hline Photosystem I subunit S & Spinacia oleracea & ENELFVGR \\
\hline Photosystem I subunit S & Spinacia oleracea & FVDEPTTGLEK \\
\hline Photosystem I subunit Q & Spinacia oleracea & VSASEILNVK \\
\hline Photosystem I subunit R & Agave tequilana & GVYQFVDK \\
\hline Photosystem II protein V & Spinacia oleracea & SFADIITSIR \\
\hline Photosystem II protein V & Spinacia oleracea & PNEYFTESR \\
\hline Photosystem II protein V & Spinacia oleracea & QGIPLITGR \\
\hline Photosystem II protein V & Spinacia oleracea & FDSLEQLDEFSR \\
\hline Cytochrome $\mathrm{f}$ & Spinacia oleracea & EVVDIIPR \\
\hline LHC II & Oryza sativa Japonica Group & VGGGPLGEGLDK \\
\hline LHC II & Spinacia oleracea & VAGGPLGEVIDPLYPGGSF \\
& DPLGLADDPEAFAELK \\
\hline
\end{tabular}

Many of the proteins identified were considerably larger than the $12-15 \mathrm{kD}$ indicated by the markers. Thus, it was surprising to find them in this low MW band. It is believed that because protease inhibitors were not present in our homogenization buffer, high MW proteins might have been cleaved during the incubation period.

\subsubsection{Conclusion}

According to the result of the experiment using both the fluorescent $\mathrm{PbTx}-2$ derivative (5) and the brevetoxin photoaffinity probe (10), it was demonstrated that the brevetoxin is located in the chloroplast. It could be argued that the labels influence the physiochemical properties of brevetoxin. However, these two labels have distinct properties, yet each of these derivatives migrated to the chloroplast. The Alexa Fluor dye, in particular, is not membrane-permeable, and the Alexa Fluor brevetoxin conjugate would seem even less likely to enter the thylakoid membrane than native brevetoxin. In addition, it is very clear that fluorescent $\mathrm{PbTx}-2$ derivative did not label any other organelles in the living cells. The finding that brevetoxins localize to the lipophilic thylakoid membranes should come as no surprise. PE ladder molecules are 
known to migrate to the cell membranes where they interact with membrane proteins. Brevetoxins have also been demonstrated to aggregate into artificial lipid bilayers (Woo, Liu et al.). Our findings are consistent with the localization of another dinoflagellate toxin, okadaic acid (Zhou and Fritz 1994), to the chloroplast and the cyanobacterial toxin, microcystin, to thylakoid area of cyanobacteria (Young, Thomson et al. 2005)

In addition, it was determined using photoaffinity probe (10) that LHC II and Trx are native proteins to which brevetoxin binds in K. brevis. The association with LHCII was reduced at neutral $\mathrm{pH}$ or low light, conditions which were used for the initial photoaffinity experiments. However, LHC II is highly concentrated in the thylakoids. It is possible that our photoaffinity probe linked to LHCII simply as a result of its high density in the thylakoids and that the true brevetoxin target in chloroplasts is a less abundant membrane protein, such as an ion channel. Ion channels selective for chloride, potassium, or divalent cations such as calcium and magnesium have been found in outer- and inner-envelope membranes of chloroplasts, as well as from thylakoid membranes, by using the patch clamp technique and have been hypothesized to regulate photosynthesis by modulating the proton motive force (Checchetto, Teardo et al. 2013).

In addition to LHC II, Trx is identified from both $25 \mathrm{kDa}$ and $12 \mathrm{kDa}$ band. It was identified in every photoaffinity binding experiment performed. Trx is a ubiquitous antioxidant enzyme that can be found in all living organisms from archaea to mammals. The role of Trx is the regulation of redox homeostasis via thiol-disulfide exchange reactions (Collet and Messens 2010) with its protein targets. It acts as a 
reductase in redox control and protects proteins from oxidative damage (Holmgren 1985). In addition Trx helps the cells tolerate various environmental stresses, such as ROS (Messens and Silver 2006). Numerous thioredoxin-dependent regulatory networks have been identified in photosynthetic organisms. Thus, a better understanding of the interaction between Trx with brevetoxin may contribute to understanding the role of brevetoxin in K. brevis and may also have implications for human and animal toxicity.

\subsection{Materials and Method}

\subsubsection{Fluorescent probe experiment}

Materials for fluorescent probe experiment Alexa Fluor 488; Fluorescent $\mathrm{PbTx}-2$ derivative; Live $K$. brevis culture, a fluorescent microscope (Leica Leitz, Model DMRB)

\section{Method for fluorescent probe experiment}

Culture growth $K$. brevis culture (Wilson strains) were obtained from Mote Marine Laboratory (Sarasota, Florida) and maintained in RE medium (Sinigalliano, Winshell et al. 2009), in a growth chamber at $\sim 20^{\circ} \mathrm{C}$ under $35 \mu$ mol.photons. $\mathrm{m}^{-2} \cdot \mathrm{s}^{-1}$. Growth was monitored by counting a 1:10 dilution of culture in $\mathrm{Z}$ pak reagent using a Beckman Z-series Coulter Counter with aperture size between 10 30 $\mu \mathrm{m}$ according to the manufacturer's instructions.

Incubation of $K$. brevis with the fluorescent PbTx-2 derivative or the Alexa Fluor 488 alkyne: Live $K$. brevis culture $(3 \mathrm{ml})$ was incubated for $1 \mathrm{~h}$ in the dark with either the fluorescent $\mathrm{PbTx}-2$ derivative (5) or Alexa Fluor 488 alkyne (4). The final 
concentration of the Alexa Fluor 488 alkyne was $4 \mu \mathrm{m}$. Because the exact concentration of the $\mathrm{PbTx}-2$ derivative was not known, the concentration of the solution of the fluorescent $\mathrm{PbTx}-2$ derivative was adjusted such that the fluorescence was equal to that of the Alexa Fluor 488 alkyne solution. After incubation, the cells were centrifuged for $8 \mathrm{~min}$ at $130 \mathrm{Xg}$. The supernatant was discarded, and the cells were resuspended in RE medium ( $1 \mathrm{ml}$ ) (Sinigalliano, Winshell et al. 2009) and centrifuged again for $8 \mathrm{~min}$ at $130 \mathrm{Xg}$. The supernatant was discarded, and the cells were resuspended in RE medium $(1 \mathrm{ml})$. The live cells were visualized by using a fluorescent microscope (Leica Leitz, Model DMRB) with a 450-490 nm band pass/515 nm long pass EX/EM filter.

\subsubsection{Photoaffinity probe experiment}

Materials for brevetoxin photoaffinity experiment $K$. brevis culture; Phosphate buffered saline (PBS) buffer; Bovine serum albumin (BSA); Coomassie Protein Assay Reagent (BioRad); Spinach; Photoaffinity probe (10); photoaffinity label (8); Streptavidin beads (streptavidin immobilized on magnetic beads, Thermo Scientific Pierce); Triton X100;

\section{Method for brevetoxin photoaffinity experiment}

Preparation of protein homogenates and membrane suspensions: The homogenate of $K$. brevis cells was separated into soluble and membrane fractions. $K$. brevis culture (200-400 ml) was concentrated by centrifugation for $5 \mathrm{~min}$ at $466 \mathrm{Xg}$, and the supernatant was discarded. The cells were resuspended in phosphate-buffered saline (PBS, $400 \mu \mathrm{l})$ and vortexed for $1 \mathrm{~min}$. This suspension was centrifuged for 10 
$\min$ at $14,000 \mathrm{X} g$, and the supernatant (soluble fractions) and the pellet (membrane fractions) were separated. The pellet was resuspended in PBS (500 $\mu 1)$. An aliquot (50 $\mu l)$ of each fraction was analyzed by Bradford protein assay. Final protein concentrations ranged from $0.5-0.9 \mu \mathrm{g} / \mu \mathrm{l}$.

Spinach (5 g) was crushed in PBS $(20 \mathrm{ml})$ and the biomass concentrated by centrifugation ( $5 \mathrm{~min}$ at $14000 \mathrm{Xg}$ ). The supernatant was discarded. The pellet was resuspended in PBS buffer $(5 \mathrm{ml}$, and an aliquot $(50 \mu \mathrm{l})$ was reserved for Bradford assay. The final protein concentration was $1.0-2.5 \mu \mathrm{g} / \mu \mathrm{l}$.

Bradford assay: BSA stock slolution $(30 \mu \mathrm{l}, 10 \mathrm{mg} / \mathrm{ml})$ was diluted to $300 \mu \mathrm{l}(1 \mathrm{mg}$ / $\mathrm{ml})$ in PBS. Six concentrations of BSA $(0 \mathrm{mg} / \mathrm{ml}, 1 \mathrm{mg} / \mathrm{ml}, 0.5 \mathrm{mg} / \mathrm{ml} 0.25 \mathrm{mg} /$ $\mathrm{ml} 0.125 \mathrm{mg} / \mathrm{ml}, 0.0625 \mathrm{mg} / \mathrm{ml}$ ) were prepared as standards. Commassie Protein Assay Reagent $(250 \mu \mathrm{l})$ was added to microplate wells. $20 \mu \mathrm{l}$ each of standard and unknown sample were mixed with Commassie Protein Assay Reagent in each well. Each protein solution was assayed in duplicate. After incubation at room temperature for $5 \mathrm{~min}$, absorbance was measured at $595 \mathrm{~nm}$ (SynergyTM ${ }^{2}$, Bioteck Instrument, Inc).

\section{Incubation of protein homogenates with photoaffinity probe or photoaffinity} label: The $\mathrm{PbTx}-2$ photoaffinity probe (10) or label (8) were incubated at room temperature with the soluble protein or membrane fractions at a probe/protein ratio of $0.2 \mu \mathrm{g}$ probe per mg protein for $1 \mathrm{~h}$. After incubation, the mixture was photolyzed (Vilber Lourmat transilluminator, Model FLX-20M) for $20 \mathrm{~min}$ at $312 \mathrm{~nm}$. The soluble fraction was applied directly to a suspension of streptavidin beads ( $200 \mu \mathrm{l}$, 
Dynabeads, $2.8 \mathrm{~mm}$ or $1.0 \mathrm{~mm}$, Life Technologies). Triton X-100 (1\%, $200 \mu \mathrm{l})$ was added to the membrane fractions $(200 \mu \mathrm{l})$. The mixture was vortexed and centrifuged for $5 \mathrm{~min}$ at $14000 \mathrm{X} g$ and applied to a suspension of streptavidin beads $(200 \mu \mathrm{l})$. After incubation for $30 \mathrm{~min}$ at room temperature, the beads were separated from the solution by using a strong magnet and washed with PBS buffer ( 4 x $200 \mu \mathrm{l})$. Each wash was analyzed for protein content, and the final wash contained no detectable protein. Protein was eluted from the beads by using $0.1 \%$ SDS solution $(3 \times 250 \mu 1)$ at $100^{\circ} \mathrm{C}$ for $5 \mathrm{~min}$. An aliquot of each elution was analyzed by Bradford protein assay, concentrated to dryness by lyophilization (FreeZone, Model 2.5, $86 \mathrm{~L} / \mathrm{min}$ ), and resuspended in water $(10 \mu \mathrm{l})$ and loading buffer $(2 \mu \mathrm{l}, 0.25 \mathrm{M}$ Tris- $\mathrm{HCl}, \mathrm{pH} 6.8,15 \%$ SDS, 20\% glycerol, 25\% mercaptoethanol, $0.01 \%$ Bromophenol Blue) for analysis by SDS-PAGE (12\% acryalamide) with Tris·glycine SDS, pH 8.3 running buffer. Acrylamide gels were stained with PAGE Blue (Fermentas), according to the manufacturer's instructions. The $25 \mathrm{kD}$ band was excised from the SDS-PAGE gel.

In-gel digestion: In-gel digestion and LC-ESI MS/MS analysis was performed by the Proteomics and Mass Spectrometry Facility at the UMass Medical School. Gel slices were cut into $1 \times 1 \mathrm{~mm}$ pieces and placed in $1.5 \mathrm{ml}$ Eppendorf tubes with water $(1 \mathrm{ml})$ for $30 \mathrm{~min}$. The water was removed, and ammonium bicarbonate $(50 \mu 1,250 \mathrm{mM})$ was added. For reduction, a solution of 1,4-dithiothreitol (DTT; $5 \mu \mathrm{l}, 45 \mathrm{mM}$ ) was added, and the samples were incubated at $50^{\circ} \mathrm{C}$ for $30 \mathrm{~min}$. The samples were cooled to room temperature and, for alkylation, iodoacetamide solution $(5 \mu 1,100 \mathrm{mM})$ was added and allowed to react for $30 \mathrm{~min}$. The gel slices were washed with water (20 X 1 $\mathrm{ml})$. The water was removed, ammonium bicarbonate/acetonitrile $(50: 50,1 \mathrm{ml}, 50$ $\mathrm{mM}$ ) was placed in each tube, and the samples were incubated at room temperature 
for $1 \mathrm{~h}$. The solution was removed, and acetonitrile (200 $\mu \mathrm{l})$ was added to each tube, at which point the gels slices turned opaque white. The acetonitrile was removed, and the gel slices were further dried in a Speed Vac. Gel slices were rehydrated in trypsin $(50 \mu \mathrm{l}, 2 \mathrm{ng} / \mu \mathrm{l}$, Sigma) in $0.01 \%$ ProteaseMAX Surfactant (Promega) / $50 \mathrm{mM}$ ammonium bicarbonate. Additional bicarbonate buffer was added to ensure complete submersion of the gel slices. Samples were incubated at $37{ }^{\circ} \mathrm{C}$ for $21 \mathrm{~h}$. The supernatant of each sample was removed and placed in a separate $1.5 \mathrm{ml}$ Eppendorf tube. Gel slices were further dehydrated with acetonitrile/1\% formic acid (80:20, 100 $\mu 1)$. The extract was combined with the supernatants of each sample. The samples were dried in a Speed Vac. Samples were dissolved in $25 \mu \mathrm{l}$ of $5 \%$ acetonitrile in $0.1 \%$ trifluoroacetic acid prior to injection on LC-MS/MS.

LC-MS/MS on Q Exactive: For peptide sequencing, a $3.0 \mu$ aliquot was directly injected onto a custom-packed $2 \mathrm{~cm} \mathrm{X} 100 \mathrm{~mm} \mathrm{C} 18$ Magic $5 \mathrm{~m}$ particle trap column. Labeled peptides were eluted and sprayed from a custom-packed emitter (75 $\mu \mathrm{m} \mathrm{X} 25$ $\mathrm{cm} \mathrm{C}_{18}$ Magic $3 \mu \mathrm{m}$ particle) with a linear gradient from $95 \%$ solvent $\mathrm{A}(0.1 \%$ formic acid in water) to $35 \%$ solvent $\mathrm{B}(0.1 \%$ formic acid in acetonitrile $)$ over $40 \mathrm{~min}$ at a flow rate of $300 \mathrm{~nL} / \mathrm{min}$ on a Waters Nano Acquity UPLC system. Data dependent acquisitions were performed on a Q Exactive mass spectrometer (Thermo Scientific), according to an experiment in which full MS scans from $300-1750 \mathrm{~m} / \mathrm{z}$ were acquired at a resolution of 70,000, followed by $12 \mathrm{MS} / \mathrm{MS}$ scans acquired under higher-energy collisional dissociation (HCD) fragmentation at a resolution of 35000 with an isolation width of 1.2 Da. 
Database searching: Raw data files were processed with Proteome Discoverer (v. 1.3). Charge state deconvolution and deisotoping were not performed. All MS/MS samples were analyzed by using Mascot (Matrix Science, London, UK; v. 2.4.1). Mascot was set up to search the NCBInr_20130907 database (32265160 entries), assuming the digestion enzyme strict trypsin. Mascot was searched with a fragment ion mass tolerance of $0.050 \mathrm{Da}$ and a parent ion tolerance of $10.0 \mathrm{ppm}$. The carbamidomethyl of cysteine was specified in Mascot as a fixed modification. Gln >pyro-Glu of the $\mathrm{N}$ terminus, oxidation of methionine, and acetylation of the $\mathrm{N}$ terminus were specified in Mascot as variable modifications.

Criteria for protein identification: Scaffold (v. 4.1.1, Proteome Software Inc., Portland, OR) was used to validate MS/MS-based peptide and protein identifications. Peptide identifications were accepted if they could be established at greater than $80.0 \%$ probability by the Peptide Prophet algorithm (Keller, Nesvizhskii et al. 2002) with Scaffold delta-mass correction. Protein identifications were accepted if they could be established at greater than $90.0 \%$ probability and contained at least two identified peptides. Protein probabilities were assigned by the Protein Prophet algorithm (Nesvizhskii, Keller et al. 2003). Proteins that contained similar peptides and could not be differentiated based on MS/MS analysis alone were grouped to satisfy the principles of parsimony. Proteins sharing significant peptide evidence were grouped into clusters. 


\section{Chapter 3 The effects of brevetoxins on the thioredoxin reductase/thioredoxin system and related enzymes.}

\subsection{Objective}

The findings described in the previous chapter indicated that brevetoxin binds to Trx. This finding promoted us to examine how brevetoxin affects the $\operatorname{TrxR} / \operatorname{Trx}$ system. Because Trx is present in all living organisms and is key to regulation of the activity of numerous enzymes and enzyme systems, this work can contribute to our understanding of the key role of berevetoxin in $K$. brevis cells and mechanism of toxicity to other organisms.

\subsection{Introduction}

Trx is the parent of a family of enzymes which share structural (but not necessarily sequence) homology and function through thiol-disulfide exchange. The thioredoxin superfamily is responsible for maintenance of the redox state within cells through the reduction of thiol disulfide bridges. The thioredoxin superfamily includes the $\operatorname{Trx} 1$ and $\operatorname{Trx} 2(\operatorname{Trx}$ A and Trx C) in the cytoplasm (Miranda-Vizuete, Damdimopoulos et al. 1997, Stewart, Åslund et al. 1998) and glutaredoxins 1, 2, 3 (GrxA, GrxB, GrxC) (Aslund, Ehn et al. 1994). A number of eukarytoic proteins such as protein disulfide isomerase (PDI) also belong to the thioredoxin superfamily (Carvalho, Fernandes et al. 2006). Some bacterial proteins like E.coli DsbA (a bacterial thiol disulfide oxidoreductase) also contains thioredoxin domains (Carvalho, Fernandes et al. 2006). Although those proteins do not all share much similarity in sequence, all proteins have a common sequence CXXC motif in the active site (Table 5). This motif is a highly conserved region which presents at the end of an $\alpha$-helix in all proteins. The amino acids between these two cysteines vary within the thioredoxin superfamily 
(Carvalho, Fernandes et al. 2006). In thioredoxin the sequence is CGPC, CPYC in glutaredoxins, CPHC in PDIs, and CGHC in DsbA.

Table 5 The motifs in thioredoxin, glutaredoxin, PDI and DsbA (Holmgren, Söderberg et al. 1975)

\begin{tabular}{|c|c|c|}
\hline Enzyme & CXXC motif & Function \\
\hline Thioredoxin & CGPC & Reductant \\
\hline Glutaredoxin & CPYC & Reductant \\
\hline PDI & CHGC & Oxidant Isomerase \\
\hline DsbA & CPHC & Oxidant \\
\hline
\end{tabular}

Trx catalyzes the disulfide reduction as a bimolecular nucleophilic substitution reaction $\left(\mathrm{S}_{\mathrm{N}} 2\right)$. During this process, the disulfide bond of the target is transferred to Trx. In other words, the substrate protein acquires the electrons from Trx and Trx becomes oxidized to the disulfide. The N-terminal cysteine of this CXXC motif is deprotonated under physiological conditions and exposed to the aqueous surroundings. This N-terminal cysteine of the motif serves as the nucleophilic cysteine. The other cysteine in the motif is usually buried in the enzyme and protonated (Carvalho, Fernandes et al. 2006). In all enzymes, the nucleophilic cysteine must be deprotonated to participate in thiol-disulfide exchange. Typically, a disulfide bond of the substrate is attacked by the N-terminal cysteine thiolate to form a mixed disulfide bond (Holmgren 1995, Jeng, Reymond et al. 1998). The thiolate on the C-terminal cysteine is stabilized with two backbone amide hydrogen bonds, lowering the pKa (Roos, Foloppe et al. 2009). N-terminal cysteine is attacked by Cterminal cysteine thiolate to form the Trx disulfide. A reduced substrate protein and oxidized Trx are the products of this exchange reaction (Figure 15). 


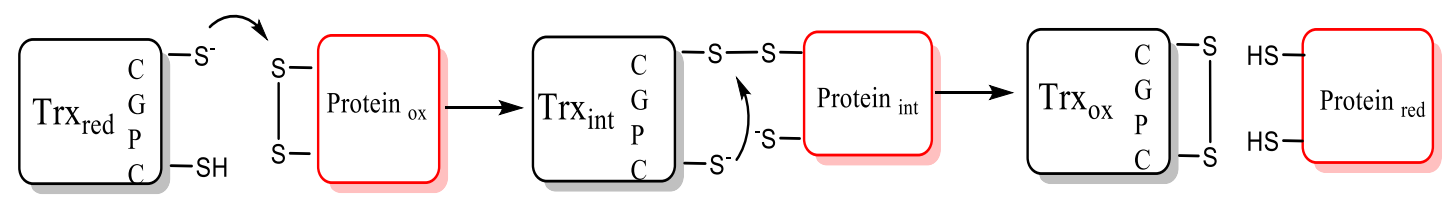

Figure 15 Trx catalyzes the reaction as a bimolecular nucleophilic substitution reaction $\left(\mathrm{S}_{\mathrm{N}} 2\right)$

The reaction between Trx and its substrate is stoichiometric. Oxidized Trx is more stable than reduced Trx (Collet and Messens 2010). It has been proposed that the rate of the thiol- disulfide exchange is affected by several factors, such as the pKa of the nucleophilic cysteine (Shaked, Szajewski et al. 1980), the local electrostatic environment of the nearby amino acid (Bulaj, Kortemme et al. 1998, Hansen, Østergaard et al. 2005), the molecular strain (Østergaard, Henriksen et al. 2001), the $\mathrm{pH}$ of the surrounding solvent (Setterdahl, Chivers et al. 2003) and the pKa values of the leaving thiol groups of the oxidized substrate (Shaked, Szajewski et al. 1980, Jensen, Hansen et al. 2009).

Over the past 50 years, Trx has been studied extensively. The first Trx was discovered in 1964 in E. coli as an electron donor to ribonucleotide reductase, an essential enzyme for DNA synthesis (Laurent, Moore et al. 1964, Moore, Reichard et al. 1964). Since then, Trx has been determined to play multiple cellular roles, such as reductase in redox control (Holmgren 1985), protecting proteins from oxidative damage and inactivation (Holmgren 1985, Holmgren 1989, Holmgren 1995) and helping the cells to combat various environmental stresses (reactive oxygen species (ROS), peroxynitrite, arsenate) (Landino, Skreslet et al. 2004). Some Trxs can also regulate cell death via denitrosylation and modulate the inflammatory response (Rahman and Adcock 2006). In addition, it has been shown that Trx plays an essential role in the life cycle of viruses. Trxs are located in various cellular compartments. For instance, a 
number of Trxs are found in the cytosol (Arnér and Holmgren 2000), while others are abundant in nucleus or mitochondria (Hirota, Matsui et al. 1997, Hirota, Murata et al. 1999). Still others are associated with the cell membrane (Martin and Dean 1991).

In 1964 the Trx/TrxR system was determined to be comprised of Trx, together with thioredoxin reductase (TrxR) and NADPH (Laurent, Moore et al. 1964). In general, the electrons which are provided by NADPH are transferred to the active site of $\operatorname{Trx}$ via TrxR. The disulfide of oxidized Trx must be reduced back to a dithiol to regain its active form. The enzyme TrxR, with reducing equivalents ultimately derived from NADPH (Figure16) performs this reduction.

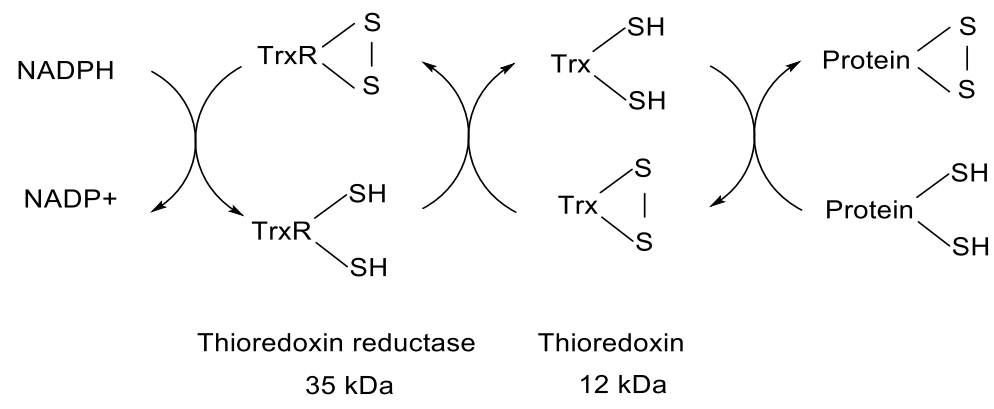

Figure 16 Electron flow of E. coli $\operatorname{TrxR} / \operatorname{Trx}$ system

TrxR is a member of the pyridine nucleotide disulfide oxidoreductase family that includes glutathione reductase (GR) and lipoamide dehydrogenase (LipDH) (Mustacich and Powis 2000). Both TrxR and GR use NADPH as a cofactor via FAD to transfer electrons to the redox centers, while LipDH uses NADH instead of NADPH (Williams Jr 1992). In addition, two types of TrxR have been identified. Although they both have same functions, the amino acid sequence and catalytic mechanisms are distinct (Gromer, Schirmer et al. 1999, Mustacich and Powis 2000). The type of TrxR with a low molecular weight $(\sim 35 \mathrm{kDa})$ has been characterized in 
Archaea, bacteria and Eukarya (Becker, Gromer et al. 2000). There are two binding domains in E. coli TrxR: FAD binding domain and NADPH binding domain. The connection of these two domains is not close (Williams 1995). In E. coli TrxR the FAD domain is rotated 66 degrees with NADPH domain remaining, so that the two prosthetic groups move into close contact. The conformational change allows electrons to pass from NADPH to FAD then to reduce the disulfide bond (Lennon and Williams 1997, Mustacich and Powis 2000). The conserved active site residues are Cys-Ala-Thr-Cys- in the redox center of E. coli TrxR.

A high molecular weight ( $\sim 55 \mathrm{kDa}) \operatorname{TrxR}$ is often referred to as mammalian as it was first identified in Homo sapiens. Subsequently, this high molecular weight TrxR has been found to be widespread in the animal kingdom (Mustacich and Powis 2000, Bauer, Gromer et al. 2003). Mammalian TrxR is distinct from bacterial TrxR by virtue of a third redox center in a C-terminal extension of the enzyme consisting of a cysteine and a selenocysteine (Sec) $\left(\mathrm{Cys}^{497}-\mathrm{Sec}^{498}-\mathrm{Gly}-\right.$ in human TrxR). The purification of rat liver Trx and TrxR demonstrated that mammalian TrxR is larger than mammalian Trx. Mammalian TrxR has broader substrate specificity than prokaryotic forms (Luthman and Holmgren 1982, Arnér 2009). Mammalian TrxR is a large selenoenzyme, which has three isoforms: TrxR1 in the cytosol (Arnér 2009), TrxR2 in mitochondria and TrxR3 or thioredoxin glutathione reductase (TGR) (testis)(Lillig and Holmgren 2007). TGR has common properties to other flavoprotein oxidoreductase. However, TGR is the unique enzyme that connects thioredoxin and glutathione system. TGR has an extra reaction sites (CVNVGC) at the N-terminal. The reducing equivalents are transferred from NADPH to the FAD. Then, the adjacent cysteine in the reaction site $(\mathrm{CVNVGC})$ at $\mathrm{C}$-terminal. The reduced cysteine 
transfers the hydride to the cysteine-selenocysteine in the C-terminal reaction center (GUCG) of the other peptide chain (Figure17 A). The reduced GUCG produces a structural change allowing to reduce either extra active site (CPYC) of TGR or oxidized thioredoxin. The reduced active site (CPYC) interacts with glutathione disulfide (Figure 17 B).

$\mathbf{A}$

Oxidized Thioredoxin

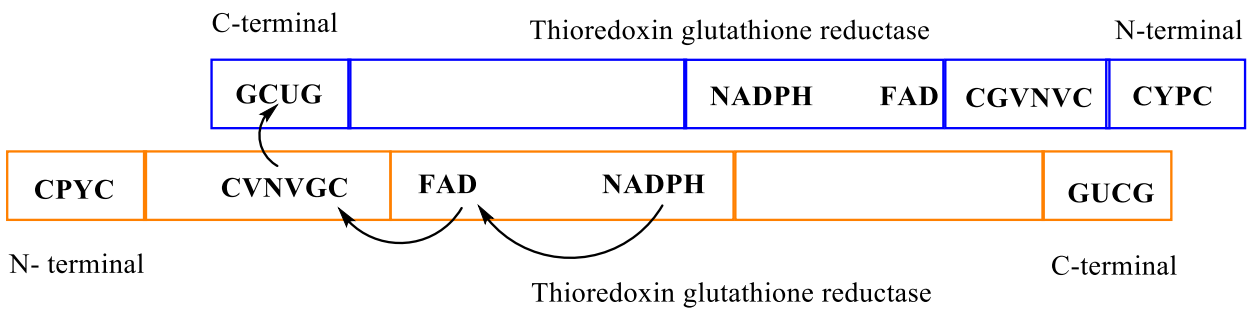

Oxidized Glutathione

B

Oxidized Thioredoxin

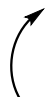

C-terminal

N-terminal

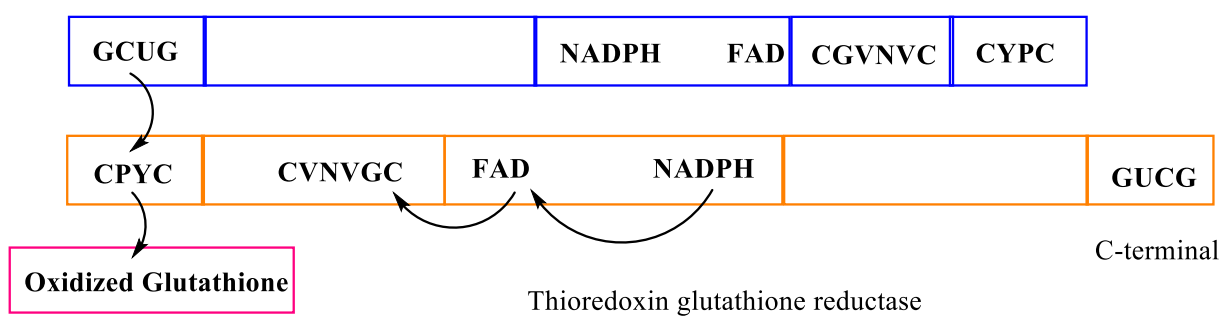

$\mathrm{N}$ - terminal

Figure 17 Reaction mechanism of TGR. (A) The reducing equivalents are transferred from NADPH to the FAD. Then, the adjacent cysteine in the reaction site (CVNVGC) at Cterminal. The reduced cysteine transfers the hydride to the cysteine-selenocysteine in the $\mathrm{C}$ terminal reaction center (GUCG) of the other peptide chain. (B) The reduced GUCG produces a structural change allowing to reduce either extra domain (CPYC) of TGR or oxidized thioredoxin. The reduced extra domain interacts with oxidized glutathione 
It has been found that the selenium is the essential active site residue in mammalian TrxR. Blocking or mutation at the selenium active site results in a loss of ability to reduce Trx (Figure18).

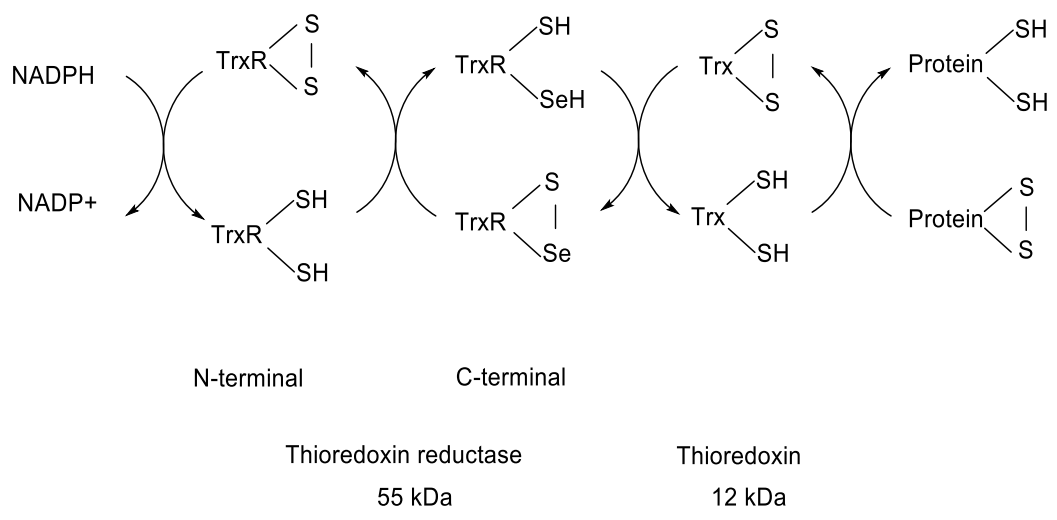

Figure 18 Electron flow of mammalian TrxR/Trx system

The Trx/ TrxR system plays a role as a general protein disulfide reductase. It is involved in regulating DNA synthesis, gene transcription, cell growth and metabolism (Krauth-Siegel and Coombs 1999, Arnér and Holmgren 2000, Mustacich and Powis 2000, Williams 2000). The Trx/TrxR system also plays a key role in biochemical mechanisms associated with many human diseases (Figure19). For instance, Trx and TrxR overexpression is observed in many cancer cells, which has been hypothesized to be a protection against apoptosis (Baker, Payne et al. 1997, Powis, Mustacich et al. 2000, Lincoln, Ali et al. 2002, Urig and Becker 2006, Anestål, Prast-Nielsen et al. 2008). TrxR is an important target for many cancer treatments. Cisplatin and arsenic trioxide as clinical drugs are used to inhibit TrxR resulting in blocking or mediating the activity of DNA synthesis and defense against oxidative stress ( $\mathrm{Lu}$, Chew et al. 2007, Arnér 2009). 


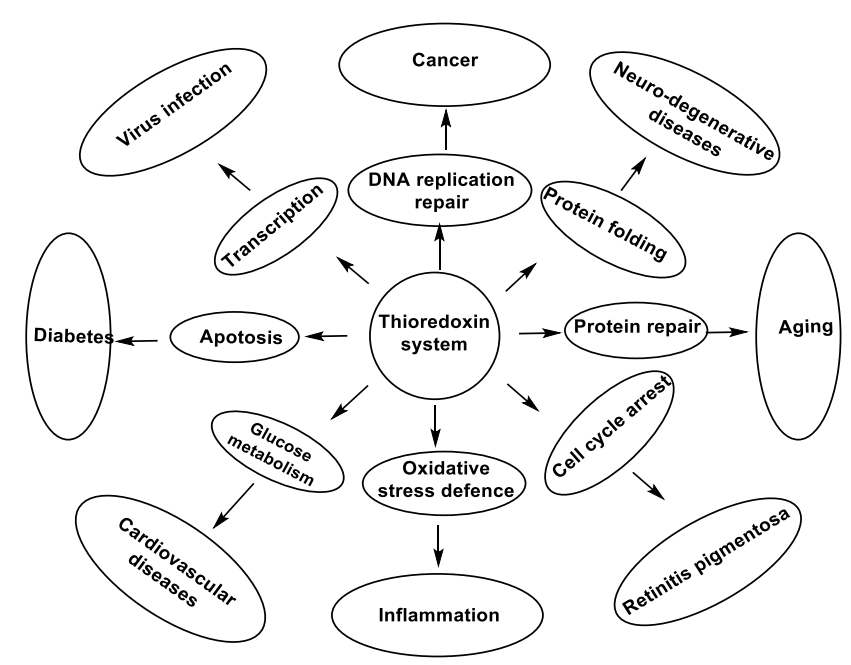

Figure 19 The Trx/TrxR system plays a key role in biochemical processes associated with many human diseases

In most organisms in addition to Trx/TrxR system, glutathione/ glutathione disulfide (GSH/GSSG) is a major pathway for regulating cellular redox homeostasis and antioxidant defense. The mammalian GSH/GSSG system involved GSH recycling of oxidized GSSG catalyzed by GR using NADPH as electron donor The N-terminal domains of GR resemble those of TrxR, including the FAD prosthetic group, the NADPH binding domain and the N-terminal redox-active CVNVGC motif (Arscott, Gromer et al. 1997). However, GR lacks the C-terminal redox center (GCUG) of TrxR (Lu and Holmgren 2014).

In addition to Trx, Grx and glutathione peroxidase (GPx) also belong to the family of oxidoreductases which function through thiol-disulfide exchange. These proteins have similar three-dimensional structures and contain an active site dithiol/disulfide group which protrudes from a hydrophobic protein surface The disulfide bond in Grx is reduced continually by GSH in the mammalian GSH/GSSG system (Figure 20). While Trx and Grx show low sequence homology, they exhibit similar three- 
dimensional topology including the so-called thioredoxin fold, consisting of an Nterminal $\beta \alpha \beta$ motif and a $C$-terminal $\beta \beta \alpha$ motif with the central $\beta$-sheets surrounded by the $\alpha$-helices and an active site CXXC motif, which protrudes from the hydrophobic surface of the protein.(Martin 1995, Netto, de Oliveira et al. 2016)

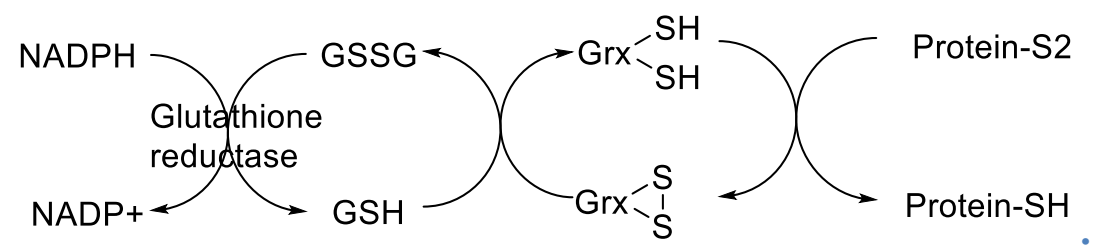

Figure 20 Electron flow of mammalian GSH/GSSG system

GPx catalyzes the reduction of ROS in cells, including hydrogen peroxide, by reduced glutathione to protect the cells from oxidative damage. Moreover, most noteworthy is that GPx is a selenoprotein. GPx has four identical subunits. Each subunit contains a selenocysteine in the active site, which participates directly within the catalytic cycle. The selenium undergoes a redox cycle involving the selenol (GPx-SeH) as an active site to reduce hydrogen peroxides and other harmful peroxide, which oxidizes GPXSeH to selenenic acid (GPx-SeOH). A reduced GSH reacts with GPx-SeOH to form selenenyl sulfide adduct (GPx-SeSG). A second GSH is the ultimate electron donor to regenerate the reduced form of the selenocysteine by attacking the GPx-SeSG to form the oxidized GSSG (Figure21) (Morgenstern 2005, Toppo, Vanin et al. 2008). 


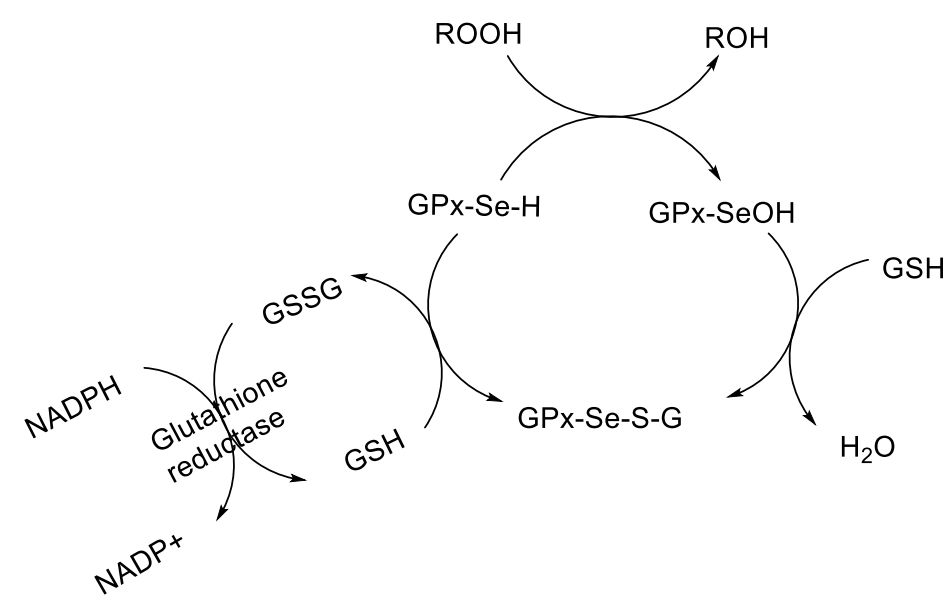

Figure 21 The redox cycle of GPx coupled with mammalian GSH/GSSG system

\subsection{Results}

\subsubsection{Modified papain assay}

The modified papain assay is a sensitive spectrophotometric assay that is commonly used for the quantitation of thiol groups. The assay involves the reaction of a thiol with an inactive mixed disulfide of papain, a cysteine protease, resulting in the stoichiometric formation of active papain (Figure 22) (Singh, Blattler et al. 1993). The active site cysteine of papain is converted to an inactive mixed disulfide which may be reduced by low MW thiols to the active form. The active papain then catalyzes the hydrolysis of $N$-benzoyl- $L$-arginine- $p$-nitroanilide to yield $p$-nitroanilide.

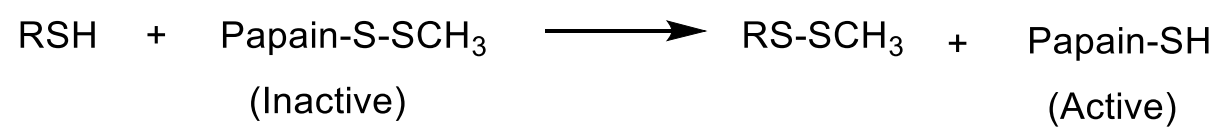

Figure 22 The equation of modified papain assay

The chromogenic product can be detected at $412 \mathrm{~nm}$. Furthermore, the addition of the disulfide cystamine to the assay allows for the detection of inaccessible protein thiols. Cystamine is reduced to cysteamine by protein thiols and the resulting cysteamine acts as a shuttle between high MW inaccessible protein thiols and modified papain. 
Thus the difference in papain activity with and without cystamine is a reflection of high MW inaccessible thiols. The initial amount of thiol can be obtained from the proportion of absorbance compared to the concentration of thiol standards. Here, this method can also be used to determine the content of reduced Trx. Because the reaction of Trx with it's substrates is stoichiometric, the modified papain assay can be used to amplify the signal of Trx. Trx is used to reduce the small disulfide cystamine to cysteamine, which will in turn reduce the papain disulfide stoichiometrically (Figure23). Thus the modified papain assay may be used to assay for Trx activity by amplification of the Trx signal.

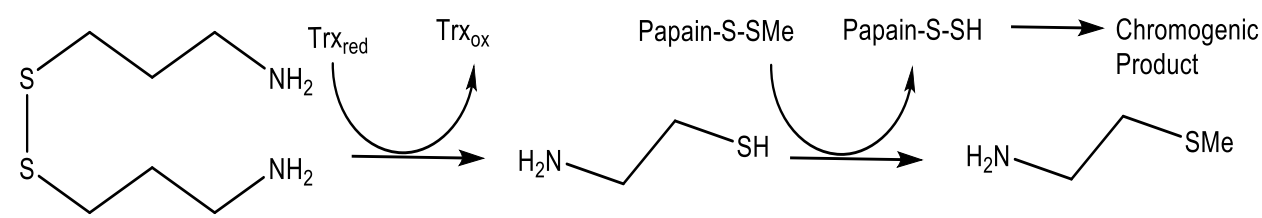

Figure 23 The principle of modified papain assay to determine Trx activity

\subsubsection{Papain assay}

The effect of PbTx-2 on Trx was examined using the modified papain assay. Inhibition of this two enzyme (Trx/papain) system was observed in the presence of PbTx-2 $(15 \mu \mathrm{M})$ when compared to the positive control reaction (no PbTx) whether the PbTx-2 was pre-incubated with Trx or not pre-incubated (Figure24). 


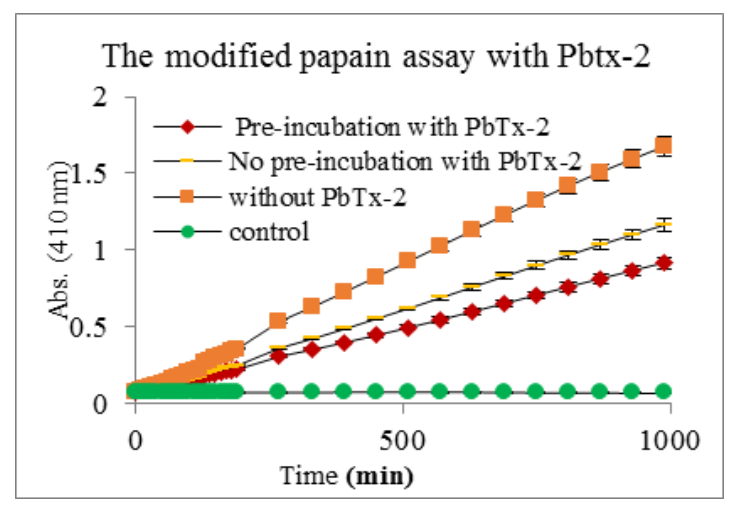

Figure 24 The modified papain assay with / without PbTx-2 The condition: PbTx-2 $(15 \mu \mathrm{M})$, substrate $(1 \mathrm{mM})$, modified papain $(10 \mu \mathrm{M})$, cystamine $(45 \mu \mathrm{M}), \operatorname{Trx}(6 \mu \mathrm{M}), \mathrm{pH} 7.0$ acetate buffer $(50 \mathrm{mM})$

However, comparison of the relative initial rates $\left(\mathrm{V}_{0}\right)$ for the pre-incubated and nonpre-incubated reactions, shows that pre-incubation with $\operatorname{Trx}$ results in a $56 \%$ reduction of $\mathrm{V}_{0}$, compared to a $36 \%$ reduction of $\mathrm{V}_{0}$, observed without pre-incubation. Thus pre-incubation of Trx with $\mathrm{PbTx}-2$ resulted in increased inhibition of Trx. Because pre-incubation of Trx and PbTx-2 increased the inhibition in the modified papain assay, this suggests that $\mathrm{PbTx}-2$ does indeed act as an inhibitor of $\operatorname{Trx}$. However, there are two complicating factors which need to be considered: first, the $\alpha$, $\beta$-unsaturated aldehyde side chain of $\mathrm{PbTx}-2$ can react as an electrophile in a Michael addition, with the generated cysteamine and second, it has been reported both PbTx-2 and -3 are inhibitors of papain (Sudarsanam, Virca et al. 1992). To address the first complication, another papain assay was used $\mathrm{PbTx}-2$ as inhibitor but without cystamine. PbTx-2 does show inhibition in the absence of cystamine, but under these conditions the reaction is slow and the assay is much less sensitive (Figure25). 


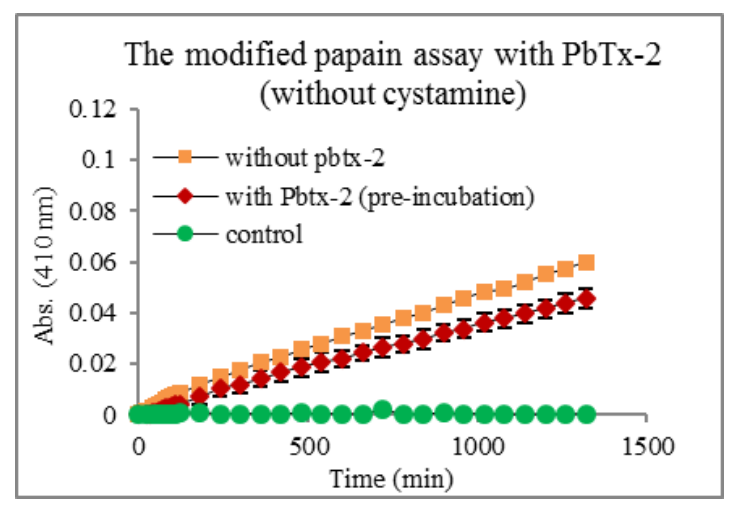

Figure 25 The modified papain assay with / without $\mathrm{PbTx}-2$ but without cystamine. The condition: PbTx-2 $(15 \mu \mathrm{M})$, substrate $(1 \mathrm{mM})$, modified papain $(10 \mu \mathrm{M})$, $\operatorname{Trx}(6 \mu \mathrm{M}), \mathrm{pH} 7.0$ acetate buffer $(50 \mathrm{mM})$

Thus, the rate of the reaction in the presence of Pbtx-3 (which does not react with cysteamine) was determined to see if the effect of brevetoxin is due to reaction with cysteamine. It is clear that the Pbtx-3 impacts the rate (Figure 26).

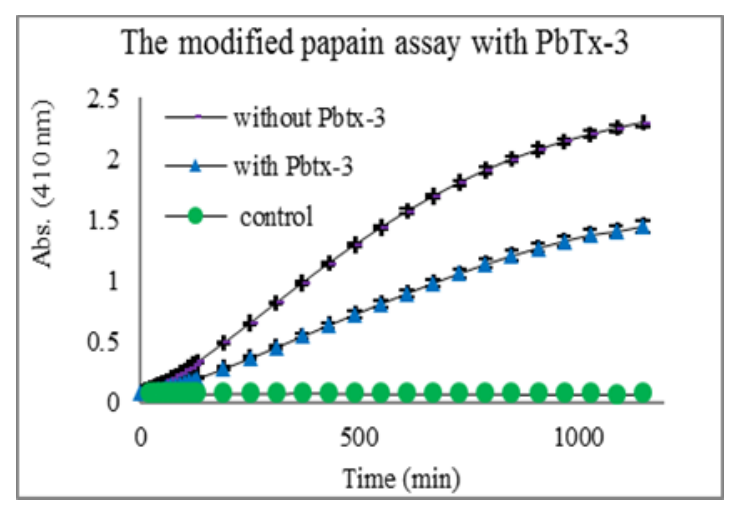

Figure 26 The modified papain assay with / without $\mathrm{PbTx}-3$ with cystamine. The condition: Pbtx-3 $(15 \mu \mathrm{M})$, substrate $(1 \mathrm{mM})$, modified papain $(10 \mu \mathrm{M})$, cystamine $(45 \mu \mathrm{M}), \operatorname{Trx}(6 \mu \mathrm{M})$, $\mathrm{pH} 7.0$ acetate buffer $(50 \mathrm{mM})$

In order to understand the inhibition of papain by Pbtx-2 and Pbtx-3, a standard papain assay which didn't contain the cystamine was performed in the presence of $\mathrm{PbTx}-2$ and $\mathrm{PbTx}-3$ (Figure27). Figure 27 shows that both brevetoxins inhibit papain. 


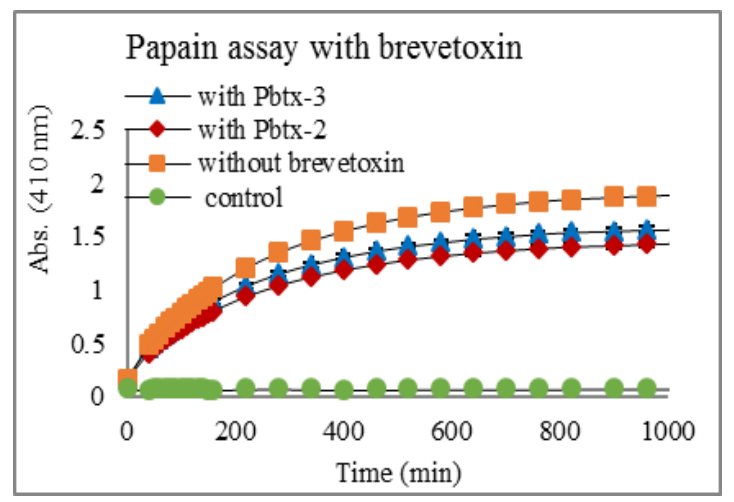

Figure 27 The papain assay with / without brevetoxin. The condition: PbTx-3 or PbTx-2 (15 $\mu \mathrm{M})$, substrate $(1 \mathrm{mM})$, papain $(10 \mu \mathrm{M}), \mathrm{MeOH} 3.2 \%$, pH 7.0 acetate buffer $(50 \mathrm{mM})$

The initial rates $\left(\mathrm{V}_{0}\right)$ are calculated based on the polynomial regression of the trend lines in Figure 2426 and 27. Table 6 compares initial rates for the papain and modified papain assays with and without inhibitor relative to the standard papain assay without inhibitor. The initial rate $\left(\mathrm{V}_{0}\right)$ of the standard papain assay is three fold higher than that of the modified papain assay. If inhibition of the modified papain assay by brevetoxin is due solely to the inhibition of papain, one would anticipate a similar reduction in $\mathrm{V}_{0}$ in the presence of brevetoxin. However, a six fold reduction of $\mathrm{V}_{0}$ was shown in the presence of brevetoxins (PbTx-2 and PbTx-3) for the modified papain assay. Table 7 shows that the addition of PbTx-3 (15 $\mu \mathrm{M})$ results in a $15 \%$ reduction of $\mathrm{V}_{0}$ in the standard papain assay when compared to the control. However, when added to the modified papain assay under the same conditions, a 52\% reduction of $\mathrm{V}_{0}$ is observed. While PbTx-2 $(15 \mu \mathrm{M})$ results a $25 \%$ reduction of $\mathrm{V}_{0}$ in the standard papain assay whereas it results in a $56 \%$ reduction of $\mathrm{V}_{0}$ in the modified papain assay. These data suggest that brevetoxins are indeed inhibitors of Trx. However, it still cannot directly prove that the inhibition is caused by brevetoxin.

Table 6 Relative $\mathrm{V}_{0}$ for the assays shown above in Figure 24,26 and 27

\begin{tabular}{|l|c|c|c|}
\hline Inhibitor & $\begin{array}{l}\text { Only } \\
\text { papain }\end{array}$ & $\begin{array}{c}\text { Modified } \\
\text { Papain assay }\end{array}$ & $\begin{array}{c}\text { Fold } \\
\text { reduction }\end{array}$ \\
\hline None & 1 & 0.32 & 3.1 \\
\hline
\end{tabular}




\begin{tabular}{|l|l|l|l|}
\hline Brevetoxin-2 (15 $\boldsymbol{\mu M})$ & 0.75 & 0.12 & 6.3 \\
\hline Brevetoxin-3 (15 $\boldsymbol{\mu M})$ & 0.85 & 0.15 & 5.6 \\
\hline
\end{tabular}

Table 7 The inhibition \% for the assays shown above in Fig 24,26 and 27

\begin{tabular}{|l|l|l|}
\hline & Only papain & Modified papain assay \\
\hline PbTx-2 & $25 \%$ & $56 \%$ \\
\hline PbTx-3 & $15 \%$ & $52 \%$ \\
\hline
\end{tabular}

\subsubsection{Fluorescent assay for Trx/TrxR system}

As an alternative, the activity of Trx can be amplified at the front end by including TrxR and NADPH in the reaction to continuously reduce the Trx. The method used is based on the reduction of insulin by reduced Trx with NADPH as ultimate electron donor via TrxR (Montano, Lu et al. 2014). The insulin is labeled with fluorescein isothiocyanate-labeled (FiTC). These FiTC-modified insulin servers as the substrate. Insulin is composed of two peptide chains which are the chain A and chain B. It is found that the fluorescence is quenched by the disulfides between chain A and B. However, the fluorescence is increased on reduced form of insulin (Heuck and Wolosiuk 1997). Here, the disulfides are able to be reduced by Trx /TrxR system, the fluorescence of FiTC is record after 30 min incubation with the mixture of Trx, TrxR and NADPH (Figure 28) (Montano, Lu et al. 2014).

$$
\begin{aligned}
\text { Trx-S } & +\mathrm{NADPH}+\mathrm{H}^{+} \stackrel{\mathrm{TrxR}}{\longrightarrow} \operatorname{Trx}(\mathrm{SH})_{2}+\mathrm{NADP}^{+} \\
\text {Trx-(SH) }{ }_{2}+\text { FiTC- Insulin- } \mathrm{S}_{2} & \left.\longrightarrow \text { Trx-(SH) }{ }_{2}+\text { FiTC- Insulin-(SH) }\right)_{2}
\end{aligned}
$$

Figure 28 The reaction in sensitive fluorescent assay for Trx/TrxR system

To determine if brevetoxin acts as inhibitor of Trx, the inhibition of Trx by $\mathrm{PbTx}-2$ and -3 was determined using a commercially available assay kit (Montano, Lu et al. 2014). $\mathrm{PbTx}-2$ and $\mathrm{PbTx}-3$ at concentrations ranging from 10 to $35 \mu \mathrm{M}$ were incubated with a mixture of pre-reduced TrxR and Trx for one hour. After adding 
FiTC-modified insulin substrate, the release of fluorescent reporter was monitored. The first 40 minutes correspond to a slow induction period where two disulfide bridges of Trx are reduced and the increase in fluorescence is not linear. Therefore, the data for the first 40 minutes is not used in accordance with the manufacturer's instructions. The rate of reaction within the linear range was determined by using the slopes of the linear trend lines. A graph was made by using the concentration of $\mathrm{PbTx}-2$ as $\mathrm{x}$-axis and the resulting values of each corresponding curve lines as $\mathrm{y}$-axis (Figure 29.) $\mathrm{IC}_{50}$ was calculated as the concentration of an inhibitor that is required for $50 \%$ inhibition. Interestingly, $\mathrm{PbTx}-2$ exhibited a dose dependent inhibition of $\operatorname{Trx} / \operatorname{Trx} R$ activity with an $\mathrm{IC}_{50}$ of $25 \mu \mathrm{M}$, whereas $\mathrm{PbTx}-3$ had no effect on the rate of insulin reduction (Figure 30). It has been shown that apparent $\mathrm{K}_{\mathrm{m}}$ values for rat $\operatorname{Trx}$ 3.7 $\mu \mathrm{M}$ (Heuck and Wolosiuk 1997). Based on Cheng-Prusoff equation, Ki was determined at $24.7 \mu \mathrm{M}$.
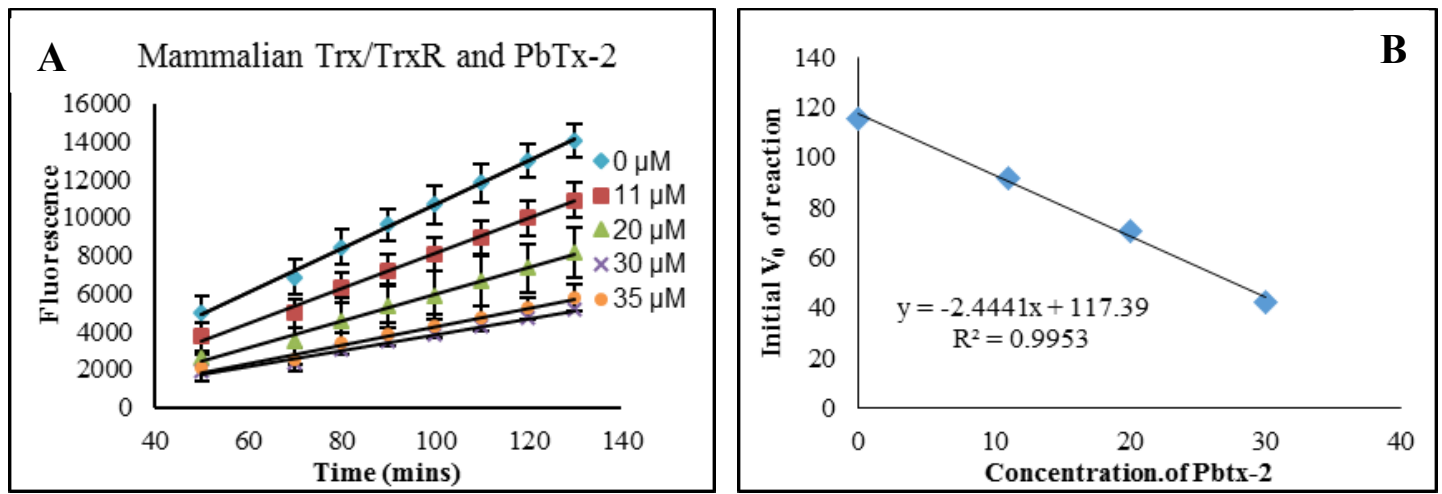

Figure 29 The effect of PbTx-2 on Trx/TrxR system. A: Rat TrxR and human Trx prereduced with NADPH $(0.35 \mathrm{mM})$ for 30 min followed by incubation with brevetoxins for $1 \mathrm{~h}$ prior to addition of insulin substrate. B: The concentration of $\mathrm{PbTx}-2$ vs the initial rate of reaction. $\mathrm{IC}_{50}$ was calculated as the concentration of an inhibitor that is required for $50 \%$ inhibition. PbTx-2 exhibited a dose dependent inhibition of Trx/TrxR activity with an $\mathrm{IC}_{50}$ of $25 \mu \mathrm{M}$ 

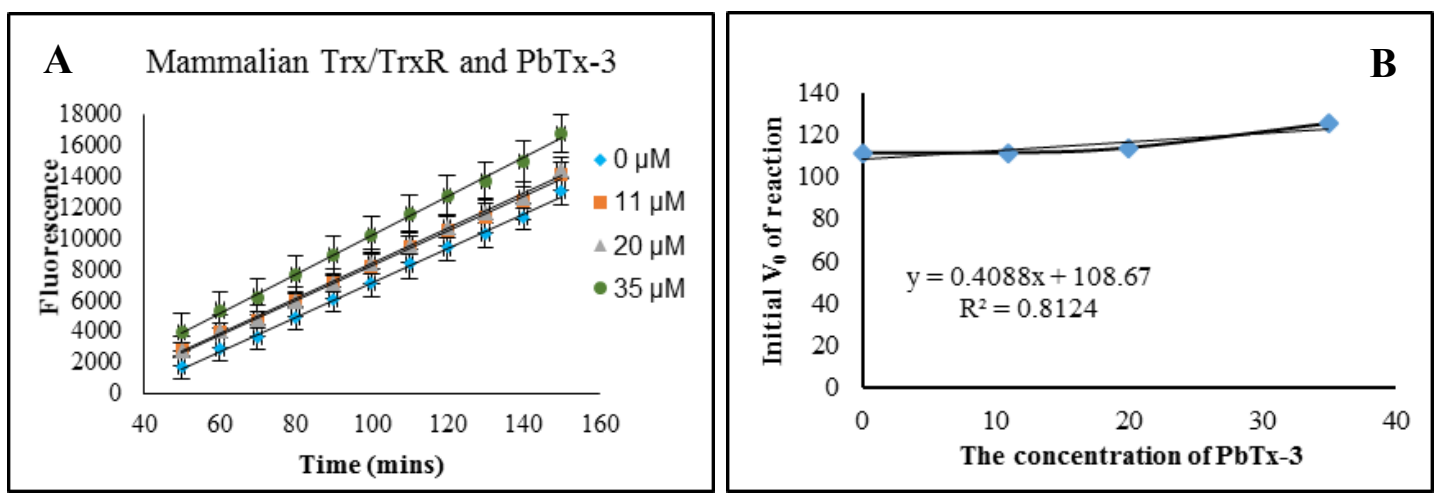

Figure 30 The effect of PbTx-3 on $\operatorname{Trx} / \operatorname{TrxR}$ system. A: Rat TrxR and human Trx prereduced with NADPH $(0.35 \mathrm{mM})$ for 30 min followed by incubation with brevetoxins for $1 \mathrm{~h}$ prior to addition of insulin substrate. B: The concentration of PbTx-2 vs the initial rate of reaction. However, $\mathrm{PbTx}-3$ had no effect on the rate of insulin reduction

\subsubsection{Ellman's assay}

Ellman's assay utilizes 5, 5'-dithio-bis-(2-nitrobenzoic acid), also known as DTNB, to react with free sulfhydryl group to yield a mixed disulfide and 2-nitro-5-thiobenzoic acid (TNB). TNB is a measurable yellow-colored product (Figure 31) which can be detected at $412 \mathrm{~nm}$ (Riener, Kada et al. 2002). To detect the Trx or TrxR activity, reduced Trx or TrxR can be used to reduce DTNB producing the yellow TNB which can be detected at $412 \mathrm{~nm}$.

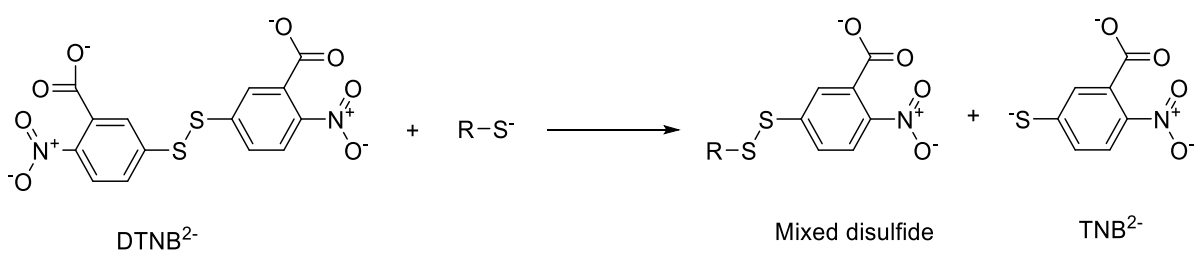

Figure 31 The reduction of Ellman's reagent

Because the Trx/TrxR assay is a two enzyme system (Trx/TrxR), it was still not clear if the inhibition observed in the presence of $\mathrm{PbTx}-2$ is due to the inhibition of Trx, or TrxR or both. Unlike bacterial TrxR, which shows high substrate selectivity for Trx, mammalian TrxR reduces a broad range of substrates, including small disulfides such as DTNB, making it possible to assay for TrxR activity in the absence of Trx. Thus, 
the activity of TrxR alone in the presence and absence of PbTx-2 was determined by using Ellman's reagent.

PbTx-2 $(22 \mu \mathrm{M})$ was incubated with the rat TrxR in the presence of NADPH. After 30 min, DTNB was added to the reaction mixture and the absorbance of TNB- was monitored for 60 mins. Surprisingly, the $V_{o}$ of DTNB reduction by TrxR was enhanced 2.5 fold in the presence of $\mathrm{PbTx}-2$ when compared to the control reaction which lacked PbTx-2. (Figure32 A). The same result was obtained when PbTx-2 was added simultaneously with DTNB. In other words, without pre-incubation of TrxR by NADPH and PbTx-2. (Figure32 B)
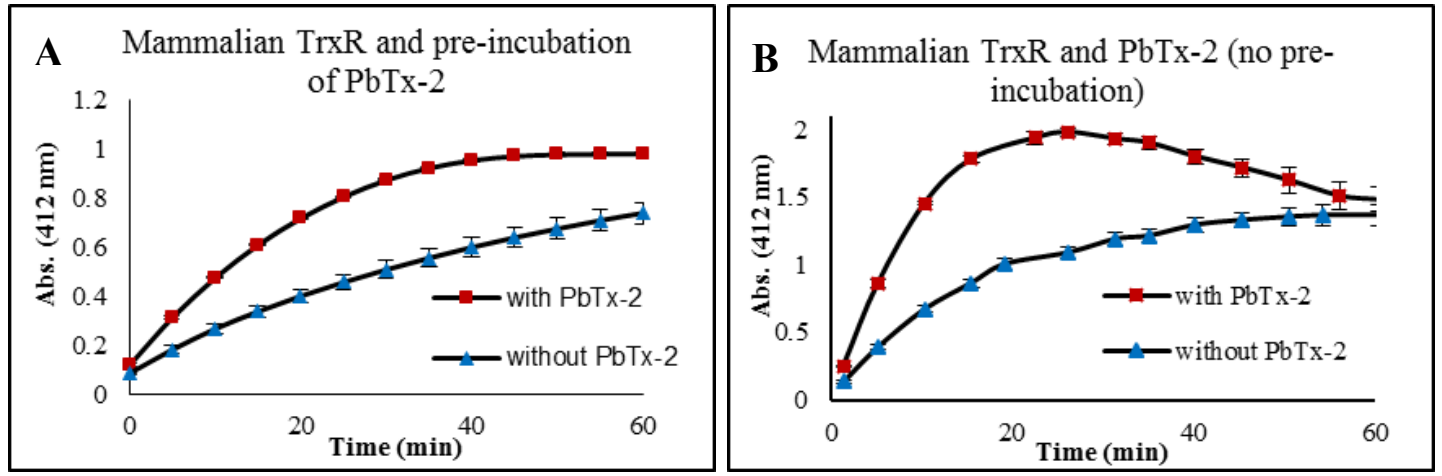

Figure 32 The effect of PbTx-2 on the Ellman's assay. (A) The effect of PbTx-2 on the DTNB reduction by pre-incubated TrxR. Rat TrxR was pre-reduced with NADPH $(0.10 \mathrm{mM})$ for 30 min with PbTx-2 $(18 \mu \mathrm{M})$, followed by addition of DTNB $(1.8 \mathrm{mM})$. (B) The effect of $\mathrm{PbTx}-2$ on the DTNB reduction by non-incubated TrxR. Rat TrxR was pre-reduced with NADPH $(0.10 \mathrm{mM})$ for $30 \mathrm{~min}$ without PbTx-2 $(18 \mu \mathrm{M})$, followed by addition of DTNB $(1.8$ $\mathrm{mM})$

That surprising result was reproducible and results triggered our curiosity: Why does $\mathrm{PbTx}-2$ enhance the activity of TrxR?

As mentioned earlier, mammalian TrxR is distinct from bacterial TrxR by virtue of a third C-terminal redox center consisting of a cysteine and a selenocysteine (Sec or U). The TrxRs which were used in all experiments to this point were mammalian. In the 
enzymatic mechanism of Trx reduction by TrxR, NADPH provides the reducing equivalents and initiates this cascade of redox reactions across three redox active sites: FAD which is first reduced by $\mathrm{NADPH}$, next $\mathrm{FADH}_{2}$ reduces an $\mathrm{N}$-terminal disulfide (in human TrxR:- $\mathrm{Cys}^{59}$-Val-Asn-Val-Gly-Cys ${ }^{64}$ ) which undergoes thiol disulfide exchange with a C-terminal disulfide or seleno-sulfide (in human TrxR:-Gly-Cys ${ }^{497}$ $\mathrm{Sec}^{498}$-Gly). The C-terminal redox center of TrxR undergoes thiol-disulfide exchange with oxidized Trx (Figure 33).

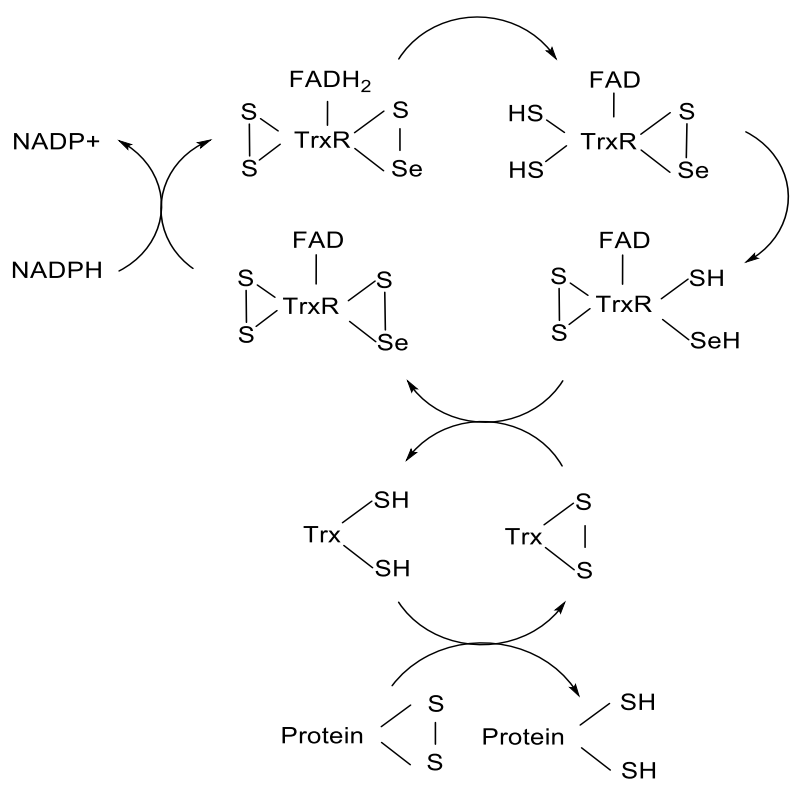

Figure 33 The electron flow in C-terminal reaction center in mammalian TrxR

Furthermore, it is reported the activity of Sec is essential for mammalian TrxR to catalyze the reduction of Trx (Lee, Bar-Noy et al. 2000, Zhong and Holmgren 2000). When the Sec site is blocked or modified, the mammalian TrxR is unable to reduce the oxidized Trx disulfide to activated $\operatorname{Trx}-(\mathrm{SH})_{2}$. Sec $(\mathrm{U})$ is a selenium containing analog of cysteine but with a stronger nucleophile, which makes Sec a highly reactive amino acid. Thus many compounds such as quinol (Bradshaw, Matthews et al. 2005), curcumin (Fang, Lu et al. 2005) and 4-hydroxy-2-nonenal (Fang and Holmgren 2006)(Figure34) inhibit TrxR as electrophilic compounds. These molecules can 
function as electrophiles, or Michael acceptors, for the nucleophilic Cys or Sec residues, resulting in irreversible inhibition of TrxR. Curcumin was found to alkylate both the C-terminal cysteine and selenocysteine of TrxR. On the other hand, 4hydroxy-2-nonenal and quinols have been demonstrated to label the C-terminal cysteine and selenocysteine of TrxR as well as the redox active cysteines of Trx.<smiles>COc1cc(/C=C/C(=O)CC(=O)/C=C/c2ccc(O)c(OC)c2)ccc1O</smiles><smiles>[R]C1(O)C=CC(=O)C=C1</smiles>

Figure 34 The Michael acceptors demonstrated to inhibit TrxR

Comparison of these compounds to $\mathrm{PbTx}-2$, reveals that they have a common functional group: an $\alpha, \beta$-unsaturated carbonyl. Thus, it is assumed that the $\alpha, \beta$ unsaturated aldehyde K-ring side chain of $\mathrm{PbTx}-2$ may function as an efficient electrophile, reacting with Sec. Thus, if the TrxR and PbTx-2 form an adduct, this would result in the irreversible inhibition of Trx reduction, which can explain the reason $\mathrm{PbTx}-2$ shows inhibition of the TrxR/Trx system towards insulin reduction while the allylic alcohol, PbTx-3 does not (Figure35). This explanation is also consistent with the observation that DTNB reduction by TrxR is actually enhanced in the presence of $\mathrm{PbTx}-2$. It has been previously demonstrated that small molecules such as DTNB can be reduced by the N-terminal redox center while the C-terminal center is alkylated (Cenas, Nivinskas et al. 2004, Eckenroth, Lacey et al. 2007). In the reduction of $\operatorname{Trx}$ by $\operatorname{TrxR}$, is has been shown that the reduction of the C-terminal seleno-sulfide is the rate-determining step. Reduction of DTNB by the N-terminal 
disulfide actually by passes the rate-determining step. Thus, the activity of TrxR towards the reduction of DTNB was increased (Figure 36).

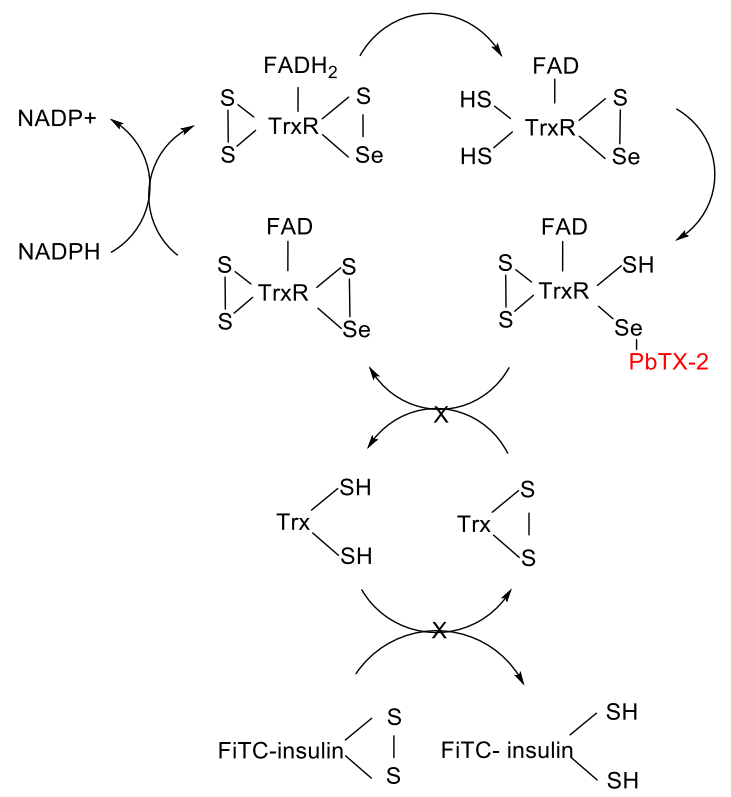

Figure 35 The hypothesized explanation for the observation in fluorescent Trx/TrxR assay with $\mathrm{PbTx}-2$

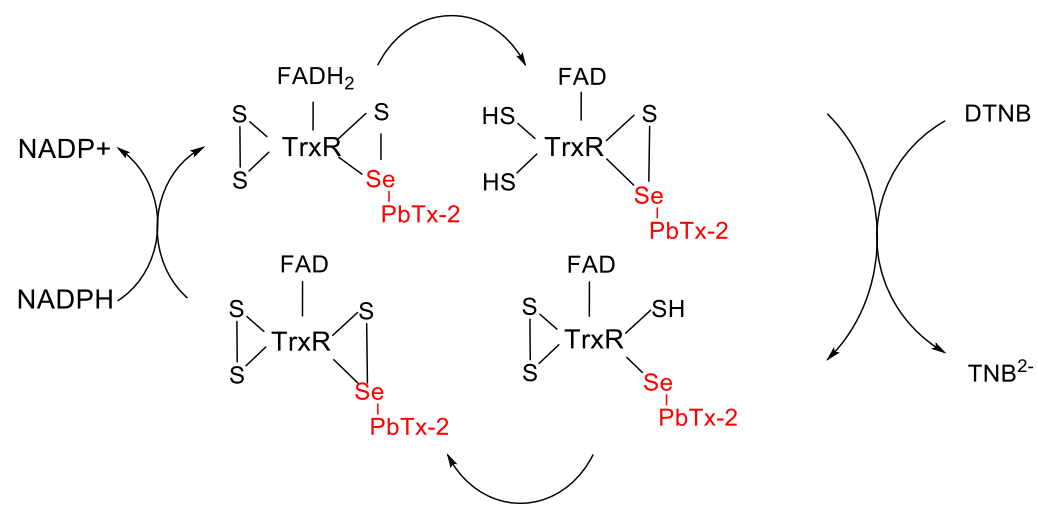

Figure 36 The hypothesized explanation for the observation in DTNB assay with TrxR and $\mathrm{PbTx}-2$

In order to support this hypothesis, we were able to obtain a truncated recombinant human TrxR which lacks the C-terminal Sec residue (Cheng, Sandalova et al. 2009, Lothrop, Ruggles et al. 2009, Snider, Dustin et al. 2014). However, truncated TrxR, which lacks the $\mathrm{C}$-terminal $\mathrm{Sec}$ residue retains its ability to reduce low molecular weight disulfides via its $\mathrm{N}$-terminal dithiol redox center. In order to identify the redox 
center which is affected by brevetoxin, the activity of truncated human TrxR was examined in the presence of PbTx-2. At $22 \mu \mathrm{M}, \mathrm{PbTx}-2$ had no effect on the activity of truncated hTrxR towards the reduction of DTNB when compared to the control sample, which lacked PbTx-2 (Figure 37). This suggests that PbTx-2 interacts with the C-terminal redox center of TrxR.

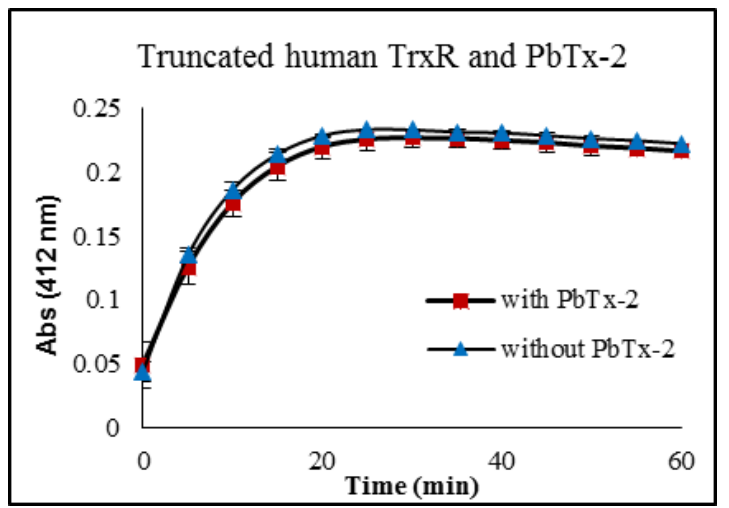

Figure 37 The effect of truncated recombinant human TrxR by PbTx-2. Truncated human TrxR was pre-reduced with NADPH $(0.10 \mathrm{mM})$ for $30 \mathrm{~min}$ in the presence of PbTx-2 (18 $\mu \mathrm{M})$, followed by DTNB $(1.8 \mathrm{mM})$

The results from all experiments support our hypothesis that PbTx-2 inhibits TrxR by forming an adduct with the $\mathrm{C}$-terminal Sec residue. However, direct evidence for adduct formation between the $\alpha, \beta$-unsaturated aldehyde K-ring side chain of $\mathrm{PbTx}-2$ with TrxR was still lacking at this point. In order to confirm the hypothesis, $\mathrm{PbTx}-3$ was used, which only has alcohol instead of aldehyde to react the mammalian TrxR under the exactly same condition. Interestingly, the rate of DTNB reduction by TrxR was also enhanced in the presence of PbTx-3 but only 1.31 fold (Figure38). However, it could be many reasons to explain the observations. For example, perhaps brevetoxin binding can induce a conformational change in TrxR. Also, perhaps the $\alpha$, $\beta$-unsaturated unsaturated carbonyl in the A ring lactone may actas a Michael acceptor, although less effectively than the $\alpha, \beta$-unsaturated unsaturated aldehyde of 
$\operatorname{PbTx}-2$

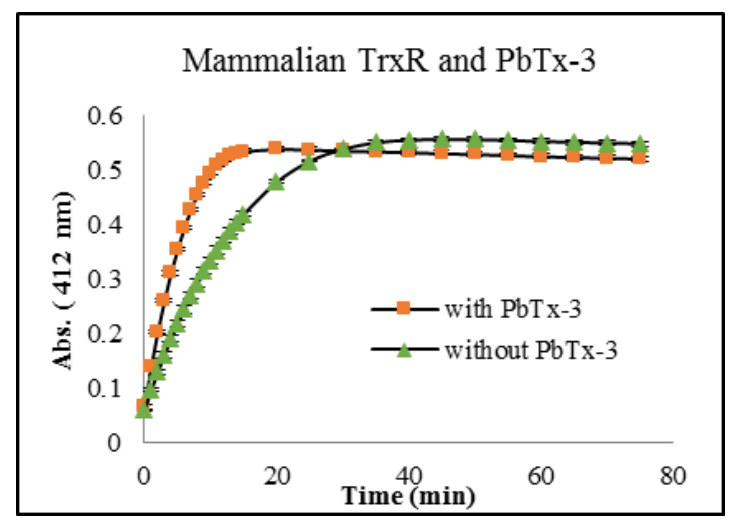

Figure 38 The effect of PbTx-3 on DTNB reduction by mammalian TrxR. Rat TrxR was prereduced with NADPH $(0.10 \mathrm{mM})$ for $30 \mathrm{~min}$ with PbTx-3 $(18 \mu \mathrm{M})$, followed by addition of $\operatorname{DTNB}(1.8 \mathrm{mM})$

\subsubsection{Adduct formation between $\mathrm{PbTx}-2$ and selenocysteine}

The demonstration of adduct formation between $\mathrm{PbTx}-2$ with selenocysteine could provide strong evidence to prove $\mathrm{PbTx}-2$ is able to react with mammalian TrxR. Thus seleno- $L$-cysteine was incubated with PbTx-2 (2:1) overnight. Two prominent peaks were revealed in mass spectrum $(m / z=1080.44355)$ corresponding to $[\mathrm{M}+\mathrm{H}]$ and $(m / z=1102.42563)$ corresponding to $[\mathrm{M}+\mathrm{Na}]$ for $\mathrm{C}_{53} \mathrm{H}_{77} \mathrm{NO}_{17} \mathrm{Se}$, an oxidized adduct of PbTx-2 and selenocysteine. An $m / z$ for PbTx-2 (894. 4766) was not observed, indicating the reaction was quantitative for $\mathrm{PbTx}-2$ (Figure39). The predicted $\mathrm{Se}$ isotopic ratio of ${ }^{76} \mathrm{Se}(9 \%),{ }^{77} \mathrm{Se}(8 \%),{ }^{78} \mathrm{Se}(24 \%),{ }^{80} \mathrm{Se}(50 \%),{ }^{82} \mathrm{Se}(9 \%)$ was observed in both products (Ip, Birringer et al. 2000) ( Table 8). 


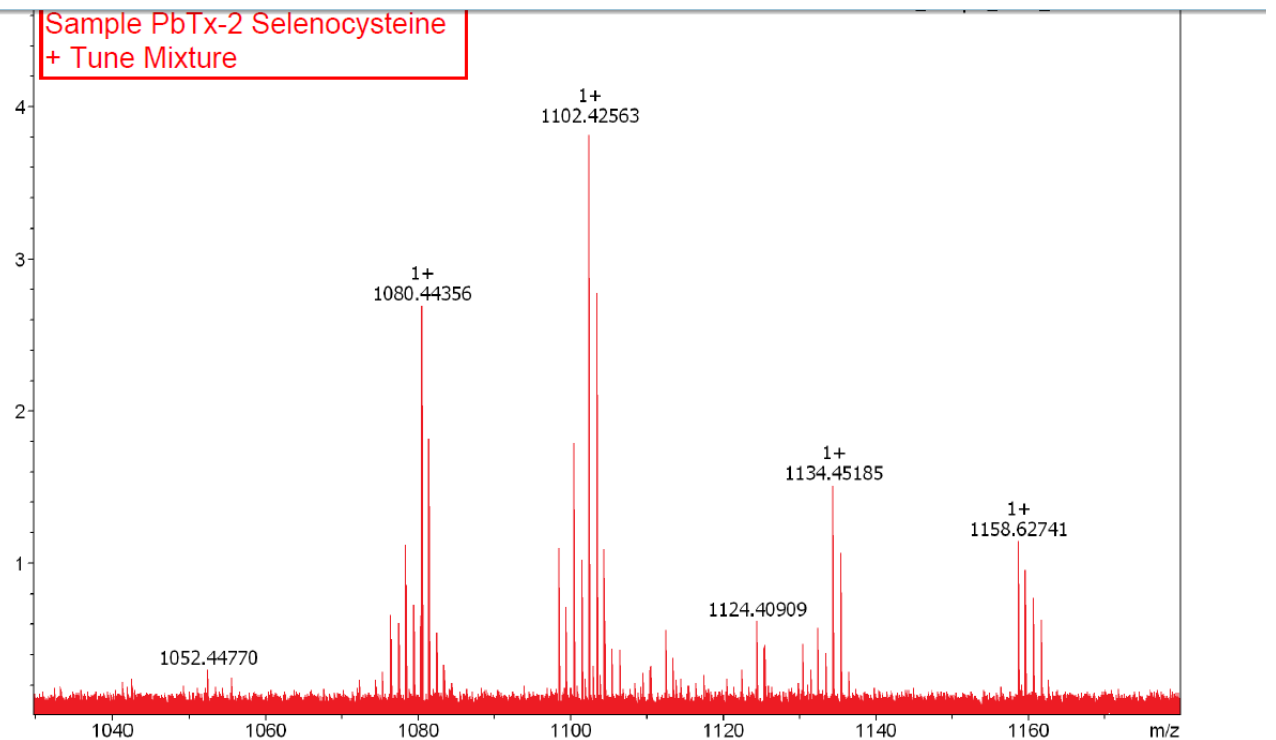

Figure 39 The mass spectrum of adduct formation between $\mathrm{PbTx}-2$ with selenocysteine. Two prominent peaks were revealed in mass spectrum $(\mathrm{m} / \mathrm{z}=1080.44355)$ corresponding to $[\mathrm{M}+$ $\mathrm{H}]$ and $(m / z=1102.42563)$ corresponding to $[\mathrm{M}+\mathrm{Na}]$ for $\mathrm{C}_{53} \mathrm{H}_{77} \mathrm{NO}_{17} \mathrm{Se}$, an oxidized adduct of PbTx-2 and selenocysteine. An $m / z$ for PbTx-2 (894. 4766) was not observed, indicating the reaction was quantitative for PbTx-2. Acknowledge to Freddy Rodriguez

Table 8 The predicted Se isotopic ratio

\begin{tabular}{|c|c|c|}
\hline Isotopic Se & {$[\mathbf{M}+\mathbf{H}]$} & {$[\mathbf{M}+\mathbf{N a}]$} \\
\hline${ }^{76} \mathrm{Se}$ & 1076 & 1098 \\
\hline${ }^{77} \mathrm{Se}$ & 1077 & 1099 \\
\hline${ }^{78} \mathrm{Se}$ & 1078 & 1100 \\
\hline${ }^{80} \mathrm{Se}$ & 1080 & 1102 \\
\hline${ }^{82} \mathrm{Se}$ & 1082 & 1104 \\
\hline
\end{tabular}

\subsubsection{Adduct formation between PbTx-2 and TrxR}

Although the previous experiment demonstrated that $\mathrm{PbTx}-2$ is capable of forming an adduct with selenocysteine, it is not a direct evidence to confirm that mammalian TrxR is alkylated by PbTx-2. In an effort to obtain direct evidence of adduct formation between PbTx-2 and TrxR, reduced TrxR was incubated overnight with a 20-fold excess of PbTx-2. Samples were analyzed by SDS PAGE and the bands of anticipated size were excised from the gel and subjected to in-gel trypsin digestion, treatment with iodoacetamide (IAC) followed by MS/MS analysis. MS/MS analysis 
of the peptides from the control sample (TrxR only and no $\mathrm{PbTx}-2$ ) revealed the presence of numerous peptides of predicted size according to the amino acid sequence and the anticipated IAC modified fragments (Fig 40). These included the predicted Cterminal peptide SGGDILQSGCUG, doubly charged and dialkylated with IAC at both the cysteine and selenocysteine residues. From the PbTx-2 incubated TrxR sample, the anticipated PbTx-2 modified C-terminal peptide SGGDILQSGCU(PbTx2)G was not observed (Figure41). Nonetheless, in the PbTx-2 treated TrxR, the peptide sequence SGGDILQSGCUG either modified with IAC or unmodified was conspicuously absent. Because it has been published that when the enzyme is oxidized, it is resistant to carboxypeptidase or trypsin treatment (Zhong, Arnér et al. 1998). In our case, DTT was used to reduce all disulfide bonds before trypsin treatment. However, the peptide sequence SGGDILQSGCUG was still un-observable. It is possible that $\mathrm{PbTx}-2$ alkylated TrxR is resistant to trypsin digestion.
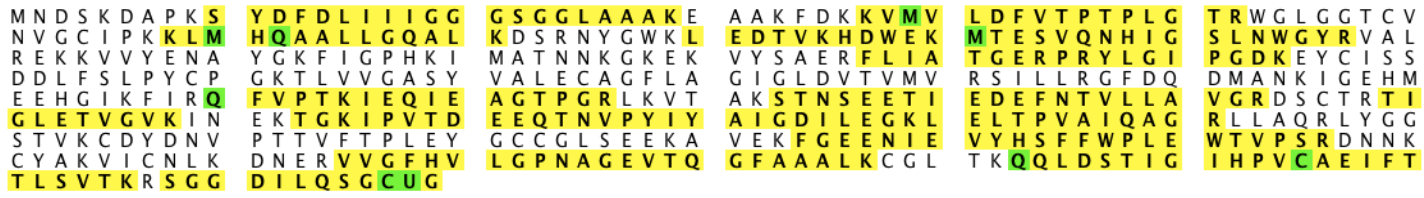

Figure $40 \mathrm{MS} / \mathrm{MS}$ analysis of the peptides from rat liver TrxR. Samples were analyzed by SDS PAGE and the bands of anticipated size were excised from the gel and subjected to ingel trypsin digestion, treatment with iodoacetamide (IAC) followed by MS/MS analysis. The peptides of predicted size according to the amino acid sequence were highlighted by yellow. The anticipated IAC modified fragments were highlighted by green. The predicted C-terminal peptide SGGDILQSGCUG, doubly charged and dialkylated with IAC at both the cysteine and selenocysteine residues (last row)
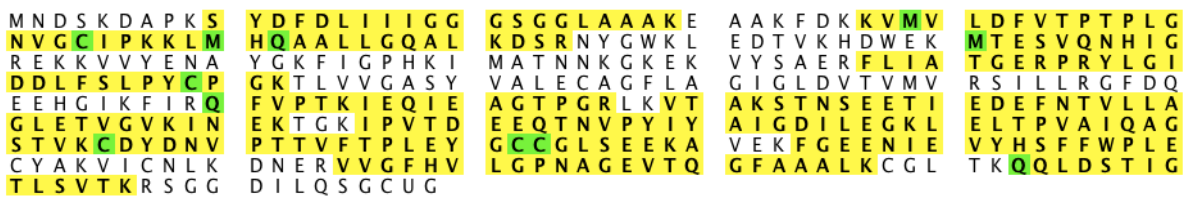

TRWGLGGTCV PLNWG YR VAL
P G D K EYC I S S DMAN K I G E H M D WT V PSR D N K I H P V CAE I F T
I

Figure $41 \mathrm{MS} / \mathrm{MS}$ analysis of the peptides from the adduct formation between $\mathrm{PbTx}-2$ and TrxR. Samples were analyzed by SDS PAGE and the bands of anticipated size were excised from the gel and subjected to in-gel trypsin digestion, treatment with iodoacetamide (IAC) followed by MS/MS analysis. The peptides of predicted size according to the amino acid sequence were highlighted by yellow. The anticipated $\mathrm{PbTx}-2$ modified C-terminal peptide SGGDILQSGCU(PbTx-2)G was not observed. Nonetheless, in the PbTx-2 treated TrxR, the 
peptide sequence SGGDILQSGCUG either modified with IAC or unmodified was conspicuously absent (last row)

\subsubsection{Reaction of TrxR with Sel-green probe}

The selenol selective probe, Sel-green (11) was prepared as previously reported (Zhang, Ge et al. 2015).The Sel-green probe undergoes a nucleophilic aromatic substitution $\left(\mathrm{S}_{\mathrm{N}} \mathrm{Ar}\right)$ reaction selectively with selenols to release a fluorescent coumarin reporter (Figure 42). After incubation of reduced TrxR with an 8 fold excess of PbTx-2, Sel-green was added and the fluorescence increase was monitored $(\lambda \mathrm{ex} / \mathrm{em}=370 / 502 \mathrm{~nm})$. The addition of the Sel-green probe, to reduced mammalian TrxR resulted in release of the fluorescent reporter. If Sec is alkylated by $\mathrm{PbTx}-2$, then the fluorescence reporter should not be released in the presence of $\mathrm{PbTx}-2$ and fluorescence should not be observed. We anticipated a 1:1 stoichiometry the reaction between TrxR and the Sel-green probe and while the concentration of TrxR $(5.3 \mu \mathrm{M}$ based on FAD absorbance) is below the limit for accurate quantitation for the reporter, the fluorescence in the absence of $\mathrm{PbTx}-2$ is comparable to the fluorescence released in the presence of selenocysteine $(6 \mu \mathrm{M})$ as a control. Fluorescence is clearly reduced in the presence of $\mathrm{PbTx}-2$ to a level that is only slightly higher than the control sample which doesn't contains PbTx-2 (Figure 43).

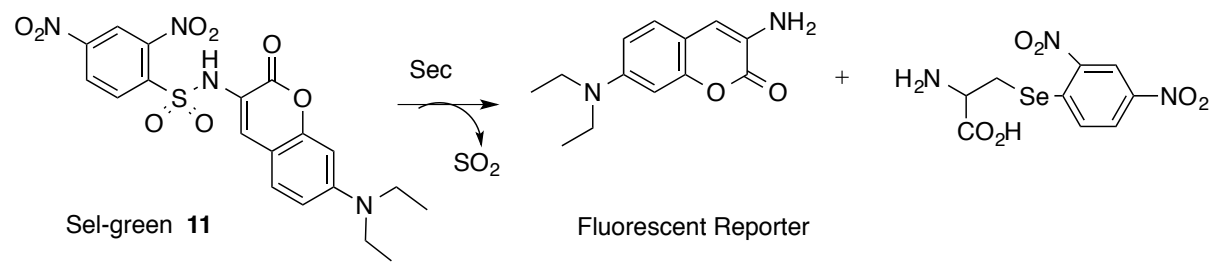

Figure 42 Reaction of Sel-Green probe with selenocysteine 


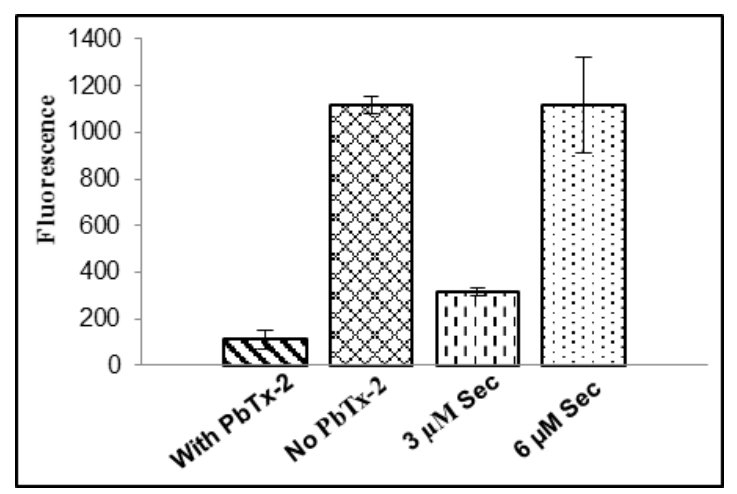

Figure 43 Release of fluorescent reporter from Sel-green probe upon incubation with TrxR in the presence and absence of PbTx-2 compared to standards of $L$ - selenocysteine ( $3 \mu \mathrm{M}$ and 6 $\mu \mathrm{M})$. Rat $\operatorname{TrxR}(5.3 \mu \mathrm{M})$ was incubated with sel-green probe $(43 \mu \mathrm{M})$ with presence and absence of PbTx-2 $(48 \mu \mathrm{M})$ ). Control experiment: Seleno-L-cysteine $(3 \mu \mathrm{M}$ and $6 \mu \mathrm{M})$ was incubated with sel-green probe ( $43 \mu \mathrm{M})$

\subsubsection{Grx, GPx fluorescent assay}

The activities of other reductases which are similar to Trx or TrxR was determined in the presence of PbTx-2. As mentioned above, Grx and GPx are both related to the GSH reduction system to protect cells from oxidative damage by thiol-disulfide exchange. Thus, it is anticipated that $\mathrm{PbTx}-2$ may affect their activity as well. The activity of Grx and GPx in the presence and absence of PbTx-2 was examined using commercially available assay kits.

In Grx assay, the Grx activity was measured by a coupled reaction of GSH /GSSH system. NADPH was added as electron donor to reduce GSSG to GSH via GR. The oxidized Grx was reduced by GSH. In this kit, an eosin- modified GSH was used as its substrate (Figure 44). An increase in fluorescence was recorded at $545 \mathrm{~nm}$ emission and $520 \mathrm{~nm}$ excitation over 120 mins. The rate of reaction was treated as activity of Grx. 


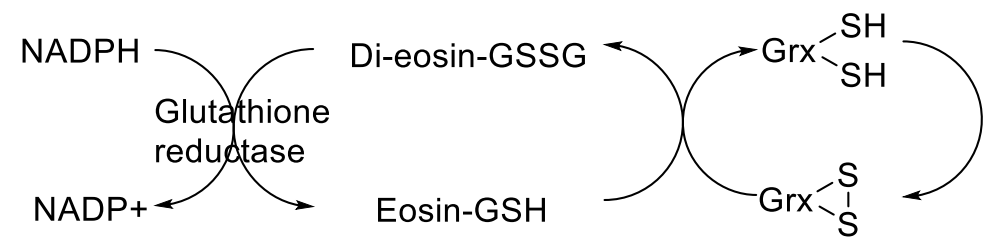

Figure 44 The principle of sensitive fluorescent assay for activity of Grx

In GPx assay, the GPx activity was measured indirectly by a coupled reaction with GR. First, the reduction of hydroperoxide by GPx produced the oxidized GSSG. Second, the GSSG is reduced by GR with NADPH. The oxidation of NADPH to $\mathrm{NADP}^{+}$can be monitored by a decrease in absorbance at $340 \mathrm{~nm}$ (Figure 45). Final, GPx activity is directly proportional to the rate of decrease in the $\mathrm{A}_{340}$.

$$
\begin{aligned}
& \mathrm{ROOH}+2 \mathrm{GSH} \stackrel{\mathrm{GPx}}{\longrightarrow} \mathrm{ROH}+\mathrm{GSSG}+\mathrm{H}_{2} \mathrm{O} \\
& \mathrm{GSSG}+\mathrm{NADPH}+\mathrm{H}^{+} \stackrel{\mathrm{GR}}{\longrightarrow} 2 \mathrm{GSH}+\mathrm{NADP}+
\end{aligned}
$$

Figure 45 The reaction in sensitive fluorescent assay for GPx system

No inhibition was observed for either enzyme in the presence of PbTx-2 (up to $56 \mu \mathrm{M}$ for Grx and $30 \mu \mathrm{M}$ for GPx) (Figure 46 and Figure47). Because these kits contain GR to provide a supply of reduced glutathione, we can conclude that $\mathrm{PbTx}-2$ also does not inhibit GR. Therefore, none of these oxidoreductases (Gx, GR or GPx) were inhibited by $\mathrm{PbTx}-2$ demonstrating the selectivity of PbTx-2 for TrxR.

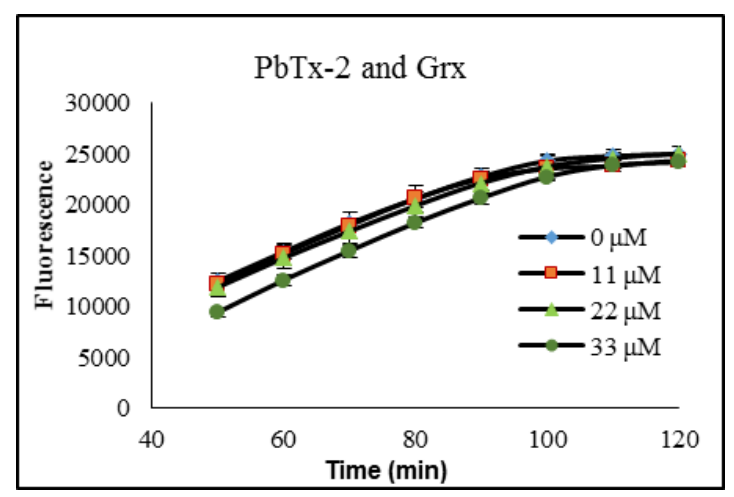

Figure 46 The effect of Grx activity by PbTx-2. Reaction mixture containing $1 \mathrm{mM} \mathrm{GSH}, 54$ $\mu \mathrm{M}$ NADPH and $0.1 \mu \mathrm{M}$ GR was incubated with PbTx-2 (10 $\mu 1$ of the following standards: $0.95,0.63,0.32$ and $0.0 \mathrm{mM}$ in methanol) for $30 \mathrm{~min}$. Human Grx $1(16 \mu 1,30 \mathrm{nM})$, PBS (102 
$\mu \mathrm{l})$ and eosin labeled GSH $(32 \mu \mathrm{l})$ were mixed with mixture. The final concentrations of PbTx-2 were, $0 \mu \mathrm{M}, 11 \mu \mathrm{M}, 22 \mu \mathrm{M}, 33 \mu \mathrm{M}$

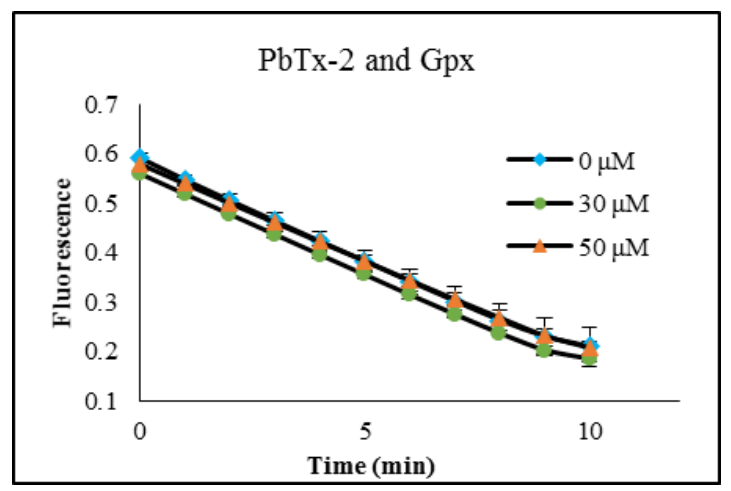

Figure 47 The effect of GPx activity by PbTx-2 PbTx-2 (15 $\mu 1$ of $2.2 \mathrm{mM}, 1.3 \mathrm{mM}$ and 0 $\mathrm{mM}$ in methanol) were each combined with the manufacturer provided assay buffer, GPx and GSH solutions to give PbTx-2 concentrations of $78 \mu \mathrm{M}, 47 \mu \mathrm{M}$ and $0 \mu \mathrm{M}$. Controls without GPx were treated as background. The final concentrations of PbTx-2 were $50 \mu \mathrm{M}, 30 \mu \mathrm{M}$ and $0 \mu \mathrm{M}$

\subsection{Conclusion}

Studying Trx inhibitors is complicated by the fact that the reaction between Trx and it's substrates is stoichiometric. This necessitates the amplification of the Trx signal. Amplification can be performed at the back end of the Trx reaction as in the modified papain assay. Alternatively, the Trx signal can be amplified by continuous reduction of oxidized Trx with NADPH, catalyzed by TrxR. In either case, a two enzyme system is used. The results from the modified papain assay suggest that brevetoxin may be an inhibitor of Trx. However, the interpretation of the results of this assay are complicated by the observation that brevetoxins are inhibitors of papain. The TrxR/Trx activity assay demonstrates that $\mathrm{PbTx}-2$ but not $\mathrm{PbTx}-3$ is an inhibitor of the mammalian TrxR/Trx system with an $\mathrm{IC}_{50}$ of $25 \mu \mathrm{M}$. However, the mechanism and target of the inhibition is still unknown. The lack of inhibition of the TrxR/Trx system by $\mathrm{PbTx}-3$ suggests that the $\alpha, \beta$-unsaturated aldehyde functionality of $\mathrm{PbTx}-2$ is key to the inhibition of the Trx/TrxR system. The Ellman's assay for TrxR activity 
shows that both $\mathrm{PbTx}-2$ and to a lesser extent, $\mathrm{PbTx}-3$ enhance the activity of mammalian TrxR. The enhancement of DTNB reduction by TrxR observed in the presence of $\mathrm{PbTx}-2$ was unexpected. According to previous reports, small molecules such as DTNB can be reduced by the N-terminal reaction center of TrxR when the Cterminal center is either alkylated with electrophiles or absent as in the case of truncated TrxR (Eckenroth, Lacey et al. 2007, Cheng, Sandalova et al. 2009, Lothrop, Ruggles et al. 2009) It can be assumed that the modification of TrxR by PbTx-2 occurs at the C-terminal redox center. The observation that truncated TrxR which lacks the C-terminal redox center, is unaffected by PbTx-2 also supports the hypothesis that $\mathrm{PbTx}-2$ affects mammalian TrxR at the $\mathrm{C}$-terminal redox center.

Furthermore, the rate of DTNB reduction was not affected by pre-incubation of reduced TrxR with PbTx-2 or addition of PbTx-2 and DTNB to pre-reduced TrxR. It indicates that the alkylation of the C-terminal redox residue(s) of TrxR by $\mathrm{PbTx}-2$ occurs rapidly relative to the reduction of DTNB. Crystal structures of TrxR with and without Trx have shown that the C-terminal $\left(\mathrm{Cys}^{496} / \mathrm{Sec}^{497}\right)$ residues of TrxR are located at the end of a mobile arm. Prior to docking with Trx, the mobile arm is in what is known as the "reduced waiting position" and the C-terminal residues are buried in the interior of the enzyme. Upon docking with Trx, the mobile arm swings out of this position to the surface of the enzyme (Fritz-Wolf, Kehr et al. 2011). It is possible that alkylation with the large brevetoxin molecule also causes the mobile are to move away from the N-terminal disulfide making it more accessible by DTNB, bypassing the slow reduction of the C-terminal selenosulfide resulting in a rate enhancement. 
Based on the adduct formed between TrxR and selenocysteine, it seems most likely that modification of TrxR takes place at the Sec residue as selenols are better nucleophiles than thiols: selenols have a lower $\mathrm{pK}_{\mathrm{a}}$ than thiols and would be deprotonated to the selenide under physiological conditions. While our MS experiments using TrxR and $\mathrm{PbTx}-2$ did not provide direct evidence for Sec alkylation, the conspicuous absence of the IAC modified C-terminal peptide, SGGDILQSGCUG, which was identified in the control sample, suggests modification at this site. Alkylation of this peptide by $\mathrm{PbTx}-2$ would prevent IAC alkylation, and the absence of this peptide suggests that the $\mathrm{PbTx}-2$ modified peptide may be resistant to trypsin digestion or may not ionize efficiently. Because the MS analysis of $\mathrm{PbTx}-2$ treated TrxR failed to provide direct evidence of alkylation of Sec, the selenol selective Sel-green probe was prepared to monitor for the presence of the reduced selenol of TrxR in the presence and absence of PbTx-2. As anticipated, in the absence of $\mathrm{PbTx}-2$ the release of an equivalent of fluorescent coumarin reporter was observed upon the addition of Sel-green to reduced TrxR. However, in the presence of PbTx-2 the observed fluorescence was significant lower which indicates that Sec had been alkylated with $\mathrm{PbTx}-2$.

\subsection{Materials and Methods}

\subsubsection{Modified papain assay}

The materials for the modified papain assay Papain, methyl methanethiosulfonate, N-benzoyl-L-arginine-p-nitroanilide, immobilized TCEP (Tris [2-carboxyethyl] phosphine hydrochloride), cystamine and thioredoxin 1 recombinant protein were purchased from Thermo Scientific Co.. Brevetoxins (PbTx-2 and -3) were isolated from K. brevis cultures according to published methods (Baden, Mende et al. 1981). 
UV/Visible measurements were performed in 96 or 384 well microplates using a Synergy ${ }^{\circledR} 2$ (Biotek Instrument, Inc.)

Preparation of papain-S-SCH $\mathbf{3}(\sim \mathbf{1 . 2} \mathbf{~ m g} / \mathbf{m l})$ Papain stock solution (1.5 ml, 26.4 $\mathrm{mg} / \mathrm{ml})$ was added to a solution of cysteine $(0.6 \mathrm{mM}, 28.5 \mathrm{ml}$ of $20 \mathrm{mM}$ sodium phosphate - $1 \mathrm{mM}$ EDTA buffer). The solution was kept at room temperature for 30 min. The methyl methanethiosulfonate $(117 \mu \mathrm{mol})$ was added in mixture. The reaction mixture was kept in ice for $4 \mathrm{hr}$. The mixture was dialyzed (Mr cutoff 60008000 ) against $5 \mathrm{mM}$ sodium acetate buffer, containing $50 \mathrm{mM} \mathrm{NaCl}, \mathrm{pH} 4.7$ at $4^{\circ} \mathrm{C} 12$ hr.

The method for the modified papain assay The thioredoxin solution $(1 \mathrm{mg} / \mathrm{ml}, 1$ $\mathrm{mM}$ Tris $-\mathrm{HCl} \mathrm{pH} .7)$ was incubated with immobilized TCEP for $1 \mathrm{hr}$. The reduced thioredoxin solution $(90 \mu \mathrm{l}, 1 \mu \mathrm{g} / \mu \mathrm{l})$ was reacted with $20 \mu \mathrm{g}$ brevetoxin $(1 \mu \mathrm{g} / \mu \mathrm{l}$, PbTx-2 or PbTx-3) for $1 \mathrm{hr}$ in one clean test tube. The solution of papain-S-SCH was diluted with an equal volume of $40 \mathrm{mM}$ sodium phosphate buffer. The resulting solution is $\sim 0.6 \mathrm{mg} / \mathrm{ml}$ papain-S-SCH 3 at $\mathrm{pH} 7.5$, containing $1 \mathrm{mM}$ EDTA. Papain$\mathrm{S}_{-\mathrm{SCH}_{3}}$ solution $(0.5 \mathrm{ml})$, substrate $(0.7 \mathrm{ml})$ and cystamine $(15 \mu \mathrm{l}, 26.4 \mathrm{mg} / \mathrm{ml})$ were added in the test tube with mixture. A tube containing papain-S-SCH 3 , without any thiol, serves as the control. The mixture is carried out in triplicate in plate. Each well was added $300 \mu \mathrm{l}$ mixture. Record the absorbance at $410 \mathrm{~nm}$ every $60 \mathrm{~min}$ up to $15 \mathrm{hr}$.

\subsubsection{Papain assay}

The materials for the papain assay Papain, N-benzoyl-L-arginine-p-nitroanilide and TCEP were purchased from Thermo Scientific Co. Brevetoxins (PbTx-2 and -3) were isolated from K. brevis cultures according to published methods (Baden, Mende et al. 1981). UV/Visible measurements were performed in 96 or 384 well microplates using a Synergy ${ }^{\circledR} 2$ (Biotek Instrument, Inc.) 
The method for the papain assay The solution of papain $(304 \mu 1,26.4 \mathrm{mg} / \mathrm{ml}), \mathrm{N}-$ benzoyl-L-arginine-p-nitroanilide $(0.7 \mathrm{ml})$ were added in the test tube with mixture. PbTx-2 and PbTx-3 (20 $\mu 1,1 \mathrm{mg} / \mathrm{ml})$ was added to the tube respectively. Using the Tris buffer filled the finial volume to $625 \mu \mathrm{l}$. A tube without any brevetoxin, served as the control. The mixture is carried out in triplicate in plate. Each well was added 300 $\mu 1$ mixture. Record the absorbance at $410 \mathrm{~nm}$ every $60 \mathrm{~min}$ up to $15 \mathrm{hr}$.

\subsubsection{Fluorescent assay for Trx/TrxR system}

The materials for the fluorescent assay for Trx/TrxR system: Unless otherwise noted, reagents were purchased from Sigma-Aldrich or Acros chemical companies and used without further purification. Brevetoxins $(\mathrm{PbTx}-2$ and -3$)$ were isolated from K. brevis cultures according to published methods (Baden, Mende et al. 1981). Enzyme assay kit was purchased from Cayman Chemical. Assay kit was used according to the manufacturer's instructions with noted exceptions. Fluorescence measurements were performed in 96 or 384 well microplates using an Infinite $\mathbb{R}$ M1000 PRO (Tecan Group Ltd.) microplate readers.

The methods for the fluorescent assay for Trx/TrxR system. Experiments were performed in 96-well plates with $270 \mu \mathrm{l}$ of assay buffer $(50 \mathrm{mM}$ Tris-HCl, $1 \mathrm{mM}$ EDTA, $0.14 \mathrm{mg} / \mathrm{ml}$ BSA, $\mathrm{pH} 7.5$ ) containing $0.13 \mu \mathrm{M}$ rat TrxR, $0.35 \mathrm{mM}$ NADPH and $0.026 \mu \mathrm{M}$ Trx. After incubation for $30 \mathrm{~min}$ at $37{ }^{\circ} \mathrm{C}$ to reduce the TrxR, stock solutions of PbTx-2 or PbTx-3 (11 $\mu$ l each of $1.1,0.96,0.64,0.35$ and $0 \mathrm{mM}$ in methanol) were added to give final toxin concentrations of $35 \mu \mathrm{M}, 30 \mu \mathrm{M}, 20 \mu \mathrm{M}, 11$ $\mu \mathrm{M}, 0 \mu \mathrm{M}$. This mixture was incubated at $37{ }^{\circ} \mathrm{C}$ for $1 \mathrm{~h}$. Fluorescent substrate $(70 \mu \mathrm{l}$, 
$0.4 \mathrm{mg} / \mathrm{ml}$, FiTC labeled bovine insulin) was added to each aliquot (final concentration of $0.016 \mathrm{mg} / \mathrm{ml}$ ). Samples were analyzed in triplicate by recording fluorescence at $545 \mathrm{~nm}\left(\lambda_{\mathrm{ex}}=520 \mathrm{~nm}\right)$ every $10 \mathrm{~min}$ for $3 \mathrm{~h}$.

\subsubsection{Ellman's assay}

The materials for the DTNB assay: Unless otherwise noted, reagents were purchased from Sigma-Aldrich or Acros chemical companies and used without further purification. Brevetoxins (PbTx-2 and -3) were isolated from K. brevis cultures according to published methods (Baden, Mende et al. 1981). Truncated human TrxR (Novus Biologicals) was purchased from Fisher Scientific. Rat liver TrxR was purchased from Cayman Chemical. DTNB was purchased from Thermo Scientific Co.. NADPH was purchased from Molecular Toxicology, Inc. UV/Visible measurements were performed in 96 or 384 well microplates using a Synergy ${ }^{\circledR} 2$ (Biotek Instrument, Inc.)

The method for the DTNB assay for TrxR or truncated TrxR. Method A (preincubation with $\mathrm{PbTx}-2)$ : Experiments were performed in 96-well plates with $160 \mu 1$ of PBS containing 0.1 mM NADPH. $22 \mu \mathrm{M}$ PbTx-2 and $0.56 \mu \mathrm{M}$ rat TrxR or 0.68 $\mu \mathrm{M}$ truncated human TrxR. After incubation for $30 \mathrm{~min}$ at $37{ }^{\circ} \mathrm{C}$ to reduce the TrxR, $40 \mu \mathrm{l}$ of a DTNB solution (Ellman's reagent: 5,5'-dithio-bis-(2-nitrobenzoic acid) (10 $\mathrm{mM}$ in $0.1 \mathrm{M}$ sodium phosphate and $1 \mathrm{mM}$ EDTA, $\mathrm{pH} 8.0$ ) was added for final concentrations of $18 \mu \mathrm{M}$ PbTx-2 and $2 \mu \mathrm{M}$ DTNB. The absorbance at $410 \mathrm{~nm}$ was measured every 5 min for up to $60 \mathrm{~min}$. Method B (no pre-incubation with $\mathrm{PbTx}-2$ ): The assay was performed as described above except that PbTx-2 and DTNB solutions were mixed and added simultaneously after NADPH reduction of TrxR. 


\subsubsection{The preparation of selenocysteine -PbTx-2 adduct}

The materials for making selenocysteine-PbTx-2 adduct $\mathrm{PbTx}-2$ isolated from $K$. brevis cultures according to published methods (Baden, Mende et al. 1981). Seleno- $L$ cysteine was borrowed from Dr. Lees lab. Immobilized TCEP was purchased from Thermo Scientific Co.. The formation was detected from a Bruker Solarix 7.0 T using ultrahigh resolution Fourier Transform Ion Cyclotron Resonance Mass Spectrometer (FT-ICR).

Preparation and analysis of selenocysteine-PbTx-2 adduct seleno- $L$-cysteine( 75 $\mu \mathrm{L}, 1 \mathrm{mg} / \mathrm{mL}$ ) was incubated with an aqueous suspension of immobilized TCEP ((tris(2-carboxyethyl) phosphine, $30 \mu \mathrm{L},>8 \mu \mathrm{mol} / \mathrm{mL}$, immobilized onto $4 \%$ crosslinked beaded agarose) for $1 \mathrm{~h}$ to reduce the diselenide. The reaction vial was flushed with nitrogen and centrifuged for $10 \mathrm{~min}$ at $14,000 \mathrm{x}$. The supernatant was transferred via syringe to a solution of PbTx-2 $(200 \mu \mathrm{L}, 1 \mu \mathrm{g} / \mu \mathrm{L}$ in methanol) and stirred under nitrogen for $24 \mathrm{~h}$. Accurate mass spectra was acquired using a Bruker Solarix 7.0 T using ultrahigh resolution Fourier Transform Ion Cyclotron Resonance Mass Spectrometer (FT-ICR) confirmed the formation of an oxidized (+15.999 amu) selenocysteine-PbTx-2 adduct of formula $\mathrm{C}_{53} \mathrm{H}_{77} \mathrm{NO}_{17} \mathrm{Se}$. HRMS calc'd for $\left[\mathrm{M}+\mathrm{H}^{+}\right]$: 1080.44355. Found: $1080.44356(\Delta=-0.56 \mathrm{ppm})$. HRMS calc'd for $\left[\mathrm{M}+\mathrm{Na}^{+}\right]$: 1102.42545. Found: $1102.42550(\Delta=-0.12 \mathrm{ppm})$.

\subsubsection{The preparation of TrxR-PbTx-2 adduct.}

The materials for making TrxR-PbTx-2 adduct Rat liver TrxR was purchased from Cayman Chemical. PbTx-2 isolated from K. brevis cultures according to published 
methods (Baden, Mende et al. 1981). NADPH was purchased from Molecular Toxicology, Inc..

Preparation and analysis of TrxR-PbTx-2 adduct. Rat TrxR $(6 \mu \mathrm{M})$ and NADPH $(0.16 \mathrm{mM})$ were incubated for $30 \mathrm{~min}$ in $44 \mathrm{mM}$ Tris base, $0.9 \mathrm{mM}$ EDTA. $0.4 \mathrm{M}$ $\mathrm{NaCl}, 0.1 \%$ glycerol, $\mathrm{pH} 7 . \mathrm{PbTx}-2\left(5.6 \mathrm{mM}\right.$ in $\left.\mathrm{Me}_{2} \mathrm{SO}\right)$ was added to give a final $\mathrm{PbTx}-2$ concentration of $0.24 \mathrm{mM}$ and the reaction was incubated for $12 \mathrm{~h}$ at room temperature. The sample was concentrated 5 fold and analyzed by SDS PAGE $(12 \%$ acrylamide, $10 \%$ SDS). The band was excised and stored at $-80{ }^{\circ} \mathrm{C}$. Gel digestion and LC-Electrospray Ionization MS/MS (LC-ESI MS/MS) analysis was performed by the Proteomics and Mass Spectrometry Facility at the UMass Medical School as previously described.

\subsubsection{Reaction of Sel-green probe with TrxR}

The materials for reaction of sel-green with TrxR Sel-Green was synthesized by Freddy Rodriguez. Rat liver TrxR was purchased from Cayman Chemical. PbTx-2 isolated from K. brevis cultures according to published methods (Baden, Mende et al. 1981). NADPH was purchased from Molecular Toxicology, Inc. Seleno- $L$-cysteine was borrowed from Dr. Lees lab. Fluorescence measurements were performed in 96 or 384 well microplates using a an Infinite ${ }^{\circledR}$ M1000 PRO (Tecan Group Ltd.) microplate readers.

Reaction of Sel-green probe with TrxR. The selenol selective probe, Sel-green, was synthesized according to published methods (Zhang, Ge et al. 2015). Rat TrxR (6 
$\mu \mathrm{M})$ and NADPH $(0.1 \mathrm{mM})$ were incubated for $30 \mathrm{~min}$ in $45 \mathrm{mM}$ Tris base, $0.9 \mathrm{mM}$ EDTA. 0.5 M NaCl, $0.1 \%$ glycerol, $\mathrm{pH}$ 7. PbTx-2 (1.1 mM in methanol) was added for a final toxin concentration of $48 \mu \mathrm{M}$. Samples were prepared in triplicate. A control sample was prepared by the addition of an equal volume of methanol without PbTx-2. A blank sample was prepared without TrxR. The solutions were incubated for $1 \mathrm{~h}$. Sel-green probe ( $9 \mu \mathrm{l}, 481 \mu \mathrm{M}$ in $20 \%$ acetone in PBS) was added to each reaction mixture $(82 \mu \mathrm{l})$. After $55 \mathrm{~min}$, fluorescence at $502(\lambda \mathrm{ex}=370 \mathrm{~nm})$ was measured. Calibration standards were prepared as follows: A stock solution of seleno$L$-cysteine $(1.0 \mathrm{ml}, 27 \mu \mathrm{M}$, in PBS) was reduced using immobilized TCEP $(1.0 \mathrm{ml},>$ $8 \mu \mathrm{mol} / \mathrm{ml}$ ) for $1 \mathrm{~h}$. After centrifugation $(14000 \times \mathrm{g}, 2 \mathrm{~min})$, the supernatant was transferred to a clean tube to provide a stock solution of $L$-selenocysteine $(54 \mu \mathrm{M})$. Aliquots of the stock solution of $L$-selenocysteine was diluted with Sel-green probe in PBS for final concentrations of $L$-selenocysteine of $0 \mu \mathrm{M}, 3 \mu \mathrm{M}, 6 \mu \mathrm{M}, 12 \mu \mathrm{M}, 25$ $\mu \mathrm{M}$ and $43 \mu \mathrm{M}$ Sel-green probe, incubated for $55 \mathrm{~min}$, and fluorescence was measured at $502 \mathrm{~nm}(\lambda \mathrm{ex}=370 \mathrm{~nm})$. Calibration standards were prepared in triplicate. For this experiment, the concentration of FAD (flavin adenine dinucleotide) was calculated to be $5.3 \mu \mathrm{M}$ by measuring the absorbance of at $450 \mathrm{~nm}$ and using an extinction coefficient $\varepsilon 450=11,300 \mathrm{M}^{-1} \mathrm{~cm}^{-1}$ for FAD (Zhong and Holmgren 2000).

\subsubsection{Fluorescent assay for Grx and GPx}

The materials for the activity assay for Grx Fluorescent Grx kit was purchase from Cayman Chemical. PbTx-2 isolated from K. brevis cultures according to published methods (Baden, Mende et al. 1981). Fluorescence measurements were performed in 
96 or 384 well microplates using an Infinite ${ }^{\circledR}$ M1000 PRO (Tecan Group Ltd.) microplate readers.

The method for the activity assay for Grx. Experiments were performed in 96-well plates with $160 \mu \mathrm{l}$ of a reaction mixture containing $0.17 \mathrm{M}$ potassium phosphate, 1.7 mM EDTA, $1 \mathrm{mM}$ GSH, $0.1 \mathrm{mg} / \mathrm{ml}$ BSA, $54 \mu \mathrm{M}$ NADPH, $0.1 \mu \mathrm{M}$ GR, $\mathrm{pH} 7.5$ which was prepared according to the manufacturer's instructions. To aliquots (160 $\mu \mathrm{l})$ of the reaction mixture was added PbTx-2 (10 $\mu$ l of the following standards: 0.95 , $0.63,0.32$ and $0.0 \mathrm{mM}$ in methanol), $16 \mu \mathrm{l}$ of human Grx $1(30 \mathrm{nM}$ in $0.83 \mathrm{M}$ potassium phosphate and $8.3 \mathrm{mM}$ EDTA, $\mathrm{pH} 7.5$, final concentration $1.5 \mathrm{nM}), 102 \mu \mathrm{l}$ of PBS and $32 \mu \mathrm{l}$ of eosin labeled GSH bound to BSA ( $0.2 \mathrm{mM}$ in distilled water). Samples were analyzed in triplicate by recording fluorescence at $545 \mathrm{~nm}\left(\lambda_{\text {ex }}=520\right.$ $\mathrm{nm}$ ) every $10 \mathrm{~min}$ for up to $2 \mathrm{~h}$. The final concentrations of PbTx-2 were, $0 \mu \mathrm{M}, 11$ $\mu \mathrm{M}, 22 \mu \mathrm{M}, 33 \mu \mathrm{M}$.

The materials for the activity assay for GPx Fluorescent GPx kit was purchase from Cayman Chemical. PbTx-2 isolated from K. brevis cultures according to published methods (Baden, Mende et al. 1981)Fluorescence measurements were performed in 96 or 384 well microplates using an Infinite ${ }^{\circledR}$ M1000 PRO (Tecan Group Ltd.) microplate readers

The method for the activity assay for GPx The assay was carried out according to the manufacturer's instructions except that stock solutions of PbTx-2 (15 $\mu$ l of 2.2 $\mathrm{mM}, 1.3 \mathrm{mM}$ and $0 \mathrm{mM}$ in methanol) were each combined with the manufacturer provided assay buffer, GPx and GSH solutions to give $\mathrm{PbTx}-2$ concentrations of 78 $\mu \mathrm{M}, 47 \mu \mathrm{M}$ and $0 \mu \mathrm{M}$. This mixture was incubated for $1 \mathrm{~h}$ at room temperature, after 
which the assay was completed according to the manufacturer's instructions. The absorbance was read once every minute at $340 \mathrm{~nm}$ for $10 \mathrm{~min}$. Samples were analyzed in triplicate. Controls without GPx were treated as background. The final concentrations of $\mathrm{PbTx}-2$ were $50 \mu \mathrm{M}, 30 \mu \mathrm{M}$ and $0 \mu \mathrm{M}$. 


\section{Chapter 4 Comparison of biochemical parameters in high toxin and low toxin producing strains of $K$. brevis.}

\subsection{Objective}

Compare and contrast various metabolic and biochemical parameters in two strains of K. brevis which have a tenfold difference in toxin content

\subsection{Introduction}

In chapter 2 and 3, by using fluorescent and photoaffinity derivatives of brevetoxin it was concluded that brevetoxin localizes to the chloroplast of $K$. brevis where it interacts with two cholorplast proteins: LHCII and Trx (Cassell, Chen et al. 2015). It was also shown that brevetoxin inhibits the $\operatorname{Trx} / \operatorname{TrxR}$ system within an $\mathrm{IC}_{50}$ of $25 \mu \mathrm{M}$. In addition to inhibition of the Trx/TrxR system, brevetoxin affects mammalian TrxR leading to the enhancement of the activity of this enzyme. The evidence indicates that brevetoxin affects mammalian TrxR at the C-terminal selenocysteine active site residue. These discoveries lead us back to our original question: what is the biochemical role of brevetoxin in K. brevis? Or more specifically: what are the implications of TrxR inhibition by brevetoxin for K. brevis? In fact, LHC II, Trx and TrxR are all common antioxidants related to reactive oxygen species (ROS) in cells. When the excess ROS accumulate in cells, the state is called oxidative stress. Various biomolecules such as proteins (Stadtman 1992, Nordberg and Arnér 2001), lipids, lipoprotein S (Yla - Herttuala 1999), and DNA (Marnett 2000, Nordberg and Arnér 2001), are threatened by the reactive oxygen intermediates. Oxidative stress is proposed to be involved in DNA damage in the mitochondria (Cadenas and Davies 2000, Finkel and Holbrook 2000). However, a small concentration of ROS is required for normal cell function as well. It has been demonstrated that ROS are involved in 
intracellular signaling and redox regulation. The term ROS includes a number of chemically reactive molecules which are derived from oxygen (Galter, Mihm et al. 1994, Halliwell 1996, Fridovich 1999, Betteridge 2000) (Table 9). Some are extremely reactive like hydroxyl radical, in contrast some are less reactive, such as superoxide anion $\left(\mathrm{O}_{2}{ }^{-}\right)$and hydrogen peroxide (Nordberg and Arnér 2001) Table 9 also shows the main sources of production and the enzymatic defense system for various ROS.

Table 9 The major ROS molecules and their metabolism

\begin{tabular}{|c|c|c|}
\hline ROS molecule & Enzymatic defense systems & Products \\
\hline Superoxide $\left(\mathrm{O}_{2}^{-}\right)$ & $\begin{array}{l}\text { Superoxide dismutase (SOD), } \\
\text { Superoxide reductase }\end{array}$ & $\begin{array}{c}\mathrm{H}_{2} \mathrm{O}_{2}+\mathrm{O}_{2} \\
\mathrm{H}_{2} \mathrm{O}_{2}\end{array}$ \\
\hline $\begin{array}{l}\text { Hydrogen peroxide } \\
\qquad\left(\mathrm{H}_{2} \mathrm{O}_{2}\right)\end{array}$ & \multirow[t]{2}{*}{$\begin{array}{c}\text { Glutathione peroxidase, } \\
\text { Catalases, } \\
\text { Peroxiredoxins (Prx) }\end{array}$} & $\begin{array}{c}\mathrm{H}_{2} \mathrm{O}+\mathrm{GSSG} \\
\mathrm{H}_{2} \mathrm{O}+\mathrm{O}_{2} \\
\mathrm{H}_{2} \mathrm{O}\end{array}$ \\
\hline $\begin{array}{l}\text { Hydroxyl radical } \\
(\cdot \mathrm{OH})\end{array}$ & & \\
\hline Nitric oxide (NO) & Glutathione/TrxR & GSNO \\
\hline
\end{tabular}

Superoxide anion $\left(\mathrm{O}_{2}^{-}\right)$is formed from molecular oxygen. Although it is a free radical, it is not highly reactive. Because it cannot penetrate lipid membranes, which means superoxide anion can only remain where it is produced (Nordberg and Arnér 2001). Usually, superoxide anion is formed in the electron-rich aerobic environment such as the inner mitochondrial membrane with the respiratory chain (Derick, Williams et al. 2001). Lipoxygenase and cyclooxygenase are also generated superoxide (Kontos, Wei et al. 1985, Mattei, Virdis et al. 1996). In addition to superoxide, hydrogen peroxide has similar intracellular effects (Sundaresan, Yu et al. 1995, Finkel 1998, Kamata and Hirata 1999, Rhee 1999, Patel, Moellering et al. 
2000). Hydrogen peroxide is a highly important ROS molecule because $\mathrm{H}_{2} \mathrm{O}_{2}$ is able to penetrate biological membranes. Many antioxidant enzyme systems, such as catalase, glutathione peroxidase and peroxiredoxins, are able to remove $\mathrm{H}_{2} \mathrm{O}_{2}$ (Chae, Kang et al. 1999, Chae, Kim et al. 1999, MatÉs, Pérez-Gómez et al. 1999). Hydroxyl radical $(\cdot \mathrm{OH})$ is the most reactive ROS molecule, causing more damage to biological systems than other ROS. Usually ${ }^{\circ} \mathrm{OH}$ is obtained from $\mathrm{H}_{2} \mathrm{O}_{2}$ (Neyens and Baeyens 2003). Last but not least is nitric oxide (NO), a well-known as a signaling molecule. Additionally, NO has been identified as an inhibitor of lipid peroxidation in cell membranes (Hogg and Kalyanaraman 1998, Rubbo, Radi et al. 2000). NO is able to regulate gene transcription and expression as well (Bogdan 2001).

Due to the high reactivity of ROS, it causes damage to numerous biomolecules. For example, ROS is treated as a mutagen. ROS causes a number of alterations such as DNA cleavage, DNA protein cross-linking and oxidation of purines when the cells are exposed to oxidative stress. It is determined that ROS are related to DNA mutation, cancer and apoptosis (Halliwell, Zentella et al. 1997, Kamata and Hirata 1999). Lipids are also an excellent target for ROS because of the multiple double bonds in polyunsaturated fatty acids (Steinberg 1997, Kamata and Hirata 1999). Lipid peroxidation is essential for the generation of atherosclerotic plaques (Halliwell 1993, Frei 1999). The incidences of cardiovascular disease are increasing in western countries. The most important prevention and medical treatments are to decrease lipid peroxidation, which is associated with excessive amounts of ROS. Furthermore, ROS has been shown to react with several amino acids in vitro, resulting in modification or inhibition of the activity of enzymes (Stadtman and Berlett 1997, Butterfield, Koppal et al. 1998). 
ROS are affected by antioxidants such as the Trx and GSH systems (Lowther, Brot et al. 2000, Nordberg and Arnér 2001). LHCII also affects ROS production. In fact, plants and algae love light but also hate light. Oxygenic photoautotrophic organisms require light for life. However, when the input of excess high light exceeds the saturation limit of the photosynthetic apparatus this leads to an increase the production of ROS. Chloroplasts have evolved a number of mechanisms to mitigate the damaging effects of ROS, which include both the scavenging of ROS and the suppression of ROS production through NPQ (Figure 48 A). When a Chl absorbs light energy, it is excited from ground state to singlet molecule $\left({ }^{1} \mathrm{Ch}{ }^{*}\right)$. The singlet ${ }^{1} \mathrm{Chl}^{*}$ can be re-emitted as $\mathrm{Chl}$ fluorescence that is used as photochemistry. Also, it can be de-excited by NPQ. However, singlet ${ }^{1} \mathrm{Chl}^{*}$ is able to turn to triplet state $\left({ }^{3} \mathrm{Chl}^{*}\right)$ which can transfer energy to ground state $\mathrm{O}_{2}$ to form singlet oxygen $\left({ }^{1} \mathrm{O}_{2}{ }^{*}\right)$. Singlet oxygen $\left({ }^{1} \mathrm{O}_{2}{ }^{*}\right)$ is an extremely damaging ROS. In normal light, the energy is transferred to photochemistry. The yield of Chl fluorescence is generally low (Krause and Weis 1991). However, under excess light, the increase of ${ }^{1} \mathrm{Chl}{ }^{*}$ leads to yield high level of ${ }^{3} \mathrm{Chl}^{*}$ which generates more ${ }^{1} \mathrm{O}_{2}{ }^{*} \cdot{ }^{1} \mathrm{O}_{2}{ }^{*}$ causes oxcide damage to the cells (Figure48 B). However, NPQ can either dissipate the ${ }^{1} \mathrm{Chl}^{*}$ as heat or quench $\mathrm{Chl}$ fluorescence to prevent cells from oxygen damage (Müller, Li et al. 2001). Thus, NPQ is one of mechanisms to suppress to ROS production. If the cells cannot perform NPQ to dissipate light energy, more ROS will be produced. As mentioned above, LHCII is an integral part of the photosynthetic apparatus where it harvests and distributes light energy using four LHCII bound carotenoid molecules. It is also central to the process of NPQ or the dissipation of light energy as heat under conditions of high light. 

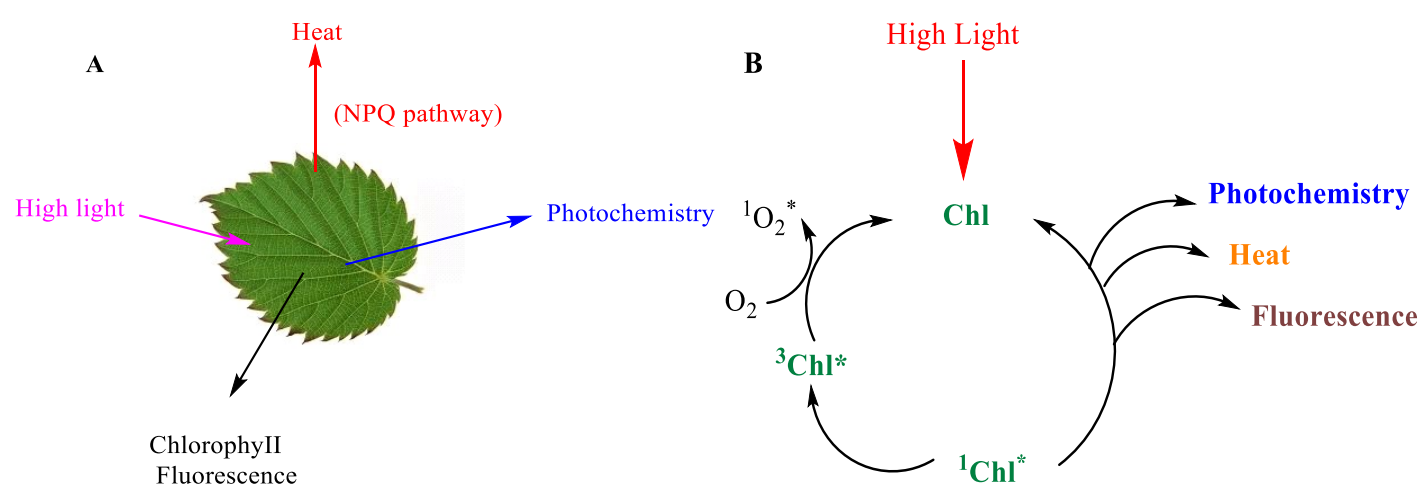

Figure 48 The common pathways to produce ROS. First, high light energy is transfered to photochemistry. (A) The common pathway to distribute high light energy in leaves. Once the photochemistry reaches saturation, the excess energy can either be dissipated to heat by NPQ or switch to chlorophyII fluorescence. (B) The possible way to release excited Chl. When Chl absorbs light it is excited from the ground state to the singlet excited state. The singlet excited form, ${ }^{1} \mathrm{Chl}^{*}$ can go back to the ground state by three ways: emitting light as fluorescence, turning to heat and being used in photosynthetic reactions (Müller, Li et al. 2001)

In addition to LHC II, in photosynthetic organisms, the Trx/TrxR system is located within the chloroplast lumen and numerous thioredoxin-dependent regulatory networks have been identified within the chloroplasts of photosynthetic organisms (Nikkanen and Rintamäki 2014), including VDE activity (Hall, Mata - Cabana et al. 2010). In plants, there are highly versatile Trx systems which include two different TrxRs: ferredoxin thioredoxin reductase (FTR) and NADPH dependent thioredoxin reductase (NTRC). These TrxRs are localized to plant chloroplast. They contribute to the regulation of proteins in chloroplast by Trx system. Additionally, it is believed that the two reductases are selective for different Trx targets. FTR is active only in the light and is believed to be responsible for regulation of light reactions. While NTRC enzyme is unique for oxygenic photosynthetic organisms (Nikkanen and Rintamäki 2014).

In mammal, Trxs are also critical to the scavenging of excess ROS by reduction of 2cysteine peroxiredoxins (2-Cys Prxs), enzymes whose sole function is the 
detoxification of peroxides (König, Baier et al. 2002) It is reported that the expression of Trx and TrxR are induced by oxidative stress in adult T cells (Nakamura, Matsuda et al. 1994, Taniguchi, Taniguchi-Ueda et al. 1996). When the cells are exposed to oxidative stress, Trx/TrxR system is the sophisticated antioxidant regulatory system to maintain the balance of ROS. In Figure49, the major physiological functions of the mammalian thioredoxin system are shown. In particular, mammalian TrxR, which reduces more substrates than mammalian Trx, reduces not only the disulfide in oxidized Trx, but also different protein disulfides, PDI, low molecular weight disulfides such as DTNB, and nondisulfide compounds, such as hydrogen peroxides, and nitroblue tetrazolium (NBT)(Arnér, Zhong et al. 1999, Nordberg and Arnér 2001). Mammalian TrxR reduces some selenium-containing enzymes and compounds either directly or by way of $\operatorname{Trx}$ (Kumar, Bjornstedt et al. 1992). For examples, selenite and selenocysteineand sec-containing GPx are reduced by mammalian TrxR as well. The active site of GPx is regenerated directly by TrxR (Nordberg and Arnér 2001). It has been determined that sulfur and selenium compounds are able to reduce the ROS generation through their antioxidant properties. For example, patients with pulmonary tuberculosis show reduced oxidative stress after taking selenium supplementation (Seyedrezazadeh, Ostadrahimi et al. 2008). Commonly, sulfur and selenium compounds protect against disease through ROS radical scavenging and enzymatic decomposition of oxygen metabolites (Mugesh and Singh 2000, Valko, Rhodes et al. 2006). 


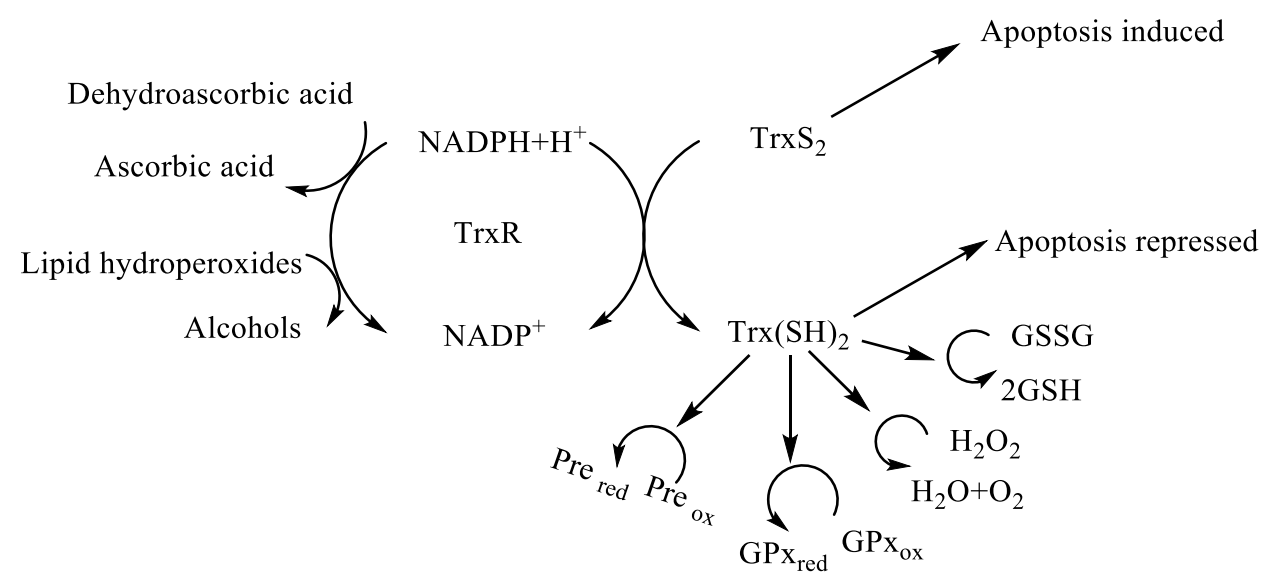

Figure 49 Major physiological function of the mammalian thioredoxin system

Furthermore, there are other cellular antioxidant enzyme systems protecting cells and organisms from excessive ROS. Superoxide dismutase (SOD) catalyzes the reaction of $\mathrm{O}_{2}{ }^{*-}$ (Yost and Fridovich 1973) to produce molecular oxygen and hydrogen peroxide. Catalases are mainly heme-containg enzymes. Catalases catalyze the conversion of hydrogen peroxide to water and molecular oxygen (Aebi 1984). All GPx catalyze the reduction of $\mathrm{H}_{2} \mathrm{O}_{2}$ through the assistance of the GSH system. The catalytic mechanism was proposed in Chapter 3. Last but not least, the GSH system is the most abundant intracellular thiol-based antioxidant. GSH can be present in millimolar concentration in living cells (Armstrong 1997, Van Bladeren 2000). GSH serves as a sulfhydryl buffer to protect against oxidative damage in cells. The oxidized GSSG can also be reduced by Trx system(Kanzok, Schirmer et al. 2000).

Both LHCII and Trx regulate the oxidative state of the cell and redox signaling. Both affect the amount of ROS production. In addition to these brevetoxin targeted proteins, the GSH system and many antioxidants are involved in preventing oxidative stress in cells. The finding that brevetoxin binds to LHCII and Trx raises an important question: Does brevetoxin influence the ROS level and the antioxidant content in $K$. 
brevis through its interaction with to LHC II and the TrxR/Trx system? In the work presented here, two different strains of $K$. brevis which have a tenfold difference in toxin content (Sun, Leeson et al. 2016), had been evaluated and compared for redox status.

In 2015, we determined the rate of production of ROS and the NPQ performance in high-toxin producing and low-toxin producing $K$. brevis strains. It was recorded by using a cell permeable ROS reactive indicator dye, known as carboxy- $\mathrm{H}_{2}$ DCFDA (Figure 50).<smiles>CC(=O)Oc1cc2c(cc1Cl)C(c1ccc(C(=O)O)cc1C(=O)O)c1cc(Cl)c(OC(C)=O)cc1O2</smiles>

\section{Figure 50 The structure of carboxy- $\mathbf{H}_{2}$ DCFDA}

Live $K$. brevis cells were mixed with carboxy- ${ }_{2}$ DCFDA in 96-wells microplates. After hydrolysis of the acetate groups by esterases, the dye is oxidized to a fluorescent product. After normalizing to chlorophyll fluorescence it was found that the low toxin culture produced ROS at twice the rate of the high toxin producing culture (Figure 51) (Cassell, Chen et al. 2015).

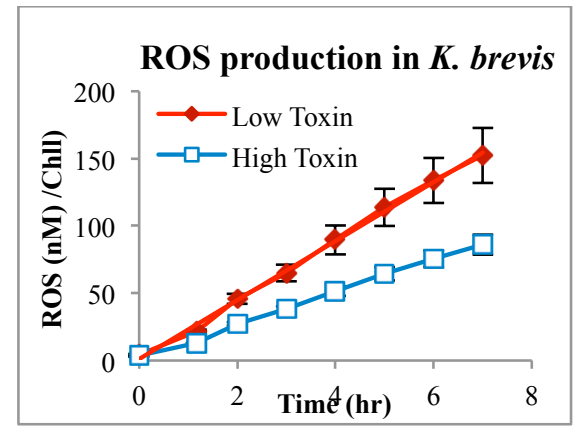

Figure 51 The ROS production in two strains of K. brevis. ROS production was normalized to chlorophyll fluorescence. Low toxic strain produces more ROS than high toxic strain 
NPQ of two strains of K. brevis was determined during log phase growth by pulsed amplitude modulation (PAM) fluorimetry at four excitation wavelengths (Cassell, Chen et al. 2015). Under the same culture conditions, the toxic culture reached an algal biomass of about $1590 \mathrm{mg} \mathrm{Chl} \mathrm{/} \mathrm{L,} \mathrm{versus} 240 \mu \mathrm{g} \mathrm{Chl} / \mathrm{L}$ for the less toxic culture, after 20 days of growth. Both algal cultures exhibited the same fluorescence yield subsequent to the pulses of four different excitation wavelengths $(470,520,645$, and $665 \mathrm{~nm}$ ). The NPQ was calculated for each excitation wavelength by measuring the saturated fluorescence at $3600 \mathrm{mmol}$ photons $/ \mathrm{m}^{2} \cdot \mathrm{s}$ of the $25 \mathrm{~min}$ dark and actinic light adapted (363 mmol photons $/ \mathrm{m}^{2} \cdot \mathrm{s}$ ) algal cultures. NPQ for the four excitation wavelengths were determined at increasing levels of 1 min actinic light adaptation, ranging from 164 to $2064 \mathrm{mmol}$ photons $/ \mathrm{m}^{2} \cdot \mathrm{s}$. NPQ increased with increasing actinic light intensities, but this increase was much lower for the less toxic culture and overall much less than for the toxic culture (Figure 52). To our surprise, a slightly negative NPQ (-0.05 to - 0.01) was observed for the less toxic culture at actinic light intensities 64-764 mmol photons $/ \mathrm{m}^{2} \cdot \mathrm{s}$, whereas all NPQ values were positive for the toxic culture.

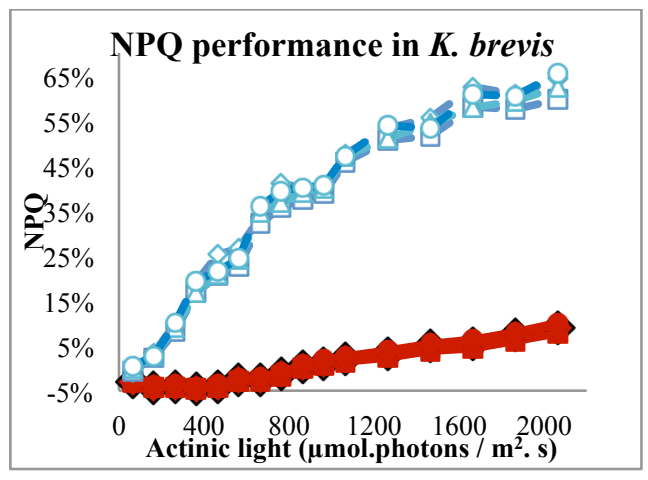

Figure 52 NPQs for the low and high toxic algal cultures to the pulses of four different excitation wavelengths $(470,520,645$, and $665 \mathrm{~nm})$. It was calculated for each sample after $1 \mathrm{~min}$ of adaptation to increasing levels of actinic lights. Both cultures exhibited an increase in NPQ with actinic light, but a sharper increase in 
magnitude of the NPQs were found for the toxic culture. (Light toxic strain in 470 $\mathrm{nm},-520 \mathrm{~nm}, \Delta 645 \mathrm{~nm}, \diamond 665 \mathrm{~nm}$, high toxic strain in $\diamond 470 \mathrm{~nm}, \square 520 \mathrm{~nm}, \triangle 645$ $\mathrm{nm}, \circ 665 \mathrm{~nm})$

The NPQ and ROS experiments revealed that the high toxic strain can perform NPQ to prevent cells from damage by ROS. In fact, the low-toxic strain produces ROS at about twice the rate of the high toxic strain, and does not perform NPQ as efficiently as the high toxic strain. It is unclear if the lack of toxin causes the NPQ deficiency or, if the NPQ deficiency results in lower toxin production.

\subsection{Results and discussion}

Initially we had assumed that K.brevis TrxR would be more like that of a plant. Plant TrxR is more similar to prokaryotic TrxR which does not have the Cys-Sec. However, it is reported a "mammalian like" TrxR was found in Emeliania huxleii which has the C-terminal selenosulfide by researching the gene sequence (Araie, Suzuki et al. 2008). Thus, it is very likely that $K$. brevis does has "mammalian like TrxR. Using the sequence from Emeliania huxleii as a query in a BLAST search of the K. brevis transcriptome library it is revealed that two "mammalian like" TrxR sequence in which the C-terminal selenosulfide is present (Darcie, Alan et al. 2014).

UGA codon is normally a termination codon, whereas UGA codon is able to code Sec in a special way. A selenocysteine insertion sequence (SECIS) presents in the mRNA, which is responsible to make UGA codon to encode Sec (U). SECIS is defined as a nucleotide sequence which typically located following the UGA codon. In Archaea and eukaryotes, the SECIS element is located in the 3' untranslated region of the mRNA. The SECIS element was found in both DNA sequence of TrxR in K. brevis. In addition, a selenocysteine residue was discovered in one amino acids sequence of 
TrxR in K. brevis, which was aligned with human TrxR and "mammalian like" TrxR sequence in Emeliania huxleii (Table 10)

Table 10 The alignments of TrxR in K. brevis, Homo sapiens and Emiliania huxleyi

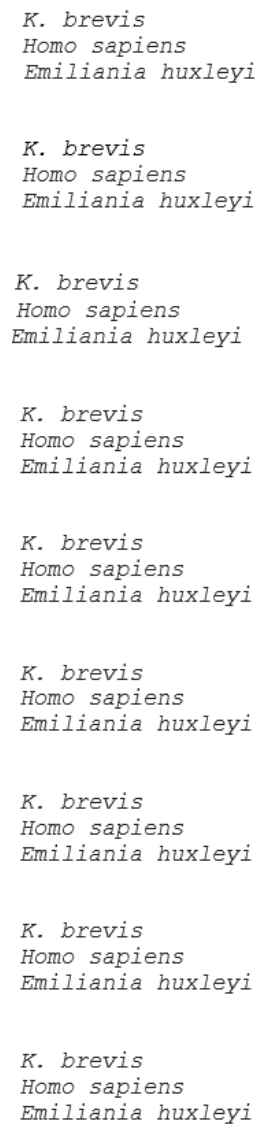

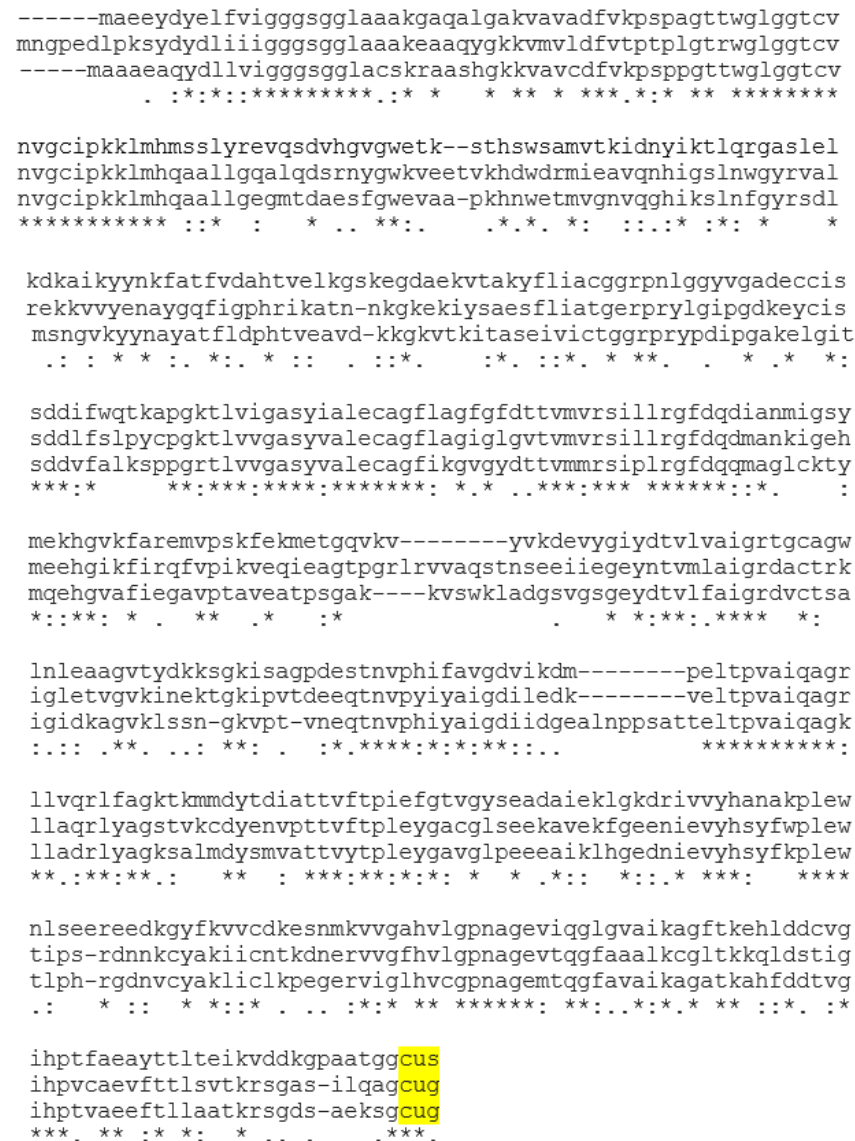

\subsubsection{The antioxidants in two strains of $K$. brevis}

Antioxidants play an important role in protecting cells from oxidative stress. GSH, ascorbic acid, Trx, carotenoids and vitamin $\mathrm{E}$ are central to the antioxidant defense in most of species. Thus, it is suspected antioxidant capacity may not be same between high toxic and low toxic strain. Examining the antioxidant capacity and ascorbic acid content may contribute to understanding the role of brevetoxin in K. brevis.

Here, the 2,2'-azino-bis (3-ethylbenzothiazoline-6-sulphonic acid (ABTS) assay was used to detect all antioxidants such as lipophilic carotenoids, GSH, Trx and ascorbic 
acid (Figure53). The ABTS assay measures the decolorization (reduction) of the ABTS radical cation which has a long wavelengthabsorption (Re, Pellegrini et al. 1999).

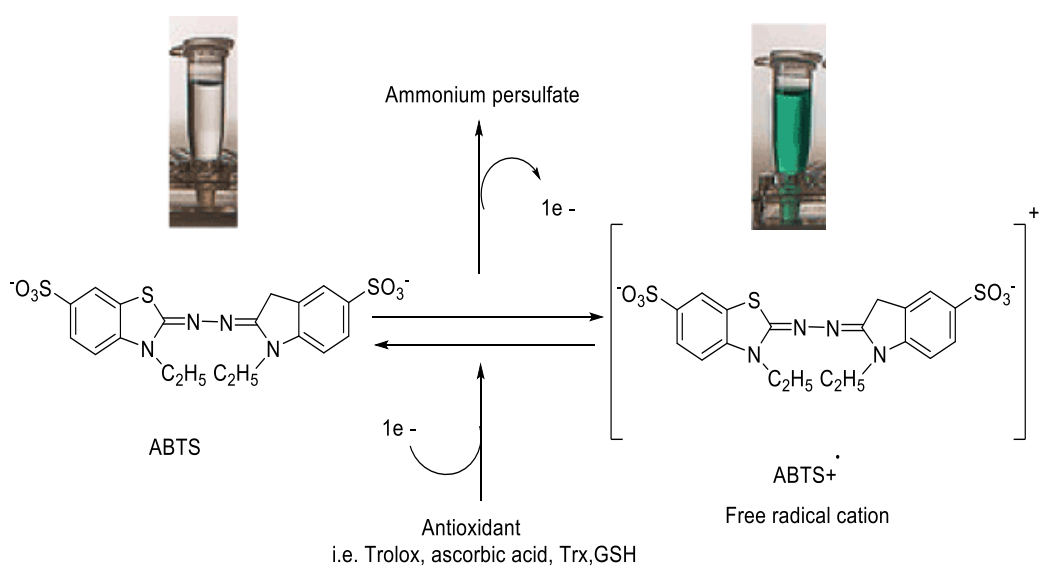

Figure 53 The reaction in ABTS assay

Total antioxidant capacity of $K$. brevis homogenates was determined using ABTS radical cation (ABTS. ${ }^{+}$) decolorization (Re, Pellegrini et al. 1999) and expressed as trolox equivalents. Trolox is similar to vitamin $\mathrm{E}$ which is used in biological applications to reduce oxidative damage. Trolox equivalent antioxidant capacity (TEAC) is commonly used as a standard in the ABTS assay for measuring the concentration of antioxidant in unknown sample. Here, the homogenate of two $K$. brevis strains or trolox standard was used to decolorizw the ABTS ${ }^{+}$in the assay. The concentration of total antioxidant was estimated based on the trolox concentration standard curve. Furthermore, ascorbic acid concentration (as trolox equivalents) in $K$. brevis homogenates was estimated by incubating with ascorbic acid oxidase (AAO). AAO catalyzes the oxidation of ascorbic acid to dehydroascorbic acid. Thus, the difference of absorbance in the presence and absence of AAO provides an estimate of ascorbic acid concentration in the homogenate. Total antioxidant or ascorbic acid content were normalized to protein concentration. It was shown that the high toxic 
strain has a 1.2-fold antioxidant capacity than the low toxic strain on three of the four days tested (Figure 54). In contrast, the low toxic strain consistently had higher levels of ascorbic acid (Figure55). It showed that the low toxic strain has maximum 4.5-fold of ascorbic acid at 19 growing days, when it compared to high toxic strain.

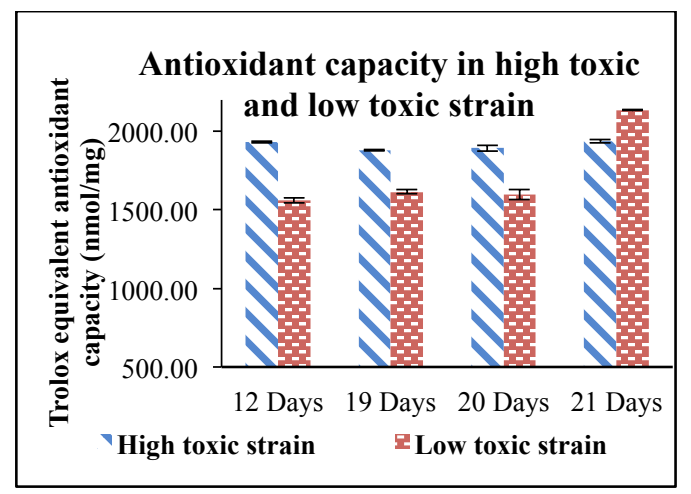

Figure 54 The antioxidant capacity in two strains of $K$. brevis. ABTS ${ }^{+}$was produced by oxidation of aqueous ABTS $(1.3 \mathrm{~mL}, 7 \mathrm{mM})$ with ammonium persulfate $(21.2 \mu 1,2.45 \mathrm{mM})$. The Either $50 \mu \mathrm{K}$. brevis homogenate or trolox standards $(0 \mu \mathrm{M}, 25 \mu \mathrm{M}, 50 \mu \mathrm{M}, 100 \mu \mathrm{M}$, $200 \mu \mathrm{M})$ were added to the $\mathrm{ABTS}^{+}$solution $(100 \mu \mathrm{l})$. The absorbance was read at $734 \mathrm{nM}$ after incubation for $5 \mathrm{~min}$

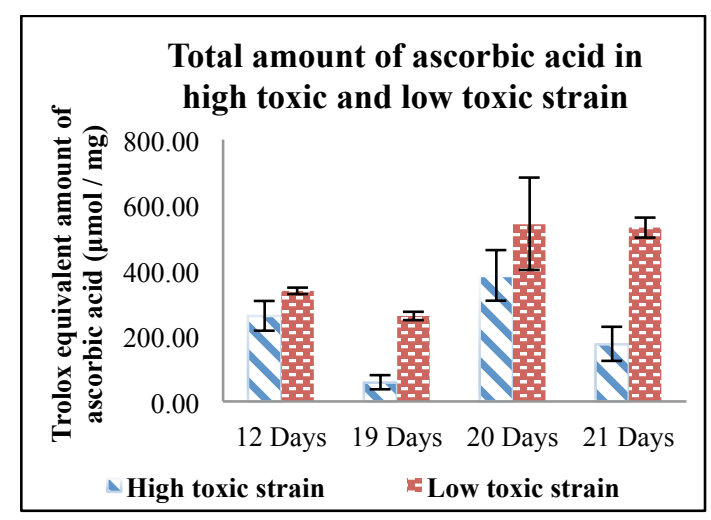

Figure 55 The total amount of ascorbic acid in two strains of $K$. brevis. Ascorbic acid concentration (as trolox equivalents) of $K$. brevis homogenate was estimated by incubating with of ascorbic acid oxidase $(2 \mu \mathrm{l}, 0.01 \mathrm{U} / \mu \mathrm{L})$ for 30 min prior to the assay and comparing absorbance to parallel samples without AAO 


\subsubsection{Redox state of protein and non-protein thiols in low vs high toxin cultures}

\section{of $K$. brevis}

Because brevetoxin is an inhibitor of the $\operatorname{Trx} / \operatorname{TrxR}$ system, it follows that the presence of brevetoxin may impact the amount of free thiols in K. brevis. Therefore, we examined the thiol content in high and low toxin producing strains of $K$. brevis.

Modified papain assay As mentioned in Chapter 3, this assay is more sensitive to thiols than the Ellman's assay as the signal is amplified by the enzymatic activity of papain. Thus, the thiol content, normalized to protein concentration, was determined first by using the modified papain assay in the high toxin and low toxin $K$. brevis strains. Because the free thiol groups may be buried in proteins and not readily accessible by modified papain, cystamine was added into the reaction to access not only low MW thiols, but also free thiols in proteins. This experiment revealed a higher thiol content is in the low toxic homogenate compared to toxic strain either under light or dark conditions (Figure56). No matter under dark adapter or sun light, a two-fold reduction of $\mathrm{V}_{0}$ was shown in the low toxic strain compared to high toxic strains for the modified papain assay. Again, this assay is complicated by the fact that brevetoxin is an inhibitor of papain. Thus, Ellman's assay has to be used to detect the thiol content in K. brevis homogenate. 


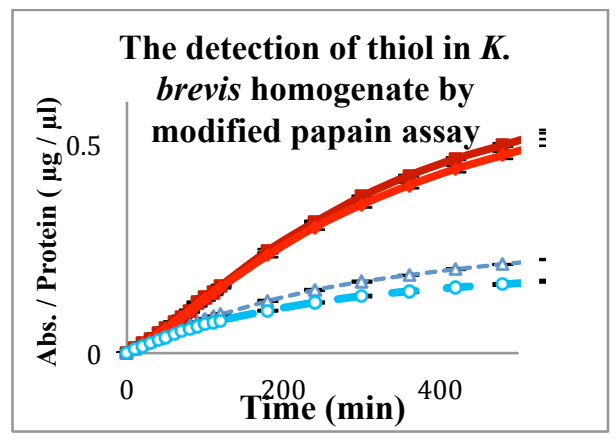

Figure 56 The detection of thiols in K. brevis homogenate by modified papain assay. The culture was either dark adapted or light adaptedfor $1 \mathrm{hr}$ before harvesting cells. Papain-S$\mathrm{SCH}_{3}$ solution $(0.5 \mathrm{ml}, 0.6 \mathrm{mg} / \mathrm{ml}), 0.7 \mathrm{ml}$ substrate and $15 \mu \mathrm{l}$ cystamine were added in one test tube which contained $200 \mu \mathrm{l}$ supernatant. ( Dark adapted low toxic strain, $\Delta$ Dark adapted high toxic strain, $\triangleleft$ Light adapted low toxic strain, $\odot$ Light adapted high toxic strain)

Ellman's assay The content of low molecular weight thiols in K. brevis homogenates of both low and high toxic strains was also determined using the Ellman's assay. This reaction is stoichiometric, allowing for accurate quantification of free thiols. Considering that the stage of the culture on a growth cycle may affect the thiol content of cells, the free thiol content was monitored using DTNB assay during the $\log$ phase of the growth cycle (Figure 57).
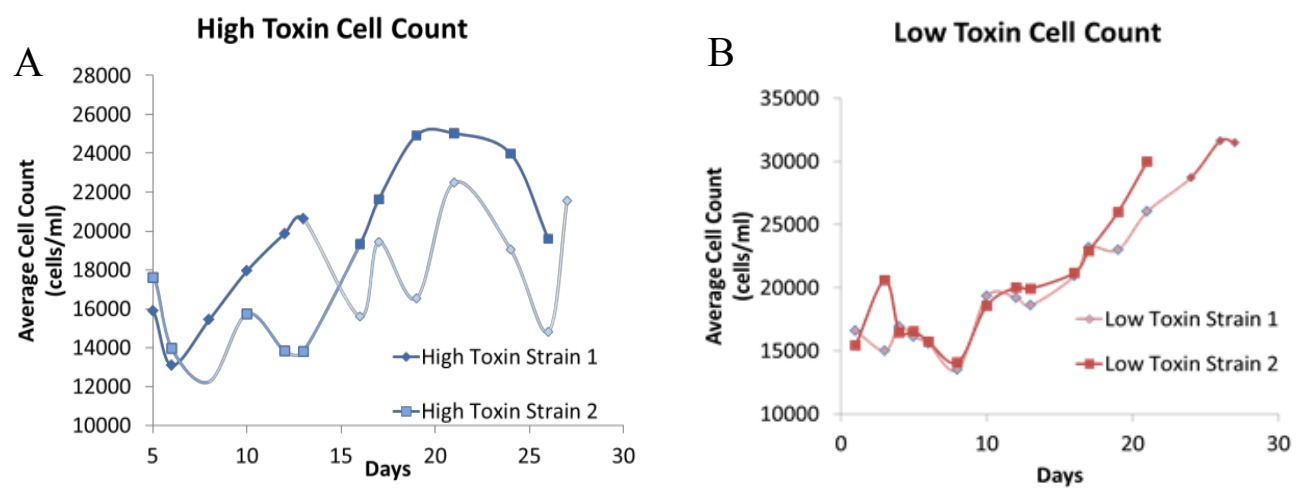

Figure 57 The concentration of cells over the lifetime of high toxin and low toxic strains

The thiols detected by the Ellman's assay are believed to be composed principally of reduced glutathione as cellular glutathione levels are typically in the $\mathrm{mM}$ range. 
However, other low molecular weight thiols and some higher molecular weight thiols, which are accessible to DTNB may also be detected. Additionally, on selected days, GR was added to parallel samples. GR will reduce any glutathione which is present as the disulfide GSSG to the thiol GSH. In this way the total GSH can be quantified. Also, the ratio of native GSH to total GSH can be calculated. At the end, the amount of thiol can be obtained from the proportion of absorbance compared to the concentration of cysteine standards. Then the amount of thiol was normalized to protein concentration in the homogenate. It is clear that the low toxic strain has a higher thiol concentration than high toxic strain, which is consistent with the previous modified papain assay (Figure 58). From $17^{\text {th }}$ to $19^{\text {th }}$ days, low toxic strain produced two folds of thiol content than high toxic strain. In 12, 21, 23 and 25 days, a 1.5-fold of thiol content was produced in low toxic strain compared to high toxic strain. However, after adding the GR prior to the assay and comparing absorbance to parallel, it is seemed that two strains had similar amount of total GSH when the cells in the log phase of growth (Figure 59 A). Finally, the ratio of reduced GSH to total GSH was calculated based on the normalized results of before and after adding GR. It has been shown that from $17^{\text {th }}$ to $19^{\text {th }}$ days low toxic strain has two-fold ratio of reduced GSH to total GSH than high toxic strain (Figure 59 B). From 23 to 25 days, low toxic strain has 1.5-fold ratio of reduced GSH to total GSH than high toxic strain.

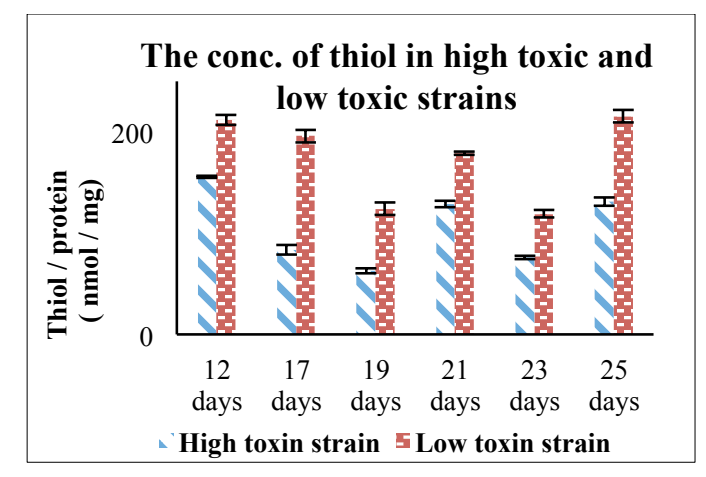


Figure 58 The concentration of thiol in high toxic and low toxic strains. K. brevis homogenates ( $300 \mu \mathrm{l}, 0.3-0.5 \mathrm{mg} / \mathrm{ml}$ protein) was mixed with reaction buffer $(700 \mu 1,0.1 \mathrm{M}$ sodium phosphate, $1 \mathrm{mM}$ EDTA, $\mathrm{pH} 8.0)$ and DTNB (20 $\mu 1,4 \mathrm{mg} / \mathrm{ml})$. Samples were quantitated against cysteine standards $(0,0.3,0.6$ and $1.2 \mathrm{mM})$ prepared in reaction buffer in place of homogenate by using the DTNB. The amount of thiol in homogenate was normalized to protein concentration in the homogenate.

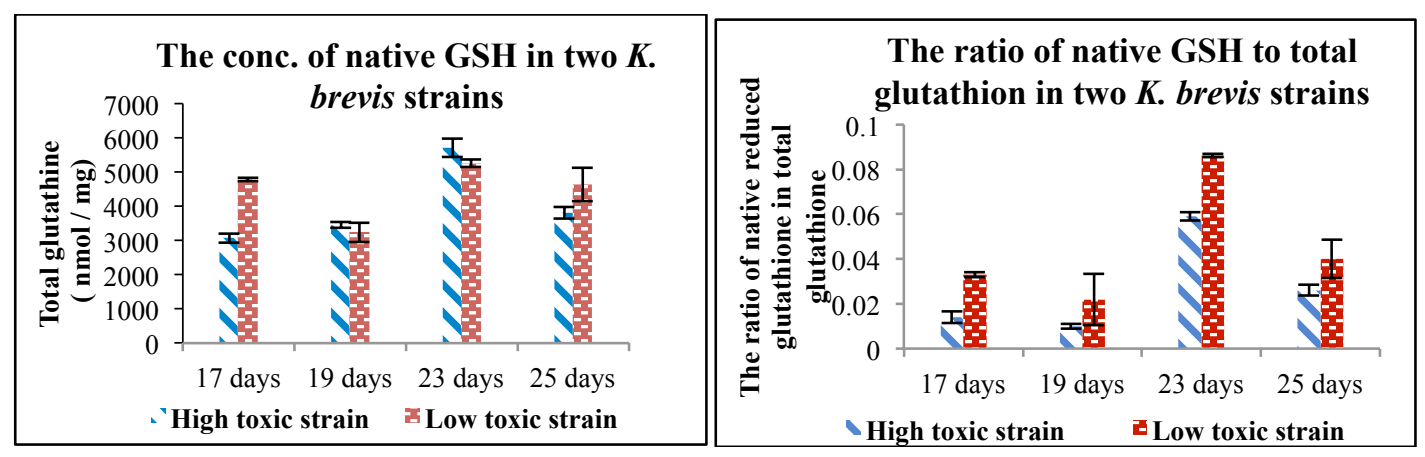

Figure 59 The total glutathione in two strains of $K$. brevis and the ratio of native reduced glutathione to total glutathione in two strains of K. brevis. (A) K. brevis homogenates ( $275 \mu$, $0.3-0.5 \mathrm{mg} / \mathrm{ml})$ was mixed with NADPH $(100 \mu \mathrm{l}, 1 \mathrm{mg} / \mathrm{ml})$, glutathione reductase $(3 \mu 1,10$ $\mu \mathrm{M})$ and Ellman's reagent $(25 \mu \mathrm{l}, 4 \mathrm{mg} / \mathrm{ml})$. Samples were quantitated against cysteine standards $(0,0.3,0.6$ and $1.2 \mathrm{mM})$ prepared in reaction buffer in place of homogenate by using the Ellman's reagent. The amount of thiol in homogenate was normalized to protein concentration in the homogenate (B) the ratio of native GSH to total GSH was calculated based on the normalized results from before and after adding GR

\subsubsection{The reaction of Sel-green probe in two K. brevis strains.}

In previous experiments, the selenol selective probe was used to react with TrxR in the presence or absence of $\mathrm{PbTx}-2$. It was revealed that in the presence of $\mathrm{PbTx}-2$ less fluorescent reporter was released in the reaction of $\operatorname{TrxR}$ with sel-green when compared to to the absence of $\mathrm{PbTx}-2$. Here, the sel-green probe was used to react with the homogenate of two different brevetoxin producing strains of K. brevis. After incubation of homogenate for $1 \mathrm{hr}$, the fluorescence increase was monitored (ex/em = $370 / 502 \mathrm{~nm})$. In the homogenate the thiol groups and selenol groups react with Selgreen probe, resulted in release of the fluorescent reporter. If Sec is alkylated by brevetoxin in homogenate, then the fluorescence reporter should not be released in the presence of brevetoxin and fluorescence should not be observed. Fluorescence is clearly reduced in the low toxin producing strains (Figure 60). It is highly likely that 
the presence of brevetoxin in K. brevis affects the amount of thiol and selenol groups in cells.

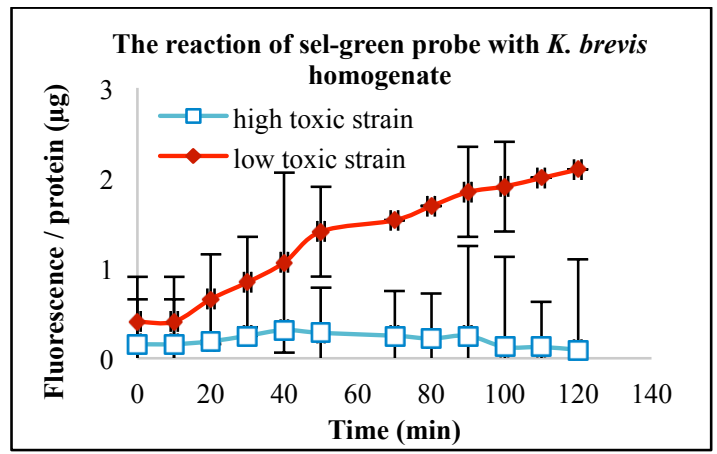

Figure 60 The fluorescence is released by the reaction of sel-green probe with thiol groups and selenol groups in K. brevis homogenate. The homogenate $(80 \mu 1,0.8 \mathrm{mg} / \mathrm{ml}$ of protein) mixed with sel- green $(20 \mu \mathrm{l}, 20 \mu \mathrm{M})$. A control sample was prepared by the addition of an equal volume of buffer instead of homogenate. The fluorescence was normalized to protein concentration in the homogenate

\subsubsection{The activity of Trx and Grx in two $K$. brevis strains}

The activities of Trx and Grx in K. brevis homogenates were determined using fluorescent activity assay kits according to the manaufacturer's (Cayman Chemical) instructions. The reactions catalyzed by these enzymes and their mechanisms were described in Chapter 3. A known concentration $\operatorname{Trx}(20 \mathrm{nM})$ was served as control. Although same amount of homogenate was used to detect the low toxic strain showed higher activity of Trx and Grx comparing to high toxic strain (Figure 61 and 62). It had been shown that 3-fold activity of Trx and 1.7-fold activity of Grx was detected in low toxic strain compaing to high toxic strain. However, the fluorescence caused by two homogenates is much less than known-concentrtion Trx. Thus the results are not persuasive. Increasing the amount of homogenate should be considered in the further studying. 


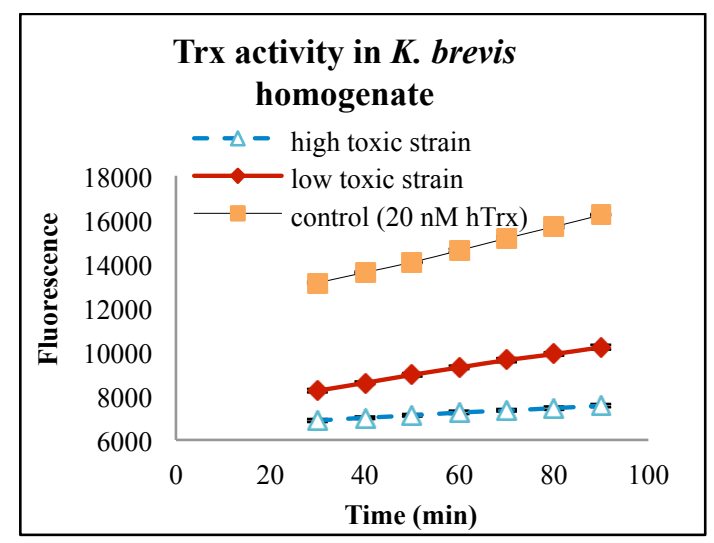

Figure 61 Using the fluorescent Trx / TrxR system kit detects the Trx activity in K. brevis homogenate. The homogenate ( $30 \mu \mathrm{g}$ of protein) was incubated with NADPH $(17.5 \mu \mathrm{l})$, TrxR $(35 \mu \mathrm{l}, 1 \mu \mathrm{M})$ and assay buffer $(113 \mu \mathrm{l})$ for $30 \mathrm{~min}$ at $37{ }^{\circ} \mathrm{C}$. Fluorescent substrate $(70 \mu \mathrm{l})$ was added in each tube

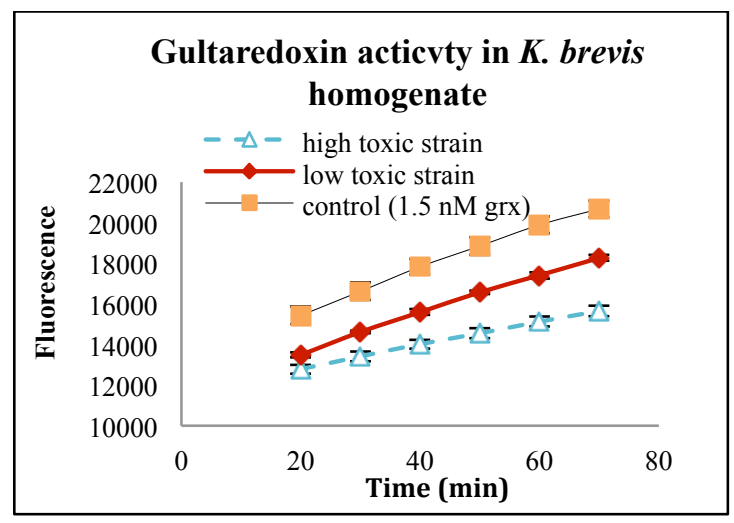

Figure 62 Using the fluorescent Grx kit detects the Grx activity in K. brevis homogenate. The homogenate (30 $\mu$ g of protein) was mixed with NADPH $(10 \mu \mathrm{l})$, reduced glutathione (10 $\mu \mathrm{l}, 0.1 \mathrm{M})$, GR $(10 \mu \mathrm{l}, 10 \mu \mathrm{M})$, assay buffer $(200 \mu \mathrm{l})$ and stabilized reagent and fluorescent substrate

\subsection{Conclusion}

Because of the discoveries found in chapter 2 and 3, we determined that the two $K$. brevis strains not only differ in the amount of toxin but also in NPQ performance and ROS level. Indeed, the low toxic strain cannot perform NPQ whereas high toxic strain does. In addition, the low toxic strain produces more ROS than high toxic strain (Table 11). 
Table 11 Comparison of NPQ and ROS in two K. brevis strains

\begin{tabular}{|c|c|c|}
\hline & NPQ & Relative rate of ROS \\
\hline High toxic strain & able & 21.9 \\
\hline Low toxic strain & disable & 12.16 \\
\hline
\end{tabular}

The modified papain assay revealed that the low toxic strain of K. brevis has twice thiol content when it compared to the high toxic strain. The free thiol was monitored via the Ellman's assay over the lifetime of the cultures, which revealed that low toxic strain has twice amount of reduced thiol than high toxic strains from 17 to 19 growing days. This is also consistent with the previous modified papain assay. Additionally, on selected days during the log phase of the living cells' growth cycle, GR that could reduce any oxidized GSSG to the GSH, was added to parallel samples to quantify total glutathione and asses the ratio of reduced GSH to total GSH. This showed that the high toxic strain and low toxic strain had similar total GSH when the cells in the $\log$ phase of growth. However, the low toxic strain has a maximum 2.4-fold ratio of reduced GSH to total GSH than high toxic strain. In addition to thiols, antioxidant capacity and ascorbic acid content are not the same in the high toxic and low toxic strains. At $19^{\text {th }}$ growing days, the high toxic strain has 1.16 -fold antioxidant capacity than low toxic strain. However, 4.5-fold less of ascorbic acid was present in high toxic strain than low toxic strain, which matched the ratio of native GSH to total GSH (Table 12). Because in cells GSH can reduce dehydroascorbic acid to ascorbic acid.

Table 12 Comparison of various biochemical parameters in two K. brevis strains at $19^{\text {th }}$ days

\begin{tabular}{|c|c|c|c|c|}
\hline & $\begin{array}{c}\text { Thiol } \\
\text { content }\end{array}$ & $\begin{array}{c}\text { Ratio of native GSH } \\
\text { to total GSH }\end{array}$ & Ascorbic acid & $\begin{array}{c}\text { Antioxidant } \\
\text { capacity }\end{array}$ \\
\hline $\begin{array}{c}\text { High toxic } \\
\text { strain }\end{array}$ & 1 & 1 & 1 & 1.16 -fold \\
\hline $\begin{array}{c}\text { Low toxic } \\
\text { strain }\end{array}$ & 1.97 -fold & 2.2 -fold & 4.5 -fold & 1 \\
\hline
\end{tabular}


Taking the results from various assays under consideration, we do find a difference of redox state, antioxidant capacity, GSH and ascorbic acid content between high and low toxin-producing strains. It has been determined that $\operatorname{TrxR}$ is related to the production of GSH and ascorbic acid, such as the reduction of dehydroascorbic acid to ascorbic acid by TrxR. In addition, the discoveries found in chapter 3 reveal that brevetoxin impacts the activity of Trx/TrxR system, which is the major reductive system in the cell. Experimental evidence indicates that the effect is caused by the alkylation of TrxR by brevetoxin. Certain antioxidants such as thiols and ascorbic acid are negatively correlated with brevetoxin content in $K$. brevis. These discoveries provide evidence to support the hypothesis that brevetoixn impacts the reductive system in cells through reaction with TrxR or other thiol containing proteins. Also, the low toxin-producing strain has higher level of ROS and ascorbic acid than high toxin-producing, which is able to support the difference at NPQ performance and ROS level in two strains. Although it seems that total antioxidant capacity is in conflict with our expectations, antioxidant capacity includes many enzymatic or nonenzymatic systems, such as the TrxR/Trx and GSH systems, carotenoids, vitamin E and so on. It is likely that brevetoxin deficiency or the reaction of brevetoxin with proteins is the factor that causes the different performance or capacity in K. brevis cells. But it still need further study to explore.

Furthermore, it is likely that those discoveries perhaps create a new horizon to understand the role of brevetoxin in $K$. brevis or the impacts of damage caused by brevetoxin. 


\subsection{Materials and Methods}

\subsubsection{Culture methods}

Method: K. brevis culture (Wilson strains) were obtained from Mote Marine Laboratory (Sarasota, Florida) and maintained in L1-Si medium, with the exception that the NH 15 vitamin supplement (Gates and Wilson 1960) replaced the L-1 supplement, in a growth chamber at $\sim 20^{\circ} \mathrm{C}$ under $35 \mu$ mol.photons. $\mathrm{m}^{-2} \mathrm{~s}^{-1}$. Growth was monitored by counting a 1:10 dilution of culture in $\mathrm{Z}$ pak reagent using a Beckman Z-series Coulter Counter with aperture size between 10 30 $\mu \mathrm{m}$ according to the manufacturer's instructions.

\subsubsection{Preparation of $K$. brevis homogenate}

Method K. brevis culture (200-500 $\mathrm{ml}$ ) was concentrated by centrifugation ( $5 \mathrm{~min}$ at $466 \mathrm{X} \mathrm{g})$ and the supernatant was discarded. The cells were resuspended in phosphate-buffered saline (PBS) and vortexed for 1 min. This suspension was centrifuged (10 min at $14,000 \mathrm{Xg}$ ) to remove cellular debris and the supernatant was transferred to a clean tube. An aliquot $(50 \mu \mathrm{l})$ was reserved for a protein assay. Samples were quantitated against BSA standards $(0,1,0.5,0.25,0.125$, and 0.0625 $\mathrm{mg} / \mathrm{ml}$ ) prepared in PBS using the Coomassie Protein Assay Reagent (BioRad) according to the manufacturer's instructions. Final protein concentrations ranged from $0.2-1 \mathrm{mg} / \mathrm{ml}$

\subsubsection{ABTS assay}

The materials for ABTS assay ABTS (2,2-azinobis (3-ethenelbenzothiazoline-6sulfonic acid)), $\left(\mathrm{NH}_{4}\right)_{2} \mathrm{~S}_{2} \mathrm{O}_{8}$, Trolox (6-hydroxy-2,5,7,8-tetramethylchroman-2carboxylic acid), ascorbic acid oxidase. High and low toxic $K$. brevis strain 
homogenate was prepared through the pervious method. UV/Visible measurements were performed in 96 or 384 well microplates using a Synergy ${ }^{\circledR} 2$ (Biotek Instrument, Inc.)

The method for ABTS assay Total antioxidant capacity of $K$. brevis homogenate was determined by 2,2-azinobis (3-ethenelbenzothiazoline-6-sulfonic acid) radical cation $\left(\mathrm{ABTS}^{+}\right)$decolorization and expressed as trolox equivalents. $\mathrm{ABTS}^{+}$was produced by oxidation of aqueous ABTS $(1.3 \mathrm{~mL}, 7 \mathrm{mM})$ with ammonium persulfate $(21.2 \mu 1,2.45 \mathrm{mM})$. The mixture was allowed to stand at room temperature in the dark for 12-16 $\mathrm{h}$ before use. The $\mathrm{ABTS}^{+}$solution was diluted with PBS to an absorbance of 0.7 . Either $50 \mathrm{ul} K$. brevis homogenate or trolox standards $(0 \mu \mathrm{M}, 25$ $\mu \mathrm{M}, 50 \mu \mathrm{M}, 100 \mu \mathrm{M}, 200 \mu \mathrm{M})$ were added to the ABTS $^{+}$solution $(100 \mu \mathrm{l})$. The absorbance was read at $734 \mathrm{nM}$ after incubation for $5 \mathrm{~min}$. Ascorbic acid concentration (as trolox equivalents) of $K$. brevis homogenate was estimated by incubating with of ascorbic acid oxidase $(2 \mu 1,0.01 \mathrm{U} / \mu \mathrm{L})$ for $30 \mathrm{~min}$ prior to the assay and comparing absorbance to parallel samples.

\subsubsection{Modified papain assay}

Materials for modified papain assay: Papain, methyl methanethiosulfonate, Nbenzoyl-L-arginine-p-nitroanilide and cystamine were purchased from Thermo Scientific Co.. High and low toxic K. brevis strain homogenate was prepared through the pervious method. UV/Visible measurements were performed in 96 or 384 well microplates using a Synergy® 2 (Biotek Instrument, Inc.) 
Preparation of papain-S-SCH $\mathbf{3}(\sim \mathbf{1 . 2} \mathbf{~ m g} / \mathbf{~ m l}) 1.5 \mathrm{ml}$ of papain stock solution (26.4 $\mathrm{mg} / \mathrm{ml})$ was added to a solution of cysteine $(0.6 \mathrm{mM}, 28.5 \mathrm{ml}$ of $20 \mathrm{mM}$ sodium phosphate $-1 \mathrm{mM}$ EDTA buffer). The solution was kept at room temperature for 30 min. The methyl methanethiosulfonate $(117 \mu \mathrm{mol})$ was added in mixture. The reaction mixture was kept in ice for $4 \mathrm{hr}$. The mixture was dialyzed (Mr cutoff 60008000 ) against $5 \mathrm{mM}$ sodium acetate buffer, containing $50 \mathrm{mM} \mathrm{NaCl}, \mathrm{pH} 4.7$ at $4^{\circ} \mathrm{C} 12$ hr.

Method for modified papain assay: The culture was treated under dark adapt or sun light for $1 \mathrm{hr}$ before making homogenate. Papain-S-SCH solution $(0.5 \mathrm{ml}, 0.6 \mathrm{mg} /$ $\mathrm{ml}), 0.7 \mathrm{ml}$ substrate and $15 \mu \mathrm{l}$ cystamine were added in one test tube which contained $200 \mu$ supernatant. A tube containing papain- $\mathrm{S}^{-} \mathrm{SCH}_{3}$, without homogenate or substrate, serves as control or background. The mixture was carried out in triplicate in plate. Each well was added $300 \mu \mathrm{l}$ mixture. Record the absorbance at $410 \mathrm{~nm}$ (Synergy $^{\text {TM }}$ 2, Bioteck Instrument, Inc.) every 60 min up to $15 \mathrm{hr}$.

\subsubsection{Ellman's assay}

Materials for Ellman's assay: DTNB and cysteine was purchased from Thermo Scientific Co.. High and low toxic K. brevis strain homogenate was prepared through the pervious method. Glutathione reductase was from Grx kit purchased from Cayman Chemical. UV/Visible measurements were performed in 96 or 384 well microplates using a Synergy® 2 (Biotek Instrument, Inc.)

Method for Ellman's assay: K. brevis homogenates $(300 \mu 1,0.3-0.5 \mathrm{mg} / \mathrm{ml}$ protein) was mixed with reaction buffer $(700 \mu 1,0.1 \mathrm{M}$ sodium phosphate, $1 \mathrm{mM}$ EDTA, $\mathrm{pH}$ 
8.0) and Ellman's reagent $(20 \mu \mathrm{l}, 4 \mathrm{mg} / \mathrm{ml})$. After incubation for $15 \mathrm{~min}$ at room temperature absorbance was read at $410 \mathrm{~nm}\left(\right.$ Synergy $^{\mathrm{TM}} 2$, Bioteck Instrument, Inc). Homogenate prepared similarly, but without Ellman's reagent was used to determine background absorbance which was subtracted from each sample. Ellman's reagent in reaction buffer served as the control. Samples were quantitated against cysteine standards $(0,0.3,0.6$ and $1.2 \mathrm{mM})$ prepared in reaction buffer in place of homogenate by using the Ellman's reagent according to the manufacturer's instructions (Thermo Fisher). Samples and cysteine standards were analyzed in triplicate. The amount of thiol in homogenate was normalized to protein concentration in the homogenate.

Ellman's assay of two strains with GR $K$. brevis homogenates $(275 \mu 1,0.3-0.5 \mathrm{mg} /$ ml) was mixed with NADPH $(100 \mu \mathrm{l}, 1 \mathrm{mg} / \mathrm{ml})$, glutathione reductase $(3 \mu \mathrm{l}, 10 \mu \mathrm{M})$ and Ellman's reagent $(25 \mu \mathrm{l}, 4 \mathrm{mg} / \mathrm{ml})$. Immediately the absorbance was read at 410 $\mathrm{nm}$ at room temperature up to $30 \mathrm{~min}$. Homogenate prepared similarly, but without Ellman's reagent was used to determine background absorbance which was subtracted from each sample. Ellman's reagent in reaction buffer served as the control. Samples were quantitated against cysteine standards $(0,0.3,0.6$ and $1.2 \mathrm{mM})$ prepared in reaction buffer in place of homogenate by using the Ellman's reagent. Samples and cysteine standards were analyzed in triplicate.

\subsubsection{Sel- green reacts with homogenate of tow $K$. brevis strains}

Materials: Sel-Green was synthesized by Freddy Rodriguez. High and low toxic $K$. brevis strain homogenate was prepared through the pervious method. UV/Visible measurements were performed in 96 or 384 well microplates using a Synergy ${ }^{\circledR} 2$ (Biotek Instrument, Inc.) 
Method: The selenol selective probe, Sel-green, was synthesized according to published methods (Zhang, Ge et al. 2015). The homogenate was made resulting in $0.8 \mathrm{mg} / \mathrm{ml}$ of protein both in high toxic and low toxic homogenate. Sel- green $(20 \mu 1$, $20 \mu \mathrm{M})$ was mixed with high toxic strain or low toxic strain homogenate $(80 \mu 1)$. Samples were prepared in triplicate. A control sample was prepared by the addition of an equal volume of buffer instead of homogenate. A blank sample was prepared without Sel-green. Fluorescence at $502\left(\lambda_{\mathrm{ex}}=370 \mathrm{~nm}\right)$ was monitored for 120 mins.

\subsubsection{Thioredoxin activity in homogenate of two strains $K$. brevis}

Materials: Enzyme assay kit was purchased from Cayman Chemical. Assay kit was used according to the manufacturer's instructions with noted exceptions. High and low toxic $K$. brevis strain homogenate was prepared through the pervious method. Fluorescence measurements were performed in 96 or 384 well microplates using an Infinite ${ }^{\circledR}$ M1000 PRO (Tecan Group Ltd.) microplate readers.

Method: The homogenate was made resulting in $1.0 \mathrm{mg} / \mathrm{ml}$ and $1.5 \mathrm{mg} / \mathrm{ml}$ of protein high toxic and low toxic homogenate. Assay buffer $(113 \mu 1,0.2 \mathrm{mg} / \mathrm{ml}$ bovine serum albumin in $50 \mathrm{mM}$ Tris- $\mathrm{HCl}$ and $1 \mathrm{mM}$ EDTA, $\mathrm{pH}$ 7.5) was mixed with $17.5 \mu \mathrm{l}$ NADPH in one clean tube. Thioredoxin reductase $(35 \mu \mathrm{l}, 1 \mu \mathrm{M})$ was added into the mixture. The homogenate was incubated with the mixture for $30 \mathrm{~min}$ at $37{ }^{\circ} \mathrm{C}$. $70 \mu \mathrm{l}$ fluorescent substrate was added in each tube. The mixture was carried out in triplicate in plate. Each well is added $100 \mu \mathrm{l}$ mixture. Record its fluorescence at the emission / excitation at $545 \mathrm{~nm} / 520 \mathrm{~nm}$ every $10 \mathrm{~min}$ for $3 \mathrm{hr}$. 


\subsubsection{Grx activity in homogenate of two strains $K$. brevis}

Materials: Fluorescent Grx kit was purchase from Cayman Chemical. High and low toxic $K$. brevis strain homogenate was prepared as mentioned above. Fluorescence measurements were performed in 96 or 384 well microplates using an Infinite ${ }^{\circledR}$ M1000 PRO (Tecan Group Ltd.) microplate readers.

Method: The homogenate was made resulting in $1.0 \mathrm{mg} / \mathrm{ml}$ and $1.5 \mathrm{mg} / \mathrm{ml}$ of protein high toxic and low toxic homogenate. Assay buffer $(200 \mu l)$ was mixed with reduced glutathione $(10 \mu \mathrm{l}, 0.1 \mathrm{M})$ in one clean tube. NADPH $(10 \mu \mathrm{l})$ and stabilized reagent were added with mixture. Glutathione reductase $(10 \mu 1,10 \mu \mathrm{M})$ was applied into the mixture. The distilled water was added it up to $1 \mathrm{ml}$. The homogenate and fluorescent substrate were added with mixture in each tube. Immediately the mixture was carried out in triplicate in plate. Each well was added $100 \mu \mathrm{l}$ mixture. Record its fluorescence at the emission / excitation at $545 \mathrm{~nm} / 520 \mathrm{~nm}$ every $10 \min$ for $3 \mathrm{hr}$. 


\section{Chapter 5 Summary and future work}

\subsection{Summary}

This dissertation describes efforts to understand the principle role that brevetoxin plays in $K$. brevis. The dissertation includes four components: i) localization of brevetoxin in $K$. brevis cells ii) identification of the target proteins of brevetoxin iii) characterization of the interaction between a target protein and brevetoxin iv) comparison of the various metabolic and biochemical parameters in two strains of $K$. brevis having different toxin content.

Brevetoxin was localized to the chloroplast of live $K$. brevis cells through the fluorescently labeled brevetoxin probe. Using a brevetoxin photoaffinity probe, two native receptors of brevetoxin were discovered from $K$. brevis. Based on the BLAST analysis, LHC II and Trx were identified as binding partners for brevetoxin in $K$. brevis. An interaction between brevetoxin and a transmembrane target protein, LHC II, was discovered, which is related to the NPQ mechanism to protect the cells from damage by ROS. Also, PbTx-2 appeared to inhibit the Trx/TrxR system. However, PbTx-2 promoted the reduction of DTNB by TrxR. Although there is no direct evidence to prove PbTx-2 reacts with mammalian TrxR by alkylation of the $\alpha, \beta$ unsaturated aldehyde of brevetoxin with selenocysteine in TrxR, several pieces of indirect evidence supported this conclusion. Because of this deactivation, mammalian TrxR could not reduce the Trx, and thus, the insulin disulfide bonds could not be reduced by Trx either. However, the reaction center on N-terminal of mammalian TrxR still can reduce some small molecule such as DTNB.

Thus, according to the identification of the two native receptors and interaction between brevetoxin with mammalian Trx/TrxR system, follows that the redox state 
and antioxidant capacity of $K$. brevis may be related to toxin content. It had been revealed that high toxic strain could perform NPQ whereas low toxic strain could not perform NPQ. The low toxic strain had higher levels of ROS than the high toxic strain. The modified papain assay, Ellman's assay, and ABTS assay were used to compare the free thiol groups and antioxidants in the high and low toxic strains. In general, the high toxic strain had a higher antioxidant capacity than the low toxic strain. However, the low toxic strain consistently exhibited higher levels of free thiol groups and ascorbic acid. Both of these would be influenced by the TrxR/Trx activity in the cells. The low toxic strain has slightly higher activity of Trx system and Grx compared to high toxic strain. Therefore, brevetoxin content seems to be correlated with redox homeostasis of the cells.

It is likely that brevetoxins plays an important role in K. brevis. It is highly possible that brevetoxin affects the reductive system in cells, leading to the impact on various metabolic and biochemical parameters in two strains of $K$. brevis. In order to better understand these phenomenons, additional experiments are still needed to be done to prove our hypothesis.

\subsection{Future work}

\subsubsection{Identify all biological receptors for brevetoxin in $K$. brevis and localize the}

\section{binding site on native receptors}

Our receptor binding experiments at $\mathrm{pH} 7$ have consistently shown one additional high MW bands between 57 and $75 \mathrm{kD}$ (Figure 63). A third band at $37 \mathrm{kD}$ has been observed sporadically. These two bands have been excised from gels and can be sent immediately to the mass spectrometry facility at the University of Massachusetts at 
Amherst to be identified.

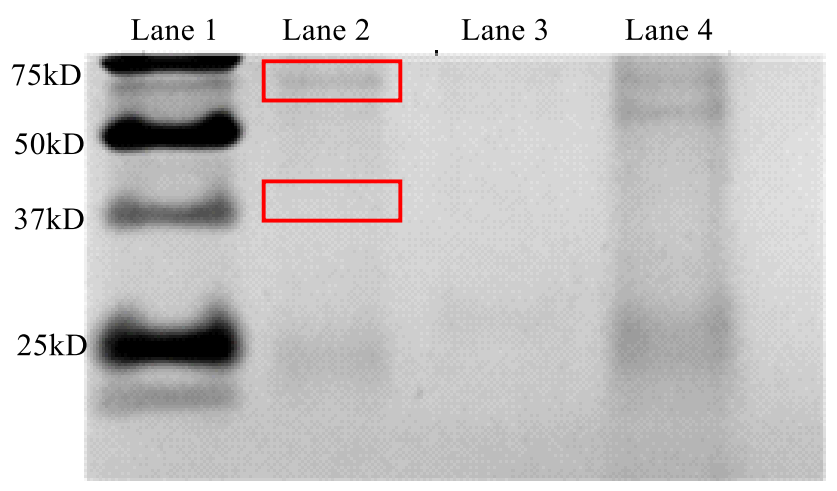

Figure 63 Spinach homogenate was incubated with photoaffinity probe in PBS $(\mathrm{pH}=7)$ for 1 hour. Lane 1: Molecular Weight markers Lane 2: The first elution. Lane3: The second elution. Lane4: Total protein.

Because the increase effect of TrxR by PbTx-3 was observed as well in DTNB assay. Also, $\mathrm{PbTx}-3$ and $\mathrm{PbTx}-2$ both have an aldehyde at A-ring. We suspect $\mathrm{PbTx}-3$ may bind or react with Trx or TrxR enzyme as well. Perhaps, the A-ring is another active site for brevetoxin $\mathrm{B}$. Thus, a brevetoxin ( $\mathrm{PbTx}-2$ or $\mathrm{PbTx}-3)$ photoaffinity probe (Figure 64) which includes a photoactive diazirine to interact with its receptor can be synthesized to incubate with $K$. brevis homogenate. This time, the ligand will be introduced A-ring position in $\mathrm{PbTx}-2$ or $\mathrm{PbTx}-3$. The photolysis, purification and identification are same as previous experiment. We may or may not discover new target proteins.

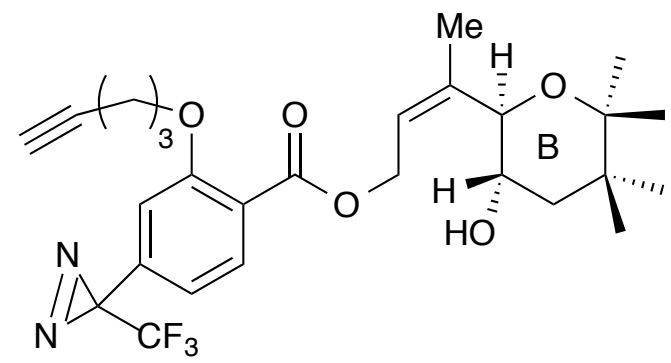

Figure 64 A-ring derivative from $\mathrm{PbTx}-2$ or $\mathrm{PbTx}-3$ A-ring diol

If in order to identify the specific binding amino acid in target protein, the same photoaffinity probe (K-ring derivative or A- ring derivative) is incubated with $K$. 
brevis homogenate. After photolysis, the probe may react to form a covalent crosslink to a variety of amino acid residues within the target protein. This time, the protein sample will be digested by trypsin to its peptide constituents before purification. The same procedure will be used to isolate the full protein by passing the digest through a strepavadin column. The target fragment, linked with biotin will be eluted from the streptavidin column by heat treatment. SDS-PAGE will be performed to analyze the captured fragments. Finally, send the bands to the mass spectrometry facility at the University of Massachusetts at Amherst.

\subsubsection{Analysis of the essential proteins, carotenoids and lipids for NPQ in low vs}

\section{high toxin $K$. brevis}

The low toxic strain does not perform NPQ. It is still unclear if the inability to perform NPQ is due to the absence of brevetoxin, or if the lack of brevetoxin is a result of the NPQ deficiency. It is necessary to determine if the low toxic strain is deficient in one or more of the essential components of NPQ: zeaxanthin and violaxanthin.

Quantitative polymerase chain reaction (qPCR) can be used to amplify and quantify the VDE and ZE mRNA in low and high toxic strains. If we can determine the RNA of VDE and ZE in two strains, we will do further study at translational level. Thus, western blot analysis can be used in further studies to compare protein extracts of the low and high toxic strains of $K$. brevis using three different antibodies: LHC II, VDE

and ZE. These three antibodies can be purchased from Swedish company Agrisera. Hopefully it is possible to determine if one or more of these essential components is absent or reduced in the low-toxin culture. 


\subsubsection{Determination the role of brevetoxin in two $K$. brevis strains}

Although the difference of NPQ, ROS, antioxidant capacity and biochemical parameters in high toxin and low toxin producing strains of $K$. brevis were determined, the reasons caused this phenomenon were still unknown. Does brevetoxin induce those difference? In order to understand it, my idea is adding PbTx-2 with low toxic strain for 25 days. The cells are used unused medium to wash at least twice. The homogenate is made as previous method. DTNB assay, ROS and ABTS assay can be applied again to compare the difference between high toxic strain and low toxic strain which is treated with $\mathrm{PbTx}-2$. The difference becomes smaller or totally disappear, which means brevetoxin is one of the reasons that cause the distinction between high and low toxic strains. 
Reference

Abraham, A., S. M. Plakas, L. J. Flewelling, K. R. El Said, E. L. Jester, H. R. Granade, K. D. White and R. W. Dickey (2008). "Biomarkers of neurotoxic shellfish poisoning." Toxicon 52(2): 237-245.

Abraham, A., S. M. Plakas, Z. Wang, E. L. Jester, K. R. El Said, H. R. Granade, M. S. Henry, P. C. Blum, R. H. Pierce and R. W. Dickey (2006). "Characterization of polar brevetoxin derivatives isolated from Karenia brevis cultures and natural blooms." Toxicon 48(1): 104-115.

Abraham, W. M. and D. G. Baden (2006). "Aerosolized Florida red tide toxins and human health effects." Oceanography 19(2): 107-109.

Abraham, W. M., A. J. Bourdelais, A. Ahmed, I. Serebriakov and D. G. Baden (2005). "Effects of inhaled brevetoxins in allergic airways: toxin-allergen interactions and pharmacologic intervention." Environmental Health Perspectives 113(6): 632637.

Abraham, W. M., A. J. Bourdelais, J. R. Sabater, A. Ahmed, T. A. Lee, I. Serebriakov and D. G. Baden (2005). "Airway responses to aerosolized brevetoxins in an animal model of asthma." American Journal of Respiratory and Critical Care Medicine Home 171(1): 26-34.

Aebi, H. (1984). "Catalase in vitro." Methods in Enzymology 105: 121-126.

Anderson, C. R., S. K. Moore, M. C. Tomlinson, J. Silke and C. K. Cusack (2015). "Living with harmful algal blooms in a changing world: strategies for modeling and mitigating their effects in coastal marine ecosystems." Coastal and Marine Hazards, Risks, and Disasters. Boston, Elsevier: 495-561.

Anestål, K., S. Prast-Nielsen, N. Cenas and E. S. J. Arnér (2008). "Cell death by SecTRAPs: thioredoxin reductase as a prooxidant killer of cells." Plos One 3(4): e1846.

Araie, H., I. Suzuki and Y. Shiraiwa (2008). "Identification and characterization of a selenoprotein, thioredoxin reductase, in a unicellular marine haptophyte alga, Emiliania huxleyi." Journal of Biological Chemistry 283(51): 35329-35336.

Armstrong, R. N. (1997). "Structure, catalytic mechanism, and evolution of the glutathione transferases." Chemical Research in Toxicology 10(1): 2-18.

Arnér, E. S. (2009). "Focus on mammalian thioredoxin reductases-important selenoproteins with versatile functions." Biochimica et Biophysica Acta 1790(6): 495526.

Arnér, E. S. and A. Holmgren (2000). "Physiological functions of thioredoxin and thioredoxin reductase." European Journal of Biochemistry 267(20): 6102-6109. 
Arnér, E. S., L. Zhong and A. Holmgren (1999). "Preparation and assay of mammalian thioredoxin and thioredoxin reductase." Methods in Enzymology 300: 226-239.

Arsalane, W., B. Rousseau and J. C. Duval (1994). "Influence of the pool size of the xanthophyll cycle on the effects of light stress in a diatom: competition between photoprotection and photoinhibition." Photochemical and Photobiological Sciences 60(3): 237-243.

Arscott, L. D., S. Gromer, R. H. Schirmer, K. Becker and C. H. Williams (1997). "The mechanism of thioredoxin reductase from human placenta is similar to the mechanisms of lipoamide dehydrogenase and glutathione reductase and is distinct from the mechanism of thioredoxin reductase from Escherichia coli." Proceedings of the National Academy of Sciences 94(8): 3621-3626.

Aslund, F., B. Ehn, A. Miranda-Vizuete, C. Pueyo and A. Holmgren (1994). "Two additional glutaredoxins exist in Escherichia coli: glutaredoxin 3 is a hydrogen donor for ribonucleotide reductase in a thioredoxin/glutaredoxin 1 double mutant." Proceedings of the National Academy of Sciences 91(21): 9813-9817.

Azzone, G. F. (1972). "Biochemistry and biophysics of mitochondrial membranes." Yale Journal of Biology and Medicine 47(1): 68.

Backer, L., L. Fleming, A. Rowan and D. Baden (2003). "Epidemiology and public health of human illnesses associated with harmful marine phytoplankton." Handbook of Developmental Neurotoxicology: 725-750.

Backer, L. C., B. Kirkpatrick, L. E. Fleming, Y. S. Cheng, R. Pierce, J. A. Bean, R. Clark, D. Johnson, A. Wanner, R. Tamer, Y. Zhou and D. G. Baden (2005). "Occupational exposure to aerosolized brevetoxins during Florida Red Tide events: effects on a healthy worker population." Environmental Health Perspectives 113(5): 644-649.

Baden, D. G. (1989). "Brevetoxins: unique polyether dinoflagellate toxins." The FASEB Journal 3(7): 1807-1817.

Baden, D. G., A. J. Bourdelais, H. Jacocks, S. Michelliza and J. Naar (2005). "Natural and derivative brevetoxins: historical background, multiplicity, and effects." Environmental Health Perspectives 113(5): 621-625.

Baden, D. G., T. J. Mende, W. Lichter and L. Wellham (1981). "Crystallization and toxicology of T34: A major toxin from Florida's red tide organism (Ptychodiscus brevis)." Toxicon 19(4): 455-462.

Baker, A., C. M. Payne, M. M. Briehl and G. Powis (1997). "Thioredoxin, a gene found overexpressed in human cancer, inhibits apoptosis in vitro and in vivo." Cancer Research 57(22): 5162-5167. 
Bauer, H., S. Gromer, A. Urbani, M. Schnölzer, R. H. Schirmer and H. M. Müller (2003). "Thioredoxin reductase from the malaria mosquito Anopheles gambiae." European Journal of Biochemistry 270(21): 4272-4281.

Becker, K., S. Gromer, R. H. Schirmer and S. Müller (2000). "Thioredoxin reductase as a pathophysiological factor and drug target." European Journal of Biochemistry 267(20): 6118-6125.

Benson, J., F. Hahn, B. Tibbetts, L. Bowen, T. March, R. Langley, T. Murray, A. Bourdelais, J. Naar and J. Zaias (2002). "Florida red tide: inhalation toxicity of Karenia brevis extract in rats." Harmful Algae 2004(10)501-504

Benson, J. M., B. B. Stagner, G. K. Martin, M. Friedman, S. E. Durr, A. Gomez, J. McDonald, L. E. Fleming, L. C. Backer and D. G. Baden (2005). "Cochlear function in mice following inhalation of brevetoxin-3." Journal of Comparative Physiology A 191(7): 619-626.

Benson, J. M., D. L. Tischler and D. G. Baden (1999). "Uptake, tissue distribution, and excretion of brevetoxin 3 administered to rats by intratracheal instillation." Journal of Toxicology and Environmental Health Part A 57(5): 345-355.

Berta, P., S. Phaneuf, J. Derancourt, J. Casanova, M. Durand-Clement, C. le Peuch, J. Haiech and J.-C. Cavadore (1988). "The effects of maitotoxin on phosphoinositides and calcium metabolism in a primary culture of aortic smooth muscle cells." Toxicon 26(2): 133-141.

Betteridge, D. J. (2000). "What is oxidative stress?" Metabolism 49(2): 3-8.

Bodeanu, N., S. Moncheva, G. Ruta and L. Popa (1998). "Long-term evolution of the algal blooms in Romanian and Bulgarian Black Sea waters." Cercetari Marine/Recherches Marines 31: 37-55.

Bogdan, C. (2001). "Nitric oxide and the regulation of gene expression." Trends in Cell Biology 11(2): 66-75.

Bormann, B. J., W. J. Knowles and V. T. Marchesi (1989). "Synthetic peptides mimic the assembly of transmembrane glycoproteins." The Journal of Biological Chemistry 264(7): 4033-4037.

Bossart, G. D., D. G. Baden, R. Y. Ewing, B. Roberts and S. D. Wright (1998). "Brevetoxicosis in manatees (Trichechus manatus latirostris) from the 1996 epizootic: gross, histologic, and immunohistochemical features." Toxicologic Pathology 26(2): 276-282.

Bourdelais, A. J., S. Campbell, H. Jacocks, J. Naar, J. L. Wright, J. Carsi and D. G. Baden (2004). "Brevenal is a natural inhibitor of brevetoxin action in sodium channel receptor binding assays." Cellular and Molecular Neurobiology 24(4): 553-563.

Bradshaw, T. D., C. S. Matthews, J. Cookson, E.-H. Chew, M. Shah, K. Bailey, A. Monks, E. Harris, A. D. Westwell, G. Wells, C. A. Laughton and M. F. G. Stevens 
(2005). "Elucidation of thioredoxin as a molecular target for antitumor quinols." Cancer Research 65(9): 3911-3919.

Bricker, S. B., B. Longstaff, W. Dennison, A. Jones, K. Boicourt, C. Wicks and J. Woerner (2008). "Effects of nutrient enrichment in the nation's estuaries: A decade of change." Harmful Algae 8(1): 21-32.

Bulaj, G., T. Kortemme and D. P. Goldenberg (1998). "Ionization-reactivity relationships for cysteine thiols in polypeptides." Biochemistry 37(25): 8965-8972.

Burkholder, J. M., D. A. Dickey, C. A. Kinder, R. E. Reed, M. A. Mallin, M. R. McIver, L. B. Cahoon, G. Melia, C. Brownie, J. Smith, N. Deamer, J. Springer, H. B. Glasgow and D. Toms (2006). "Comprehensive trend analysis of nutrients and related variables in a large eutrophic estuary: A decadal study of anthropogenic and climatic influences." Limnology and Oceanography 51(1part2): 463-487.

Butterfield, D. A., T. Koppal, B. Howard, R. Subramaniam, N. Hall, K. Hensley, S. Yatin, K. Allen, M. Aksenov and M. Aksenova (1998). "Structural and functional changes in proteins Iinduced by free radical-mediated oxidative stress and protective action of the antioxidants N-tert-butyl- $\alpha$-phenylnitrone and vitamin E." Annals of the New York Academy of Sciences 854(1): 448-462.

Cadenas, E. and K. J. Davies (2000). "Mitochondrial free radical generation, oxidative stress, and aging." Free Radical Biology and Medicine 29(3): 222-230.

Carvalho, A. P., P. A. Fernandes and M. J. Ramos (2006). "Similarities and differences in the thioredoxin superfamily." Progress in Biophysics and Molecular Biology 91(3): 229-248.

Cassell, R. T., W. Chen, S. Thomas, L. Liu and K. S. Rein (2015). "Brevetoxin, the dinoflagellate neurotoxin, localizes to thylakoid membranes and interacts with the light-harvesting complex II (LHCII) of photosystem II." ChemBioChem 16(7): 10601067.

Catterall, W. A. (1977). "Activation of the action potential $\mathrm{Na}+$ ionophore by neurotoxins. An allosteric model." The Journal of Biological Chemistry 252(23): 8669-8676.

Catterall, W. A. (1980). "Neurotoxins that act on voltage-sensitive sodium channels in excitable membranes." Annual Review of Pharmacology and Toxicology 20(1): 1543.

Catterall, W. A. (1986). "Molecular properties of voltage-sensitive sodium channels." Annual Review Biochemistry 55: 953-985.

Catterall, W. A., C. Morrow, J. Daly and G. Brown (1981). "Binding of batrachotoxinin A 20-alpha-benzoate to a receptor site associated with sodium channels in synaptic nerve ending particles." The Journal of Biological Chemistry 256(17): 8922-8927. 
Cenas, N., H. Nivinskas, Z. Anusevicius, J. Sarlauskas, F. Lederer and E. S. J. Arnér (2004). "Interactions of quinones with thioredoxin reductase: a challenge of the antioxidant role of the mammalian selenoprotein." The Journal of Biological Chemistry 279(4): 2583-2592.

Chae, H. Z., S. W. Kang and S. G. Rhee (1999). "Isoforms of mammalian peroxiredoxin that reduce peroxides in presence of thioredoxin." Methods in Enzymology 300: 219-226.

Chae, H. Z., H. J. Kim, S. W. Kang and S. G. Rhee (1999). "Characterization of three isoforms of mammalian peroxiredoxin that reduce peroxides in the presence of thioredoxin." Diabetes Research and Clinical Practice 45(2): 101-112.

Checchetto, V., E. Teardo, L. Carraretto, E. Formentin, E. Bergantino, G. M. Giacometti and I. Szabo (2013). "Regulation of photosynthesis by ion channels in cyanobacteria and higher plants." Biophysical Chemistry 182: 51-57.

Cheng, Q., T. Sandalova, Y. Lindqvist and E. S. Arnér (2009). "Crystal structure and catalysis of the selenoprotein thioredoxin reductase 1." Journal of Biological Chemistry 284(6): 3998-4008.

Cheng, Y. S., J. D. McDonald, D. Kracko, C. M. Irvin, Y. Zhou, R. H. Pierce, M. S. Henry, A. Bourdelaisa, J. Naar and D. G. Baden (2005). "Concentration and particle size of airborne toxic algae (brevetoxin) derived from ocean red tide events." Environmental Science and Technology 39(10): 3443-3449.

Cheng, Y. S., T. A. Villareal, Y. Zhou, J. Gao, R. H. Pierce, D. Wetzel, J. Naar and D. G. Baden (2005). "Characterization of red tide aerosol on the Texas coast." Harmful Algae 4(1): 87-94.

Cheng, Y. S., Y. Zhou, C. M. Irvin, R. H. Pierce, J. Naar, L. C. Backer, L. E. Fleming, B. Kirkpatrick and D. G. Baden (2005). "Characterization of marine aerosol for assessment of human exposure to brevetoxins." Environmental Health Perspectives 113(5): 638-643.

Collet, J.-F. and J. Messens (2010). "Structure, function, and mechanism of thioredoxin proteins." Antioxidants and Redox Signaling 13(8): 1205-1216.

Collins, M., R. Knutti, J. Arblaster, J. Dufresne, T. Fichefet, P. Friedlingstein, X. Gao, W. Gutowski, T. Johns and G. Krinner (2013). "Contribution of working group I to the fifth assessment report of the intergovernmental panel on climate change." Climate Change.

Darcie, E. R., E. P. Alan and L. Campbell (2014). "De novo assembly and characterization of the transcriptome of the toxic dinoflagellate Karenia brevis." BioMedCentral Genomics 15(1) 888

Dechraoui, M. Y., J. Naar, S. Pauillac and A.-M. Legrand (1999). "Ciguatoxins and brevetoxins, neurotoxic polyether compounds active on sodium channels." Toxicon 37(1): 125-143. 
Dechraoui, M.-Y. B. and J. S. Ramsdell (2003). "Type B brevetoxins show tissue selectivity for voltage-gated sodium channels: comparison of brain, skeletal muscle and cardiac sodium channels." Toxicon 41(7): 919-927.

Demers, S., S. Roy and R. Gagnon (1991)." Rapid light-induced changes in cell fluorescence and in xanthophyll-cycle pigments of Alexandrium excavatum (dinophyceae) and Thalassiosira pseudonana (bacillariophyceae): a photo-protection mechanism." Marine Ecology Progress Series 76: 185-193.

Derick, H., E. Williams and E. Cadenas (2001). "Mitochondrial respiratory chaindependent generation of superoxide anion and its release into the intermembrane space." Biochemical Journal 353(2): 411-416.

Dickinson, B. C. and C. J. Chang (2008). "A targetable fluorescent probe for imaging hydrogen peroxide in the mitochondria of living cells." Journal of the American Chemical Society 130(30): 9638-9639.

Dormán, G. and G. D. Prestwich (2000). "Using photolabile ligands in drug discovery and development." Trends in Biotechnology 18(2): 64-77.

Dyson, K. and D. D. Huppert (2010). "Regional economic impacts of razor clam beach closures due to harmful algal blooms (HABs) on the Pacific coast of Washington." Harmful Algae 9(3): 264-271.

Eckenroth, B. E., B. M. Lacey, A. P. Lothrop, K. M. Harris and R. J. Hondal (2007). "Investigation of the C-Terminal redox center of high-Mr thioredoxin reductase by protein engineering and semisynthesis." Biochemistry 46(33): 9472-9483.

Errera, R. M., A. Bourdelais, M. Drennan, E. Dodd, D. Henrichs and L. Campbell (2010). "Variation in brevetoxin and brevenal content among clonal cultures of Karenia brevis may influence bloom toxicity." Toxicon 55(2): 195-203.

Errera, R. M. and L. Campbell (2011). "Osmotic stress triggers toxin production by the dinoflagellate Karenia brevis." Proceedings of the National Academy of Sciences, USA 108(26): 10597-10601.

Evans, G. and L. Jones (2001). "Economic impact of the 2000 red tide on Galveston County, Texas: A case study." Department of Agricultural Economics, Texas A\&M University.

Fang, J. and A. Holmgren (2006). "Inhibition of thioredoxin and thioredoxin reductase by 4-hydroxy-2-nonenal in vitro and in vivo." Journal of the American Chemical Society 128(6): 1879-1885.

Fang, J., J. Lu and A. Holmgren (2005). "Thioredoxin reductase is irreversibly modified by curcumin: a novel molecular mechanism for its anticancer activity " Journal of Biological Chemistry 280(26): 25284-25290.

Finkel, T. (1998). "Oxygen radicals and signaling." Current Opinion in Cell Biology 10(2): 248-253. 
Finkel, T. and N. J. Holbrook (2000). "Oxidants, oxidative stress and the biology of ageing." Nature 408(6809): 239-247.

Fischer, A. H., K. A. Jacobson, J. Rose and R. Zeller (2008). "Hematoxylin and eosin staining of tissue and cell sections." Cold Spring Harbor Protocols 2008(5): pdb. prot4986.

Fleming, L. E., L. C. Backer and D. G. Baden (2005). "Overview of aerosolized Florida red tide toxins: exposures and effects." Environmental Health Perspectives 113(5): 618-620.

Fleming, L. E., E. Jerez, W. B. B. Stephan, A. Cassedy, J. A. Bean, A. Reich, B. Kirkpatrick, L. Backer, K. Nierenberg and S. Watkins (2007). "Evaluation of harmful algal bloom outreach activities." Marine Drugs 5(4): 208-219.

Fleming, L. E., B. Kirkpatrick, L. C. Backer, J. A. Bean, A. Wanner, D. Dalpra, R. Tamer, J. Zaias, Y. S. Cheng and R. Pierce (2005). "Initial evaluation of the effects of aerosolized Florida red tide toxins (brevetoxins) in persons with asthma." Environmental Health Perspectives 113(5): 650-657.

Fleming, L. E., B. Kirkpatrick, L. C. Backer, J. A. Bean, A. Wanner, A. Reich, J. Zaias, Y. S. Cheng, R. Pierce and J. Naar (2007). "Aerosolized red-tide toxins (brevetoxins) and asthma." Chest Journal 131(1): 187-194.

Fleming, L. E., B. Kirkpatrick, L. C. Backer, C. J. Walsh, K. Nierenberg, J. Clark, A. Reich, J. Hollenbeck, J. Benson and Y. S. Cheng (2011). "Review of Florida red tide and human health effects." Harmful Algae 10(2): 224-233.

Fleming, S. A. (1995). "Chemical reagents in photoaffinity labeling." Tetrahedron 51(46): 12479-12520.

Flewelling, L. J. (2008). "PhD dissertation: vectors of brevetoxins to marine mammals."

Flewelling, L. J., J. P. Naar, J. P. Abbott, D. G. Baden, N. B. Barros, G. D. Bossart, M.-Y. D. Bottein, D. G. Hammond, E. M. Haubold and C. A. Heil (2005). "Brevetoxicosis: red tides and marine mammal mortalities." Nature 435(7043): 755756.

Frei, B. (1999). "On the role of vitamin C and other antioxidants in atherogenesis and vascular dysfunction." Experimental Biology and Medicine 222(3): 196-204.

Fridovich, I. (1999). "Fundamental aspects of reactive oxygen species, or what's the matter with oxygen?" Annals of the New York Academy of Sciences 893(1): 13-18.

Friedman, M. A., L. E. Fleming, M. Fernandez, P. Bienfang, K. Schrank, R. Dickey, M.-Y. Bottein, L. Backer, R. Ayyar and R. Weisman (2008). "Ciguatera fish poisoning: treatment, prevention and management." Marine Drugs 6(3): 456-479. 
Fritz-Wolf, K., S. Kehr, M. Stumpf, S. Rahlfs and K. Becker (2011). "Crystal structure of the human thioredoxin reductase-thioredoxin complex." Nature Communications 2: 383.

Fuciman, M., M. M. Enriquez, T. Polívka, L. Dall'Osto, R. Bassi and H. A. Frank (2012). "Role of xanthophylls in light harvesting in green plants: a spectroscopic investigation of mutant LHCII and Lhcb pigment-protein complexes." The Journal of Physical Chemistry B 116(12): 3834-3849.

Galter, D., S. Mihm and W. Droge (1994). "Distinct effects of glutathione disulphide on the nuclear transcription factors kappa B and the activator protein-1." European Journal of Biochemistry 221(2): 639-648.

Gates, J. A. and W. B. Wilson (1960). "The toxicity of Gonyaulax monilata Howell to Mugil cephalus." Limnology and Oceanography 5(2): 171-174.

Griffin, B. A., S. R. Adams and R. Y. Tsien (1998). "Specific covalent labeling of recombinant protein molecules inside live cells." Science 281(5374): 269-272.

Grimes, D. J. (2009). "Oceans and human health: risks and remedies from the sea." Environmental Health Perspectives 117(3): A124-A124.

Gromer, S., R. H. Schirmer and K. Becker (1999). "News and views on thioredoxin reductases." Redox Report 4(5): 221-228.

Grzebyk, D., C. Béchemin, C. J. Ward, C. Vérité, G. A. Codd and S. Y. Maestrini (2003). "Effects of salinity and two coastal waters on the growth and toxin content of the dinoflagellate Alexandrium minutum." Journal of Plankton Research 25(10): 11851199 .

Gusovsky, F. and J. W. Daly (1990). "Maitotoxin: a unique pharmacological tool for research on calcium-dependent mechanisms." Biochemical Pharmacology 39(11): 1633-1639.

Hall, M., A. Mata-Cabana, H. E. Åkerlund, F. J. Florencio, W. P. Schröder, M. Lindahl and T. Kieselbach (2010). "Thioredoxin targets of the plant chloroplast lumen and their implications for plastid function." Proteomics 10(5): 987-1001.

Hallegraeff, G. M. (1993). "A review of harmful algal blooms and their apparent global increase." Phycologia 32(2): 79-99.

Hallegraeff, G. M. (2010). "Ocean climate change, phytoplankton community responses, and harmful algal blooms: a formidable predictive challenge1." Journal of Phycology 46(2): 220-235.

Halliwell, B. (1993). "The role of oxygen radicals in human disease, with particular reference to the vascular system." Pathophysiology of Haemostasis and Thrombosis 23(Suppl. 1): 118-126. 
Halliwell, B. (1996). "Antioxidants in human health and disease." Annual Review of Nutrition 16(1): 33-50.

Halliwell, B., A. Zentella, E. O. Gomez and D. Kershenobich (1997). "Antioxidants and human disease: a general introduction." Nutrition Reviews 55(1): S44.

Hansen, R. E., H. Østergaard and J. R. Winther (2005). "Increasing the reactivity of an artificial dithiol-disulfide pair through modification of the electrostatic milieu." Biochemistry 44(15): 5899-5906.

Harrison, J. A., N. Caraco and S. P. Seitzinger (2005). "Global patterns and sources of dissolved organic matter export to the coastal zone: Results from a spatially explicit, global model." Global Biogeochemical Cycles 19(4): GB4S04

Hashimoto, M., Y. Hatanaka, J. Yang, J. Dhesi and G. D. Holman (2001). "Synthesis of biotinylated bis (D-glucose) derivatives for glucose transporter photoaffinity labelling." Carbohydrate Research 331(2): 119-127.

Heinemann, S. H., H. Terlau, W. Stühmer, K. Imoto and S. Numa (1992). "Calcium channel characteristics conferred on the sodium channel by single mutations." Nature 356(6368): 441-443.

Heisler, J., P. M. Glibert, J. M. Burkholder, D. M. Anderson, W. Cochlan, W. C. Dennison, Q. Dortch, C. J. Gobler, C. A. Heil and E. Humphries (2008). "Eutrophication and harmful algal blooms: a scientific consensus." Harmful Algae 8(1): 3-13.

Heuck, A. P. and R. A. Wolosiuk (1997). "Fluoresceinthiocarbamyl-insulin: a potential analytical tool for the assay of disulfide bond reduction." Journal of Biochemical and Biophysical Methods 34(3): 213-225.

Hille, B. (2001). Book: Ion channels of excitable membranes

Hirota, K., M. Matsui, S. Iwata, A. Nishiyama, K. Mori and J. Yodoi (1997). "AP-1 transcriptional activity is regulated by a direct association between thioredoxin and Ref-1." Proceedings of the National Academy of Sciences 94(8): 3633-3638.

Hirota, K., M. Murata, Y. Sachi, H. Nakamura, J. Takeuchi, K. Mori and J. Yodoi (1999). "Distinct roles of thioredoxin in the cytoplasm and in the nucleus a two-step mechanism of redox regulation of transcription factor NF-kB." Journal of Biological Chemistry 274(39): 27891-27897.

Hitchcock, G. L., J. W. Fourqurean, J. L. Drake, R. N. Mead and C. A. Heil (2012). "Brevetoxin persistence in sediments and seagrass epiphytes of east Florida coastal waters." Harmful Algae 13: 89-94.

Hitchcock, G. L., G. Kirkpatrick, P. Minnett and V. Palubok (2010). "Net community production and dark community respiration in a Karenia brevis (Davis) bloom in West Florida coastal waters, USA." Harmful Algae 9(4): 351-358. 
Hoagland, P., D. Anderson, Y. Kaoru and A. White (2002). "The economic effects of harmful algal blooms in the United States: estimates, assessment issues, and information needs." Estuaries 25(4): 819-837.

Hoagland, P., D. Jin, A. Beet, B. Kirkpatrick, A. Reich, S. Ullmann, L. E. Fleming and G. Kirkpatrick (2014). "The human health effects of Florida red tide (FRT) blooms: An expanded analysis." Environment International 68: 144-153.

Hoagland, P., D. Jin, L. Y. Polansky, B. Kirkpatrick, G. Kirkpatrick, L. E. Fleming, A. Reich, S. M. Watkins, S. G. Ullmann and L. C. Backer (2009). "The costs of respiratory illnesses arising from Florida Gulf Coast Karenia brevis blooms." Environmental Health Perspectives 117(8): 1239.

Hogg, N. and B. Kalyanaraman (1998). "Nitric oxide and low-density lipoprotein oxidation." Free Radical Research 28(6): 593-600.

Holmgren, A. (1985). "Thioredoxin." Annual Review of Biochemistry 54(1): 237271.

Holmgren, A. (1989). "Thioredoxin and glutaredoxin systems." The Journal of Biological Chemistry 264(24): 13963-13966.

Holmgren, A. (1995). "Thioredoxin structure and mechanism: conformational changes on oxidation of the active-site sulfhydryls to a disulfide." Structure 3(3): 239243.

Holmgren, A., B. Söderberg, H. Eklund and C. Brändén (1975). "Three-dimensional structure of Escherichia coli thioredoxin-S2 to 2.8 A resolution." Proceedings of the National Academy of Sciences 72(6): 2305-2309.

Huang, J. M., C. H. Wu and D. G. Baden (1984). "Depolarizing action of a red-tide dinoflagellate brevetoxin on axonal membranes." Journal of Pharmacology and Experimental Therapeutics 229(2): 615-621.

Ip, C., M. Birringer, E. Block, M. Kotrebai, J. F. Tyson, P. C. Uden and D. J. Lisk (2000). "Chemical speciation influences comparative activity of selenium-enriched garlic and yeast in mammary cancer prevention." Journal of Agricultural and Food Chemistry 48(6): 2062-2070.

Jeglitsch, G., K. Rein, D. G. Baden and D. J. Adams (1998). "Brevetoxin-3 (PbTx-3) and its derivatives modulate single tetrodotoxin-sensitive sodium channels in rat sensory neurons." Journal of Pharmacology and Experimental Therapeutics 284(2): 516-525.

Jeng, M. F., M. T. Reymond, L. L. Tennant, A. Holmgren and H. J. Dyson (1998). "NMR characterization of a single-cysteine mutant of Escherichia coli thioredoxin and a covalent thioredoxin-peptide complex." European Journal of Biochemistry 257(2): 299-308. 
Jensen, K. S., R. E. Hansen and J. R. Winther (2009). "Kinetic and thermodynamic aspects of cellular thiol-disulfide redox regulation." Antioxidants and Redox Signaling 11(5): 1047-1058.

Johnson, L. V., M. L. Walsh and L. B. Chen (1980). "Localization of mitochondria in living cells with rhodamine 123." Proceedings of the National Academy of Sciences 77(2): 990-994.

Kamata, H. and H. Hirata (1999). "Redox regulation of cellular signalling." Cellular Signalling 11(1): 1-14.

Kanzok, S. M., R. H. Schirmer, I. Türbachova, R. Iozef and K. Becker (2000). "The thioredoxin system of the malaria parasite Plasmodium falciparum glutathione reduction revisited." Journal of Biological Chemistry 275(51): 40180-40186.

Keller, A., A. I. Nesvizhskii, E. Kolker and R. Aebersold (2002). "Empirical statistical model to estimate the accuracy of peptide identifications made by MS/MS and database search." Analytical Chemistry 74(20): 5383-5392.

Kirkpatrick, B., J. A. Bean, L. E. Fleming, G. Kirkpatrick, L. Grief, K. Nierenberg, A. Reich, S. Watkins and J. Naar (2010). "Gastrointestinal emergency room admissions and Florida red tide blooms." Harmful Algae 9(1): 82-86.

Kirkpatrick, B., L. E. Fleming, L. C. Backer, J. A. Bean, R. Tamer, G. Kirkpatrick, T. Kane, A. Wanner, D. Dalpra and A. Reich (2006). "Environmental exposures to Florida red tides: effects on emergency room respiratory diagnoses admissions." Harmful Algae 5(5): 526-533.

Kirkpatrick, B., L. E. Fleming, D. Squicciarini, L. C. Backer, R. Clark, W. Abraham, J. Benson, Y. S. Cheng, D. Johnson and R. Pierce (2004). "Literature review of Florida red tide: implications for human health effects." Harmful Algae 3(2): 99-115.

Koide, Y., Y. Urano, S. Kenmoku, H. Kojima and T. Nagano (2007). "Design and synthesis of fluorescent probes for selective detection of highly reactive oxygen species in mitochondria of living cells." Journal of the American Chemical Society 129(34): 10324-10325.

König, J., M. Baier, F. Horling, U. Kahmann, G. Harris, P. Schürmann and K.-J. Dietz (2002). "The plant-specific function of 2-Cys peroxiredoxin-mediated detoxification of peroxides in the redox-hierarchy of photosynthetic electron flux." Proceedings of the National Academy of Sciences 99(8): 5738-5743.

Konoki, K., M. Hashimoto, K. Honda, K. Tachibana, R. Tamate, F. Hasegawa, T. Oishi and M. Murata (2009). "Maitotoxin-photoactive probe binds to membrane proteins in blood cells." Heterocycles 79(1): 1007-1017.

Kontos, H. A., E. P. Wei, E. F. Ellis, L. W. Jenkins, J. T. Povlishock, G. T. Rowe and M. L. Hess (1985). "Appearance of superoxide anion radical in cerebral extracellular space during increased prostaglandin synthesis in cats." Circulation Research 57(1): 142-151. 
Krause, G. and E. Weis (1991). "Chlorophyll fluorescence and photosynthesis: the basics." Annual Review of Plant Biology 42(1): 313-349.

Krauth-Siegel, R. and G. Coombs (1999). "Enzymes of parasite thiol metabolism as drug targets." Parasitology Today 15(10): 404-409.

Kubanek, J., T. W. Snell and C. Pirkle (2007). "Chemical defense of the red tide dinoflagellate Karenia brevis against rotifer grazing." Limnology and Oceanography 52(3): 1026-1035.

Kumar-Roiné, S., M. Matsui, S. Pauillac and D. Laurent (2011). "Ciguatera fish poisoning and other seafood intoxication syndromes: A revisit and a review of the existing treatments employed in ciguatera fish poisoning." The South Pacific Journal of Natural and Applied Sciences 28(1): 1-26.

Kumar, S., M. Bjornstedt and A. Holmgren (1992). "Selenite is a substrate for calf thymus thioredoxin reductase and thioredoxin and elicits a large non-stoichiometric oxidation of NADPH in the presence of oxygen." European Journal of Biochemistry 207(2): 435-439.

Landino, L. M., T. E. Skreslet and J. A. Alston (2004). "Cysteine oxidation of tau and microtubule-associated protein-2 by peroxynitrite modulation of microtubule assembly kinetics by the thioredoxin reductase system." Journal of Biological Chemistry 279(33): 35101-35105.

Laurent, T. C., E. C. Moore and P. Reichard (1964). "Enzymatic synthesis of deoxyribonucleotides IV. Isolation and characterization of thioredoxin, the hydrogen donor from Escherichia coli B." Journal of Biological Chemistry 239(10): 3436-3444.

Lee, M. S., G. Qin, K. Nakanishi and M. G. Zagorski (1989). "Biosynthetic studies of brevetoxins, potent neurotoxins produced by the dinoflagellate Gymnodinium breve." Journal of the American Chemical Society 111(16): 6234-6241.

Lee, S.-R., S. Bar-Noy, J. Kwon, R. L. Levine, T. C. Stadtman and S. G. Rhee (2000). "Mammalian thioredoxin reductase: oxidation of the C-terminal cysteine/selenocysteine active site forms a thioselenide, and replacement of selenium with sulfur markedly reduces catalytic activity." Proceedings of the National Academy of Sciences of the United States of America 97(6): 2521-2526.

Lehane, L. and R. J. Lewis (2000). "Ciguatera: recent advances but the risk remains." International Journal of Food Microbiology 61(2): 91-125.

Lennon, B. W. and C. H. Williams (1997). "Reductive half-reaction of thioredoxin reductase from Escherichia coli." Biochemistry 36(31): 9464-9477.

Levine, D. (1995). "Ciguatera: current concepts." The Journal of the American Osteopathic Association 95(3): 193-198.

Lillig, C. H. and A. Holmgren (2007). "Thioredoxin and related molecules-from biology to health and disease." Antioxidants and Redox Signaling 9(1): 25-47. 
Lin, M. and O. Alfi (1976). "Detection of sister chromatid exchanges by 4'-6diamidino-2-phenylindole fluorescence." Chromosoma 57(3): 219-225.

Lin, M., D. Comings and O. Alfi (1977). "Optical studies of the interaction of 4'-6diamidino-2-phenylindole with DNA and metaphase chromosomes." Chromosoma 60(1): $15-25$.

Lin, Y.-Y., M. Risk, S. M. Ray, D. Van Engen, J. Clardy, J. Golik, J. C. James and K. Nakanishi (1981). "Isolation and structure of brevetoxin B from the" red tide" dinoflagellate Ptychodiscus brevis (Gymnodinium breve)." Journal of the American Chemical Society 103(22): 6773-6775.

Lincoln, D. T., E. E. Ali, K. F. Tonissen and F. M. Clarke (2002). "The thioredoxinthioredoxin reductase system: over-expression in human cancer." Anticancer Research 23(3B): 2425-2433.

Lothrop, A. P., E. L. Ruggles and R. J. Hondal (2009). "No selenium required: reactions catalyzed by mammalian thioredoxin reductase that are independent of a selenocysteine residue." Biochemistry 48(26): 6213-6223.

Lowther, W. T., N. Brot, H. Weissbach, J. F. Honek and B. W. Matthews (2000). "Thiol-disulfide exchange is involved in the catalytic mechanism of peptide methionine sulfoxide reductase." Proceedings of the National Academy of Sciences 97(12): 6463-6468.

Lu, J., E.-H. Chew and A. Holmgren (2007). "Targeting thioredoxin reductase is a basis for cancer therapy by arsenic trioxide." Proceedings of the National Academy of Sciences 104(30): 12288-12293.

Lu, J. and A. Holmgren (2014). "The thioredoxin antioxidant system." Free Radical Biology and Medicine 66: 75-87.

Luthman, M. and A. Holmgren (1982). "Rat liver thioredoxin and thioredoxin reductase: purification and characterization." Biochemistry 21(26): 6628-6633.

Magaña, H. A., C. Contreras and T. A. Villareal (2003). "A historical assessment of Karenia brevis in the western Gulf of Mexico." Harmful Algae 2(3): 163-171.

Marnett, L. J. (2000). "Oxyradicals and DNA damage." Carcinogenesis 21(3): 361370.

Martin, D. F. and B. B. Martin (1976). "Red tide, red terror. Effects of red tide and related toxins." Journal of Chemical Education 53(10): 614.

Martin, H. and M. Dean (1991). "Identification of a thioredoxin-related protein associated with plasma membranes." Biochemical and Biophysical Research Communications 175(1): 123-128.

Martin, J. L. (1995). "Thioredoxin — a fold for all reasons." Structure 3(3): 245-250. 
MatÉs, J. M., C. Pérez-Gómez and I. N. De Castro (1999). "Antioxidant enzymes and human diseases." Clinical Biochemistry 32(8): 595-603.

Matile, S., N. Berova and K. Nakanishi (1996). "Exciton coupled circular dichroic studies of self-assembled brevetoxin-porphyrin conjugates in lipid bilayers and polar solvents." Chemistry and Biology 3(5): 379-392.

Matsuo, G., K. Kawamura, N. Hori, H. Matsukura and T. Nakata (2004). "Total synthesis of brevetoxin-B." Journal of the American Chemical Society 126(44): 14374-14376.

Mattei, P., A. Virdis, L. Ghiadoni, S. Taddei and A. Salvetti (1996). "Endothelial function in hypertension." Journal of Nephrology 10(4): 192-197.

Messens, J. and S. Silver (2006). "Arsenate Reduction: thiol cascade chemistry with convergent evolution." Journal of Molecular Biology 362(1): 1-17.

Milian, A., K. Nierenberg, L. E. Fleming, J. A. Bean, A. Wanner, A. Reich, L. C. Backer, D. Jayroe and B. Kirkpatrick (2007). "Reported respiratory symptom intensity in asthmatics during exposure to aerosolized Florida red tide toxins." Journal of Asthma 44(7): 583-587.

Miranda-Vizuete, A., A. E. Damdimopoulos, J.-Å. Gustafsson and G. Spyrou (1997). "Cloning, expression, and characterization of a novel Escherichia coli thioredoxin." Journal of Biological Chemistry 272(49): 30841-30847.

Moisan, T. A., M. Olaizola and B. G. Mitchell (1998). "Xanthophyll cycling in Phaeocystis antarctica: changes in cellular fluorescence." Marine Ecology Progress Series 169: 113-121.

Montano, S. J., J. Lu, T. N. Gustafsson and A. Holmgren (2014). "Activity assays of mammalian thioredoxin and thioredoxin reductase: fluorescent disulfide substrates, mechanisms, and use with tissue samples." Analytical Biochemistry 449: 139-146.

Moore, E. C., P. Reichard and L. Thelander (1964). "Enzymatic synthesis of deoxyribonucleotides V. Purification and properties of thioredoxin reductase from Escherichia coli B." Journal of Biological Chemistry 239(10): 3445-3452.

Morgenstern, R. (2005). Microsomal glutathione transferase 1. Methods in Enzymology. S. Helmut and P. Lester, Academic Press. 401: 136-146.

Mugesh, G. and H. B. Singh (2000). "Synthetic organoselenium compounds as antioxidants: glutathione peroxidase activity." Chemical Society Reviews 29(5): 347357.

Müller, P., X.-P. Li and K. K. Niyogi (2001). "Non-photochemical quenching. A response to excess light energy." Plant Physiology 125(4): 1558-1566. 
Murata, M., M. Kumagai, J. S. Lee and T. Yasumoto (1987). "Isolation and structure of yessotoxin, a novel polyether compound implicated in diarrhetic shellfish poisoning." Tetrahedron Letters 28(47): 5869-5872.

Murata, M., A. M. Legrand, Y. Ishibashi, M. Fukui and T. Yasumoto (1990). "Structures and configurations of ciguatoxin from the moray eel Gymnothorax javanicus and its likely precursor from the dinoflagellate Gambierdiscus toxicus." Journal of the American Chemical Society 112(11): 4380-4386.

Murata, M., A. M. Legrand, Y. Ishibashi and T. Yasumoto (1989). "Structures of ciguatoxin and its congener." Journal of the American Chemical Society 111(24): 8929-8931.

Murrell, R. N. and J. E. Gibson (2009). "Brevetoxins 2, 3, 6, and 9 show variability in potency and cause significant induction of DNA damage and apoptosis in Jurkat E6-1 cells." Archives of Toxicology 83(11): 1009-1019.

Mustacich, D. and G. Powis (2000). "Thioredoxin reductase." Biochemical Journal 346(1): 1-8.

Nair, D. P., M. Podgorski, S. Chatani, T. Gong, W. Xi, C. R. Fenoli and C. N. Bowman (2013). "The Thiol-Michael Addition Click Reaction: A Powerful and Widely Used Tool in Materials Chemistry." Chemistry of Materials 26(1): 724-744.

Nakamura, H., M. Matsuda, K. Furuke, Y. Kitaoka, S. Iwata, K. Toda, T. Inamoto, Y. Yamaoka, K. Ozawa and J. Yodoi (1994). "Adult T cell leukemia-derived factor/human thioredoxin protects endothelial F-2 cell injury caused by activated neutrophils or hydrogen peroxide." Immunology Letters 42(1): 75-80.

Nakanishi, K. (1985). "The chemistry of brevetoxins: A review." Toxicon 23(3): 473479.

Nesvizhskii, A. I., A. Keller, E. Kolker and R. Aebersold (2003). "A statistical model for identifying proteins by tandem mass spectrometry." Analytical Chemistry 75(17): 4646-4658.

Netto, L. E. S., M. A. de Oliveira, C. A. Tairum and J. F. da Silva Neto (2016). "Conferring specificity in redox pathways by enzymatic thiol/disulfide exchange reactions." Free Radical Research 50(2): 206-245.

Neyens, E. and J. Baeyens (2003). "A review of classic Fenton's peroxidation as an advanced oxidation technique." Journal of Hazardous Materials 98(1): 33-50.

Nicolaou, K., Z. Yang, G.-q. Shi, J. L. Gunzner, K. A. Agrios and P. Gärtner (1998). "Total synthesis of brevetoxin A." Nature 392(6673): 264-269.

Nicolaou, K. C. (1996). "The total synthesis of brevetoxin B: a twelve-year odyssey in organic synthesis." Angewandte Chemie International Edition in English 35(6): 588-607. 
Nicolaou, K. C., C. K. Hwang, M. E. Duggan, D. A. Nugiel, Y. Abe, K. B. Reddy, S. A. DeFrees, D. R. Reddy and R. A. Awartani (1995). "Total synthesis of brevetoxin B. 1. First gneration atrategies and new approaches to oxepane systems." Journal of the American Chemical Society 117(41): 10227-10238.

Nicolaou, K. C., F. P. J. T. Rutjes, E. A. Theodorakis, J. Tiebes, M. Sato and E. Untersteller (1995). "Total synthesis of brevetoxin B. 3. Final strategy and completion." Journal of the American Chemical Society 117(41): 10252-10263.

Nicolaou, K. C., E. A. Theodorakis, F. P. J. T. Rutjes, M. Sato, J. Tiebes, X. Y. Xiao, C. K. Hwang, M. E. Duggan and Z. Yang (1995). "Total synthesis of brevetoxin B. 2. Second generation strategies and construction of the dioxepane region [DEFG]." Journal of the American Chemical Society 117(41): 10239-10251.

Nikkanen, L. and E. Rintamäki (2014). "Thioredoxin-dependent regulatory networks in chloroplasts under fluctuating light conditions." Philosophical Transactions of the Royal Society B 369(1640): 20130224.

Nordberg, J. and E. S. J. Arnér (2001). "Reactive oxygen species, antioxidants, and the mammalian thioredoxin system1." Free Radical Biology and Medicine 31(11): $1287-1312$.

O'Shea, T. J., G. B. Rathbun, R. K. Bonde, C. D. Buergelt and D. K. Odell (1991). "An epizootic of Florida manatees associated with a dinoflagellate bloom." Marine Mammal Science 7(2): 165-179.

Østergaard, H., A. Henriksen, F. G. Hansen and J. R. Winther (2001). "Shedding light on disulfide bond formation: engineering a redox switch in green fluorescent protein." The European Molecular Biology Organization journal 20(21): 5853-5862.

Patel, R. P., D. Moellering, J. Murphy-Ullrich, H. Jo, J. S. Beckman and V. M. Darley-Usmar (2000). "Cell signaling by reactive nitrogen and oxygen species in atherosclerosis." Free Radical Biology and Medicine 28(12): 1780-1794.

Pearn, J. (2001). "Neurology of ciguatera." Journal of Neurology, Neurosurgery and Psychiatry 70(1): 4-8.

Pierce, R., M. Henry, P. Blum, S. Hamel, B. Kirkpatrick, Y. Cheng, Y. Zhou, C. Irvin, J. Naar and A. Weidner (2005). "Brevetoxin composition in water and marine aerosol along a Florida beach: Assessing potential human exposure to marine biotoxins." Harmful Algae 4(6): 965-972.

Pierce, R., M. Henry, P. Blum, J. Lyons, Y. Cheng, D. Yazzie and Y. Zhou (2003). "Brevetoxin concentrations in marine aerosol: human exposure levels during a Karenia brevis harmful algal bloom." Bulletin of Environmental Contamination and Toxicology 70(1): 161-165.

Poli, M., T. J. Mende and D. G. Baden (1986). "Brevetoxins, unique activators of voltage-sensitive sodium channels, bind to specific sites in rat brain synaptosomes." Molecular Pharmacology 30(2): 129-135. 
Powis, G., D. Mustacich and A. Coon (2000). "The role of the redox protein thioredoxin in cell growth and cancer." Free Radical Biology and Medicine 29(3): 312-322.

Rahman, I. and I. Adcock (2006). "Oxidative stress and redox regulation of lung inflammation in COPD." European Respiratory Journal 28(1): 219-242.

Raj, A., P. Van Den Bogaard, S. A. Rifkin, A. Van Oudenaarden and S. Tyagi (2008). "Imaging individual mRNA molecules using multiple singly labeled probes." Nature Methods 5(10): 877-879.

Re, R., N. Pellegrini, A. Proteggente, A. Pannala, M. Yang and C. Rice-Evans (1999). "Antioxidant activity applying an improved ABTS radical cation decolorization assay." Free Radical Biology and Medicine 26(9-10): 1231-1237.

Rein, K. S., D. G. Baden and R. E. Gawley (1994). "Conformational analysis of the sodium channel modulator, brevetoxin A, comparison with brevetoxin B conformations, and a hypothesis about the common pharmacophore of the" site 5" toxins." The Journal of Organic Chemistry 59(8): 2101-2106.

Rein, K. S. and J. Borrone (1999). "Polyketides from dinoflagellates: origins, pharmacology and biosynthesis." Comparative Biochemistry and Physiology Part B: Biochemistry and Molecular Biology 124(2): 117-131.

Rein, K. S., B. Lynn, R. E. Gawley and D. G. Baden (1994). "Brevetoxin B: chemical modifications, synaptosome binding, toxicity, and an unexpected conformational effect." The Journal of Organic Chemistry 59(8): 2107-2113.

Rhee, S. G. (1999). "Redox signaling: hydrogen peroxide as intracellular messenger." Experimental and Molecular Medicine 31(2): 53-59.

Riener, C. K., G. Kada and H. J. Gruber (2002). "Quick measurement of protein sulfhydryls with Ellman's reagent and with 4, 4'-dithiodipyridine." Analytical and Bioanalytical Chemistry 373(4-5): 266-276.

Rogers, J. C., Y. Qu, T. N. Tanada, T. Scheuer and W. A. Catterall (1996). "Molecular determinants of high affinity binding of $\alpha$-scorpion toxin and sea anemone toxin in the S3-S4 extracellular loop in domain IV of the $\mathrm{Na}^{+}$channel $\alpha$ subunit." Journal of Biological Chemistry 271(27): 15950-15962.

Roos, G., N. Foloppe, K. Van Laer, L. Wyns, L. Nilsson, P. Geerlings and J. Messens (2009). "How thioredoxin dissociates its mixed disulfide." PLOS Computational Biology 5(8): e1000461.

Ross, C., R. Ritson-Williams, R. Pierce, J. B. Bullington, M. Henry and V. J. Paul (2010). "Effects of the Florida red tide dinoflagellate, Karenia brevis, on oxidative stress and metamorphosis of larvae of the coral Porites astreoides." Harmful Algae 9(2): 173-179. 
Rubbo, H., R. Radi, D. Anselmi, M. Kirk, S. Barnes, J. Butler, J. P. Eiserich and B. A. Freeman (2000). "Nitric oxide reaction with lipid peroxyl radicals spares $\alpha$-tocopherol during lipid peroxidation greater oxidant protection from pair nitric oxide/ $\alpha-$ tocopherol than $\alpha$ - tocopherol/ascorbate." Journal of Biological Chemistry 275(15): 10812-10818.

Satake, M., A. Campbell, R. M. Van Wagoner, A. J. Bourdelais, H. Jacocks, D. G. Baden and J. L. Wright (2009). "Brevisin: an aberrant polycyclic ether structure from the dinoflagellate Karenia brevis and its implications for polyether assembly." The Journal of Organic Chemistry 74(3): 989-994.

Satake, M., L. MacKenzie and T. Yasumoto (1997). "Identification of Protoceratium reticulatum as the biogenetic origin of yessotoxin." Natural Toxins 5(4): 164-167.

Sayer, A., Q. Hu, A. J. Bourdelais, D. G. Baden and J. E. Gibson (2006). "The inhibition of CHO-K1-BH4 cell proliferation and induction of chromosomal aberrations by brevetoxins in vitro." Food and Chemical Toxicology 44(7): 10821091.

Schettini, G., K. Koike, A. Judd, M. Cronin, T. Yasumoto and R. MacLeod (1984). "Maitotoxin stimulates hormonal release and calcium flux in rat anterior pituitary cells in vitro." American Journal of Physiology-Endocrinology and Metabolism 247(4): E520-E525.

Schweizer, D. (1976). "DAPI fluorescence of plant chromosomes prestained with actinomycin D." Experimental Cell Research 102(2): 408-413.

Schweizer, D. (1976). "Reverse fluorescent chromosome banding with chromomycin and DAPI." Chromosoma 58(4): 307-324.

Seitzinger, S. P., J. A. Harrison, E. Dumont, A. H. W. Beusen and A. F. Bouwman (2005). "Sources and delivery of carbon, nitrogen, and phosphorus to the coastal zone: An overview of Global Nutrient Export from Watersheds (NEWS) models and their application." Global Biogeochemical Cycles 19(4): doi:10.1029/2005GB002606

Setterdahl, A. T., P. T. Chivers, M. Hirasawa, S. D. Lemaire, E. Keryer, M. MiginiacMaslow, S.-K. Kim, J. Mason, J.-P. Jacquot and C. C. Longbine (2003). "Effect of pH on the oxidation-reduction properties of thioredoxins." Biochemistry 42(50): 1487714884 .

Seyedrezazadeh, E., A. Ostadrahimi, S. Mahboob, Y. Assadi, J. Ghaemmagami and M. Pourmogaddam (2008). "Effect of vitamin E and selenium supplementation on oxidative stress status in pulmonary tuberculosis patients." Respirology 13(2): 294298.

Shaked, Z. e., R. P. Szajewski and G. M. Whitesides (1980). "Rates of thiol-disulfide interchange reactions involving proteins and kinetic measurements of thiol $\mathrm{pKa}$ values." Biochemistry 19(18): 4156-4166. 
Shimizu, Y., H. Bando, H.-N. Chou, G. Van Duyne and J. C. Clardy (1986). "Absolute configuration of brevetoxins." Journal of the Chemical Society, Chemical Communications (22): 1656-1658.

Sikorski, Z. E. (2006). Book :Chemical and functional properties of food components

Simon, J. and D. Dauer (1972). "A quantitative evaluation of red-tide induced mass mortalities of benthic invertebrates in Tampa Bay, Florida." Environmental Letters 3(4): 229-234.

Singh, R., W. A. Blattler and A. R. Collinson (1993). "An amplified assay for thiols based on reactivation of papain." Analytical Biochemistry 213(1): 49-56.

Sinigalliano, C. D., J. Winshell, M. A. Guerrero, G. Scorzetti, J. W. Fell, R. W. Eaton, L. Brand and K. S. Rein (2009). "Viable cell sorting of dinoflagellates by multiparametric flow cytometry." Phycologia 48(4): 249-257.

Smayda, T. J. (2007). "Reflections on the ballast water dispersal-harmful algal bloom paradigm." Harmful Algae 6(4): 601-622.

Snider, G. W., C. M. Dustin, E. L. Ruggles and R. J. Hondal (2014). "A mechanistic investigation of the C-terminal redox motif of thioredoxin reductase from Plasmodium falciparum." Biochemistry 53(3): 601-609.

Stadtman, E. R. (1992). "Protein oxidation and aging." Science 257(5074): 12201224.

Stadtman, E. R. and B. S. Berlett (1997). "Reactive oxygen-mediated protein oxidation in aging and disease." Chemical Research in Toxicology 10(5): 485-494.

Steinberg, D. (1997). "Low density lipoprotein oxidation and its pathobiological significance." Journal of Biological Chemistry 272(34): 20963-20966.

Stephen, J. and J. G. Kettle (1997). "Synthesis of brevetoxin sub-units by sequential ring-closing metathesis and hydroboration." Tetrahedron Letters 38(1): 123-126.

Stewart, E. J., F. Åslund and J. Beckwith (1998). "Disulfide bond formation in the Escherichia coli cytoplasm: an in vivo role reversal for the thioredoxins." The EMBO journal 17(19): 5543-5550.

Stuart, A. M. and D. G. Baden (1988). "Florida red tide brevetoxins and binding in fish brain synaptosomes." Aquatic Toxicology 13(4): 271-279.

Stumpf, R. P., M. E. Culver, P. A. Tester, M. Tomlinson, G. J. Kirkpatrick, B. A. Pederson, E. Truby, V. Ransibrahmanakul and M. Soracco (2003). "Monitoring Karenia brevis blooms in the Gulf of Mexico using satellite ocean color imagery and other data." Harmful Algae 2(2): 147-160.

Sudarsanam, S., G. D. Virca, C. March and S. Srinivasan (1992). "An approach to computer-aided inhibitor design: Application to cathepsin L." Journal of ComputerAided Molecular Design 6(3): 223-233. 
Sugimoto, T., T. Fujii, Y. Idutu, S. Yamamura and M. Ueda (2004). "Detection of potential membrane receptor proteins concerning circadian rhythmic leaf movement of legumes using novel photoaffinity probe compounds." Tetrahedron Letters $\mathbf{4 5}(2)$ : 335-338.

Sun, P., C. Leeson, X. Zhi, F. Leng, R. H. Pierce, M. S. Henry and K. S. Rein (2016). "Characterization of an epoxide hydrolase from the Florida red tide dinoflagellate, Karenia brevis." Phytochemistry 122: 11-21.

Sunda, W. G., C. Burleson, D. R. Hardison, J. S. Morey, Z. Wang, J. Wolny, A. A. Corcoran, L. J. Flewelling and F. M. Van Dolah (2013). "Osmotic stress does not trigger brevetoxin production in the dinoflagellate Karenia brevis." Proceedings of the National Academy of Sciences of the United States of America 110(25): 1022310228 .

Sundaresan, M., Z.-X. Yu, V. J. Ferrans, K. Irani and T. Finkel (1995). "Requirement for generation of $\mathrm{H}_{2} \mathrm{O}_{2}$ for platelet-derived growth factor signal transduction." Science 270(5234): 296.

Suzuki, T., T. Matsuzaki, H. Hagiwara, T. Aoki and K. Takata (2007). "Recent advances in fluorescent labeling techniques for fluorescence microscopy." Acta Histochemica et Cytochemica 40(5): 131-137.

Taglialatela, M., S. Amoroso, T. Yasumoto, G. Di Renzo and L. Annunziato (1986). "Maitotoxin and BAY-K-8644: two putative calcium channel activators with different effects on endogenous dopamine release from tuberoinfundibular neurons." Brain Research 381(2): 356-358.

Takahashi, W., H. Kawamura, T. Omura and K. Furuya (2009). "Detecting red tides in the eastern Seto inland sea with satellite ocean color imagery." Journal of Oceanography 65(5): 647-656.

Taniguchi, Y., Y. Taniguchi-Ueda, K. Mori and J. Yodoi (1996). "A novel promoter sequence is involved in the oxidative stress-induced expression of the adult T-cell leukemia-derived factor (ADF)/human thioredoxin (Trx) gene." Nucleic ACids Research 24(14): 2746-2752.

Tejedor, F. J. and W. A. Catterall (1988). "Site of covalent attachment of alphascorpion toxin derivatives in domain I of the sodium channel alpha subunit." Proceedings of the National Academy of Sciences of the United States of America 85(22): 8742-8746.

Tester, P. A. and K. A. Steidinger (1997). "Gymnodinium breve red tide blooms: Initiation, transport, and consequences of surface circulation." Limnology and Oceanography 42(5part2): 1039-1051.

Thyng, K. M., R. D. Hetland, M. T. Ogle, X. Zhang, F. Chen and L. Campbell (2013). "Origins of Karenia brevis harmful algal blooms along the Texas coast." Limnology and Oceanography: Fluids and Environments 3(1): 269-278. 
Toppo, S., S. Vanin, V. Bosello and S. C. Tosatto (2008). "Evolutionary and structural insights into the multifaceted glutathione peroxidase (Gpx) superfamily." Antioxidants and Redox Signaling 10(9): 1501-1514.

Trainer, V. L. and D. G. Baden (1991). "An enzyme immunoassay for the detection of Florida red tide brevetoxins." Toxicon 29(11): 1387-1394.

Trainer, V. L. and D. G. Baden (1999). "High affinity binding of red tide neurotoxins to marine mammal brain." Aquatic Toxicology 46(2): 139-148.

Trainer, V. L., D. G. Baden and W. A. Catterall (1994). "Identification of peptide components of the brevetoxin receptor site of rat brain sodium channels." Journal of Biological Chemistry 269(31): 19904-19909.

Trainer, V. L., W. J. Thomsen, W. A. Catterall and D. G. Baden (1991). "Photoaffinity labeling of the brevetoxin receptor on sodium channels in rat brain synaptosomes." Molecular Pharmacology 40(6): 988-994.

Twiner, M. J., M.-Y. Bottein Dechraoui, Z. Wang, C. M. Mikulski, M. S. Henry, R. H. Pierce and G. J. Doucette (2007). "Extraction and analysis of lipophilic brevetoxins from the red tide dinoflagellate Karenia brevis." Analytical Biochemistry 369(1): 128-135.

Ujihara, S., T. Oishi, K. Torikai, K. Konoki, N. Matsumori, M. Murata, Y. Oshima and S. Aimoto (2008). "Interaction of ladder-shaped polyethers with transmembrane $\alpha$-helix of glycophorin A as evidenced by saturation transfer difference NMR and surface plasmon resonance." Bioorganic and Medicinal Chemistry Letters 18(23): 6115-6118.

Urig, S. and K. Becker (2006). "On the potential of thioredoxin reductase inhibitors for cancer therapy." Seminars in cancer biology 16(6):452-65

Valko, M., C. Rhodes, J. Moncol, M. Izakovic and M. Mazur (2006). "Free radicals, metals and antioxidants in oxidative stress-induced cancer." Chemico Biological Interactions 160(1): 1-40.

Van Bladeren, P. J. (2000). "Glutathione conjugation as a bioactivation reaction." Chemico-biological Interactions 129(1): 61-76.

Van Deventer, M., K. Atwood, A. Vargo Gabriel, J. Flewelling Leanne, H. Landsberg Jan, P. Naar Jerome and D. Stanek (2012). "Karenia brevis red tides and brevetoxincontaminated fish: a high risk factor for Florida's scavenging shorebirds? "Botanica Marina. 55(1): 31 .

Vargo, G. A., C. A. Heil, D. N. Ault, M. B. Neely, S. Murasko, J. Havens, K. M. Lester, L. K. Dixon, R. Merkt and J. Walsh (2002). "Four Karenia brevis blooms: a comparative analysis." Harmful Algae: 14-16. 
Vijayan, A. K. and S. A. Somayajula (2014). "Effect of accessory pigment composition on the absorption characteristics of dinoflagellate bloom in a coastal embayment." Oceanologia 56(1): 107-124.

Walsh, C., S. Leggett, K. Strohbehn, R. Pierce and J. Sleasman (2008). "Effects of in vitro brevetoxin exposure on apoptosis and cellular metabolism in a leukemic $\mathrm{T}$ cell line (Jurkat)." Marine Drugs 6(2): 291-307.

Walsh, C. J., M. Butawan, J. Yordy, R. Ball, L. Flewelling, M. de Wit and R. K. Bonde (2015). "Sublethal red tide toxin exposure in free-ranging manatees (Trichechus manatus) affects the immune system through reduced lymphocyte proliferation responses, inflammation, and oxidative stress." Aquatic Toxicology 161: 73-84.

Walsh, C. J., S. R. Leggett, B. J. Carter and C. Colle (2010). "Effects of brevetoxin exposure on the immune system of loggerhead sea turtles." Aquatic Toxicology 97(4): 293-303.

Walsh, C. J., S. R. Leggett, M. S. Henry, P. C. Blum, S. Osborn and R. H. Pierce (2009). "Cellular metabolism of brevetoxin $(\mathrm{PbTx}-2)$ by a monocyte cell line (U937)." Toxicon 53(1): 135-145.

Walsh, C. J., J. E. Stuckey, H. Cox, B. Smith, C. Funke, J. Stott, C. Colle, J. Gaspard and C. A. Manire (2007). "Production of nitric oxide by peripheral blood mononuclear cells from the Florida manatee, Trichechus manatus latirostris." Veterinary Immunology and Immunopathology 118(3-4): 199-209.

Walsh, J., R. Weisberg, J. Lenes, F. Chen, D. Dieterle, L. Zheng, K. Carder, G. Vargo, J. Havens and E. Peebles (2009). "Isotopic evidence for dead fish maintenance of Florida red tides, with implications for coastal fisheries over both source regions of the West Florida shelf and within downstream waters of the South Atlantic Bight." Progress in Oceanography 80(1): 51-73.

Watkins, S. M., A. Reich, L. E. Fleming and R. Hammond (2008). "Neurotoxic shellfish poisoning." Marine Drugs 6(3): 431-455.

Weber, P. J. and A. G. Beck-Sickinger (1997). "Comparison of the photochemical behavior of four different photoactivatable probes." The Journal of Peptide Research 49(5): 375-383.

Williams, C. (1995). "Mechanism and structure of thioredoxin reductase from Escherichia coli." The Federation of American Societies for Experimental Biology journal 9(13): 1267-1276.

Williams, C. H. (2000). "Thioredoxin-thioredoxin reductase-a system that has come of age." European Journal of Biochemistry 267(20): 6101-6101.

Williams Jr, C. H. (1992). "Lipoamide dehydrogenase, glutathione reductase, thioredoxin reductase, and mercuric ion reductase - a family of flavoenzyme transhydrogenases." Chemistry and Biochemistry of Flavoenzymes 3: 121-211. 
Williamson, D. and D. Fennell (1975). "The use of fluorescent DNA-binding agent for detecting and separating yeast mitochondrial DNA." Methods in Cell Biology 12: 335-351.

Woo, S. P. S., W. Liu, D. W. T. Au, D. M. Anderson and R. S. S. Wu (2006). "Antioxidant responses and lipid peroxidation in gills and erythrocytes of fish (Rhabdosarga sarba) upon exposure to Chattonella marina and hydrogen peroxide: implications on the cause of fish kills." Journal of Experimental Marine Biology and Ecology 336(2): 230-241.

Yla-Herttuala, S. (1999). "Oxidized LDL and atherogenesisa." Annals of the New York Academy of Sciences 874(1): 134-137.

Yost, F. J. and I. Fridovich (1973). "An iron-containing superoxide dismutase from Escherichia coli." Journal of Biological Chemistry 248(14): 4905-4908.

Young, F. M., C. Thomson, J. S. Metcalf, J. M. Lucocq and G. A. Codd (2005). "Immunogold localisation of microcystins in cryosectioned cells of Microcystis." Journal of Structural Biology 151(2): 208-214.

Zhang, B., C. Ge, J. Yao, Y. Liu, H. Xie and J. Fang (2015). "Selective selenol fluorescent probes: design, synthesis, structural determinants, and biological applications." Journal of the American Chemical Society 137(2): 757-769.

Zhong, L., E. S. Arnér, J. Ljung, F. Åslund and A. Holmgren (1998). "Rat and calf thioredoxin reductase are homologous to glutathione reductase with a carboxylterminal elongation containing a conserved catalytically active penultimate selenocysteine residue." Journal of Biological Chemistry 273(15): 8581-8591.

Zhong, L. and A. Holmgren (2000). "Essential role of selenium in the catalytic activities of mammalian thioredoxin reductase revealed by characterization of recombinant enzymes with selenocysteine mutations." Journal of Biological Chemistry 275(24): 18121-18128.

Zhou, J. and L. Fritz (1994). "Okadaic acid antibody localizes to chloroplasts in the DSP-toxin-producing dinoflagellates Prorocentrum lima and Prorocentrum maculosum." Phycologia 33(6): 455-461. 


\section{WEI CHEN}

EDUCATION

$2007-2011$

B.S., Chemistry

Wuhan institute of technology, Wuhan, China

$2011-2016$

Doctoral Candidate

Florida International University, Miami, Florida, USA

\section{PUBLICATIONS and PRESENTATIONS}

${ }^{*}$ Cassell, R. T., *W. Chen, S. Thomas, L. Liu and K. S. Rein "Brevetoxin, the dinoflagellate neurotoxin, localizes to thylakoid membranes and interacts with the light-harvesting complex II (LHCII) of photosystem II." ChemBioChem Volume 16, Issue 7, pages 1060-1067, May 4, 2015 (* represents the equal contribution)

W. Chen, F. Rodriguez del Rey, T. Anupama, C. E. Zavala and K. S. Rein "Brevetoxin-2, inhibits the C-terminal redox center of mammalian thioredoxin reductase-1: Implications for a new mechanism of toxicity." Chemical Research in Toxicology (in- progress)

W. Chen, F. Rodriguez del Rey, R. Colon, M. Durham and K. S. Rein "Brevetoxin-2, is an Inhibitor of thioredoxin reductase: lmplcations for endogenous function and toxicity" Harmful Algae (in- progress)

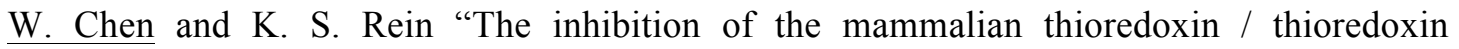
reductase system by brevetoxins" 2016 Florida Annual Meeting and Exposition of the Florida Section of the American Chemical Society, Tampa, FL 05/06-05/08 (Oral Presentation)

W. Chen, F. Rodriguez and K. S. Rein "Characterizing the redox status of high and low toxin producing K. brevis strains" 2016 Florida Annual Meeting and Exposition of the Florida Section of the American Chemical Society, Tampa, FL 05/06-05/08 (Poster Presentation)

W. Chen and K. S. Rein "The interaction between the dinoflagellate neurotoxin and the thioredoxin system" 2015 8th Symposia of Harmful Algae in the U.S., Long beach, CA, 11/15-11/19. (Oral Presentation)

W. Chen and K. S. Rein "The interaction between the dinoflagellate neurotoxin and the thioredoxin system" 2015 8th Symposia of Harmful Algae in the U.S., Long beach, CA, 11/15-11/19. (Poster Presentation)

W. Chen and K. S. Rein "The interaction between the dinoflagellate neurotoxin and its native receptors" 2015 Florida Annual Meeting and Exposition of the Florida Section of the American Chemical Society, Tampa, FL, 05/08-05/10. (Oral Presentation)

W. Chen, Cassell, R. T. and K. S. Rein "Localiaztion of brevetoxins and photoaffinity labeling of target proteins" 2013 7th Symposia of Harmful Algae in the U.S. Sarasota, FL, 10/27-10/31 (Poster Presentation) 
T. Anupama, W. Chen, S. Rolle, Y. Liu and K. S. Rein "The effect of trolox on brevetoxicosis in human lymphoblast cells" 2016 XII congress of the pan American section of the international society of toxinology, Miami beach, FL, 09/18-09/23 (Poster presentation) 